\title{
Astroglia-specific contributions to the regulation of synapses, cognition and behaviour
}

DOI:

10.1016/j.neubiorev.2020.07.039

\section{Document Version}

Accepted author manuscript

Link to publication record in Manchester Research Explorer

\section{Citation for published version (APA):}

Augusto-oliveira, M., Arrifano, G. P., Takeda, P. Y., Lopes-araújo, A., Santos-sacramento, L., Anthony, D. C., Verkhratsky, A., \& Crespo-lopez, M. E. (2020). Astroglia-specific contributions to the regulation of synapses, cognition and behaviour. Neuroscience \& Biobehavioral Reviews, 118, 331-357.

https://doi.org/10.1016/j.neubiorev.2020.07.039

Published in:

Neuroscience \& Biobehavioral Reviews

\section{Citing this paper}

Please note that where the full-text provided on Manchester Research Explorer is the Author Accepted Manuscript or Proof version this may differ from the final Published version. If citing, it is advised that you check and use the publisher's definitive version.

\section{General rights}

Copyright and moral rights for the publications made accessible in the Research Explorer are retained by the authors and/or other copyright owners and it is a condition of accessing publications that users recognise and abide by the legal requirements associated with these rights.

\section{Takedown policy}

If you believe that this document breaches copyright please refer to the University of Manchester's Takedown Procedures [http://man.ac.uk/04Y6Bo] or contact uml.scholarlycommunications@manchester.ac.uk providing relevant details, so we can investigate your claim.

\section{OPEN ACCESS}


Neuroscience and Biobehavioral Reviews

Astroglia-specific contributions to the regulation of synapses, cognition and behaviour --Manuscript Draft--

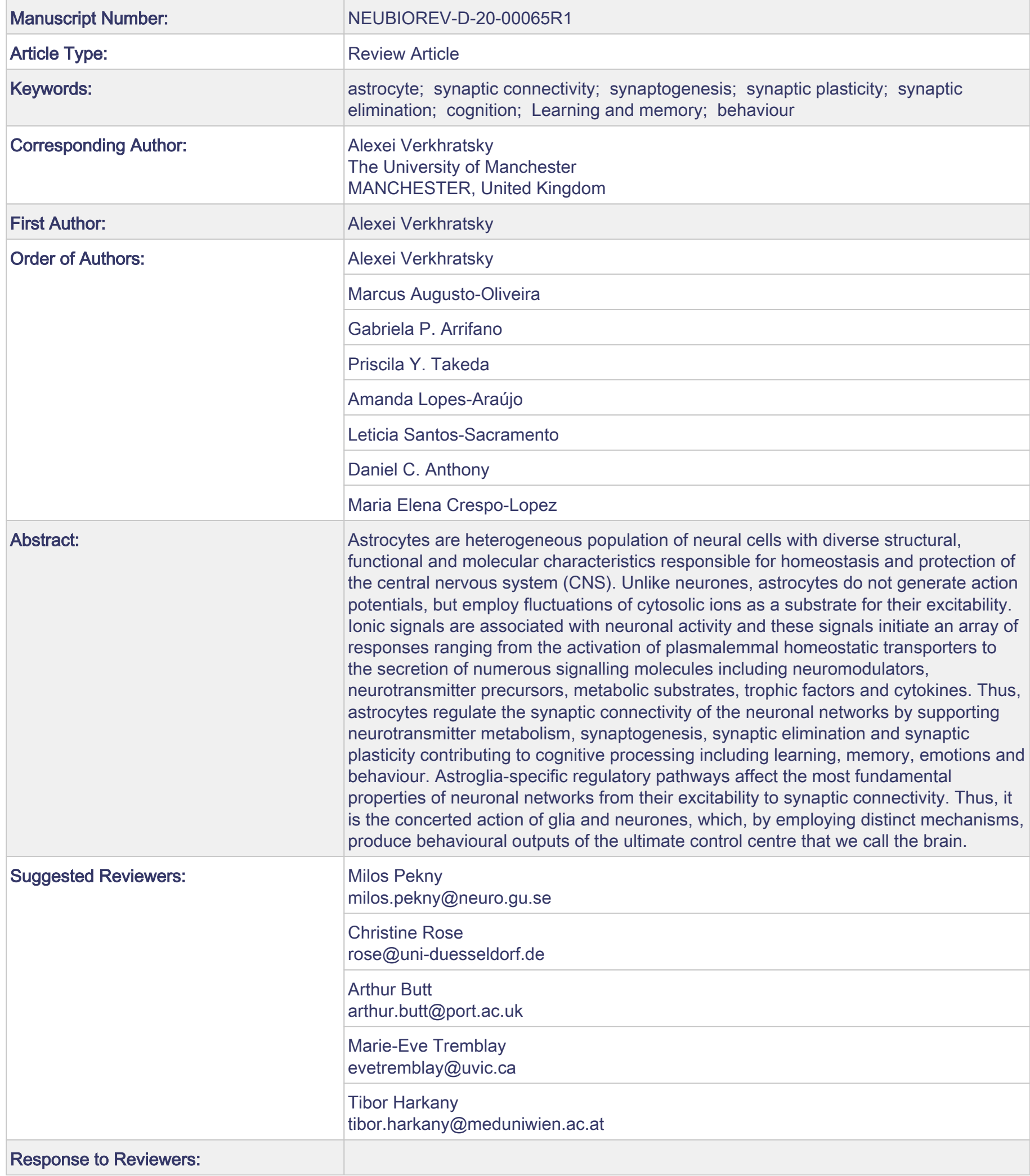


Alexei Verkhratsky, MD, PhD, Dr.Sc., MAE, ML, MRANF, MPAN, MSASA

Professor of Neurophysiology

Member of Academia Europaea,

Vice President of Academia Europaea

Member of Academia Leopoldina,

Member of Real Academia de Farmacia of Spain

Member of Polish Academy of Sciences

Corresponding Member of Slovenian Academy of Sciences and Arts

tel: (+44 161) 2755414

fax: (+44 161) 2755363

email: Alexej.Verkhratsky@manchester.ac.uk

July 28, 2020

Manuscript Number: NEUBIOREV-D-20-00065

Prof. Francesca Cirulli

Associate Editor

Neuroscience \& Biobehavioral Reviews

Dear Professor Cirulli,

We are submitting the revised paper "Astroglia-specific contributions to the regulation of synapses, cognition and behaviour" by M. Augusto-Oliveira, G. P. Arrifano, P. Y. Takeda, A. Lopes-Araújo, L. Santos-Sacramento, D. C. Anthony, A. Verkhratsky \& Maria Elena CrespoLopez. We appreciated constructive comments of the referees and we modified the text in accordance with their suggestions. Detailed response to reviewers concerns you may find below.

We hope that our revised manuscript meets acceptance criteria of Neuroscience and Biobehavioral Reviews.

With best regards

On behalf of all co-authors

With best regards, I shall remain

Yours sincerely

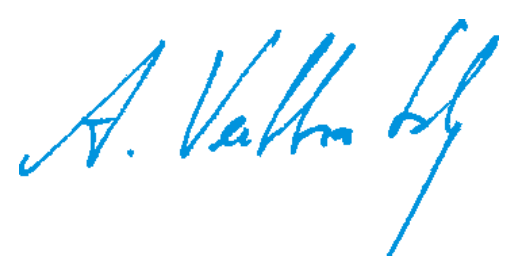




\section{Response to referees comments}

Reviewer \#1: This is a timely and authoritative review. The writing is in a narrative style that covers both historical and current ideas.

Our reply: We are very grateful for this evaluation

I have only one minor comment, in that the English grammar is less than perfect in places, and the paper would benefit from careful editing. I provide two examples below, taken from the very first paragraph, but there are many similar examples throughout the manuscript, in particular missing definite or indefinite articles.

i) The following sentence is missing a definitive article and commas: "Mechanisms underlying THE astroglial contribution to cognition remains DEBATABLE, however, and are in need of further investigation".

ii) The next sentence lacks a definite or indefinite article in front of 'tripartite synapse', whereby the sentence "The concept of tripartite synapse..." should read "The concept of the tripartite synapse" or "The concept of a tripartite synapse'.

Our reply: thank you for these suggestions which we of course accept; one of us (DCA) who is a native speaker made a careful proofreading

Reviewer \#2: This review by Augusto-Oliveira is very well written, interesting and provides a comprehensive view of astroglial structure and function across species, stages of the lifespan and CNS regions. I only have a few suggestions to improve further the impact of the manuscript.

Our reply: We are very grateful for this evaluation

3.1.

When discussing astrocytic markers, it could be mentioned that GLT1 and GLAST can also be expressed by microglia

Our reply: Done

\section{3.}

It would be interesting to mention other environmental stimulations known to drive morphological astrocytic changes, in addition to physical activity and environmental enrichment

Our reply: Thank you - very good point - we added some discussion on the role of diet (caloric restriction) which similarly affects astroglial morphology.

4.

There is a typo to correct in "structures"

\section{Our reply: Corrected}

\subsection{3.}


I would revise the sentence

"TNFa is directly involved in this type of plasticity, and astroglia were identified as the principal source of this cytokine (Stellwagen and Malenka, 2006)."

Importantly, this paper mentions both microglia and astrocytes as sources of the cytokine.

Subsequent work from David Stellwagen also identified microglia as mediating these effects of

TNFa (in a context of cocaine-induced plasticity; https://pubmed.ncbi.nlm.nih.gov/27112496/)

Our reply: Corrected as suggested and reference added

Figure 3

I would recommend to use the wording 'In concert with microglia'

Our reply: Done

This figure illustrates the roles of astroglia in the modulation of the blood brain barrier Considering the importance of this function, I would recommend to add a small dedicated section to the review

Our reply: We added a small section on BBB and glio-vascular coupling.

Conclusion

The review often mentions other glial cells, e.g. microglia. It would be interesting to mention briefly that astroglial functions are performed in coordination with these other cells

Our reply: We cannot agree more about the importance of microglia; and throughout the text we made several notions that astrocytes are working together with microglia (for example in synaptic elimination, where microglial cells are actual strippers of the unwanted synaptic structures). At the same time this topic I quite wide and requires a dedicated paper; in this our review we tried to focus specifically on astroglial mechanisms controlling behavior and synaptic transmission, and we are very much afraid that extending these mechanisms to astrogliamicroglial interactions may dilute the message and increase the volume of this review beyond reason. 


\section{Response to referees comments}

Reviewer \#1: This is a timely and authoritative review. The writing is in a narrative style that covers both historical and current ideas.

Our reply: We are very grateful for this evaluation

I have only one minor comment, in that the English grammar is less than perfect in places, and the paper would benefit from careful editing. I provide two examples below, taken from the very first paragraph, but there are many similar examples throughout the manuscript, in particular missing definite or indefinite articles.

i) The following sentence is missing a definitive article and commas: "Mechanisms underlying THE astroglial contribution to cognition remains DEBATABLE, however, and are in need of further investigation".

ii) The next sentence lacks a definite or indefinite article in front of 'tripartite synapse', whereby the sentence "The concept of tripartite synapse..." should read "The concept of the tripartite synapse" or "The concept of a tripartite synapse'.

Our reply: thank you for these suggestions which we of course accept; one of us (DCA) who is a native speaker made a careful proofreading

Reviewer \#2: This review by Augusto-Oliveira is very well written, interesting and provides a comprehensive view of astroglial structure and function across species, stages of the lifespan and CNS regions. I only have a few suggestions to improve further the impact of the manuscript.

Our reply: We are very grateful for this evaluation

\section{1.}

When discussing astrocytic markers, it could be mentioned that GLT1 and GLAST can also be expressed by microglia

\section{Our reply: Done}

\section{3.}

It would be interesting to mention other environmental stimulations known to drive morphological astrocytic changes, in addition to physical activity and environmental enrichment

Our reply: Thank you - very good point - we added some discussion on the role of diet (caloric restriction) which similarly affects astroglial morphology.

4.

There is a typo to correct in "structures"

\section{Our reply: Corrected}




\subsection{3.}

I would revise the sentence

"TNFa is directly involved in this type of plasticity, and astroglia were identified as the principal source of this cytokine (Stellwagen and Malenka, 2006)."

Importantly, this paper mentions both microglia and astrocytes as sources of the cytokine. Subsequent work from David Stellwagen also identified microglia as mediating these effects of TNFa (in a context of cocaine-induced plasticity; https://pubmed.ncbi.nlm.nih.gov/27112496/)

Our reply: Corrected as suggested and reference added

Figure 3

I would recommend to use the wording 'In concert with microglia'

Our reply: Done

This figure illustrates the roles of astroglia in the modulation of the blood brain barrier Considering the importance of this function, I would recommend to add a small dedicated section to the review

Our reply: We added a small section on BBB and glio-vascular coupling.

\section{Conclusion}

The review often mentions other glial cells, e.g. microglia. It would be interesting to mention briefly that astroglial functions are performed in coordination with these other cells

Our reply: We cannot agree more about the importance of microglia; and throughout the text we made several notions that astrocytes are working together with microglia (for example in synaptic elimination, where microglial cells are actual strippers of the unwanted synaptic structures). At the same time this topic I quite wide and requires a dedicated paper; in this our review we tried to focus specifically on astroglial mechanisms controlling behavior and synaptic transmission, and we are very much afraid that extending these mechanisms to astroglia-microglial interactions may dilute the message and increase the volume of this review beyond reason. 
- Astrocytes represent heterogeneous in form and function population of cells responsible for homeostasis of the CNS

- Astroglial cradle modulates synaptic transmission through secretion of multiple signalling molecules

- Astrocyte-specific pathways regulate synaptogenesis, synaptic plasticity and synaptic elimination

- Astrocyte-specific molecular cascades contribute to learning, memory and cognition

- Astrocyte-specific mechanisms modify behaviours such as motor activity, mood, emotion, sleep, and food intake 


\begin{abstract}
Astrocytes are heterogeneous population of neural cells with diverse structural, functional and molecular characteristics responsible for homeostasis and protection of the central nervous system (CNS). Unlike neurones, astrocytes do not generate action potentials, but employ fluctuations of cytosolic ions as a substrate for their excitability. Ionic signals are associated with neuronal activity and these signals initiate an array of responses ranging from the activation of plasmalemmal homeostatic transporters to the secretion of numerous signalling molecules including neuromodulators, neurotransmitter precursors, metabolic substrates, trophic factors and cytokines. Thus, astrocytes regulate the synaptic connectivity of the neuronal networks by supporting neurotransmitter metabolism, synaptogenesis, synaptic elimination and synaptic plasticity contributing to cognitive processing including learning, memory, emotions and behaviour. Astroglia-specific regulatory pathways affect the most fundamental properties of neuronal networks from their excitability to synaptic connectivity. Thus, it is the concerted action of glia and neurones, which, by employing distinct mechanisms, produce behavioural outputs of the ultimate control centre that we call the brain.
\end{abstract}




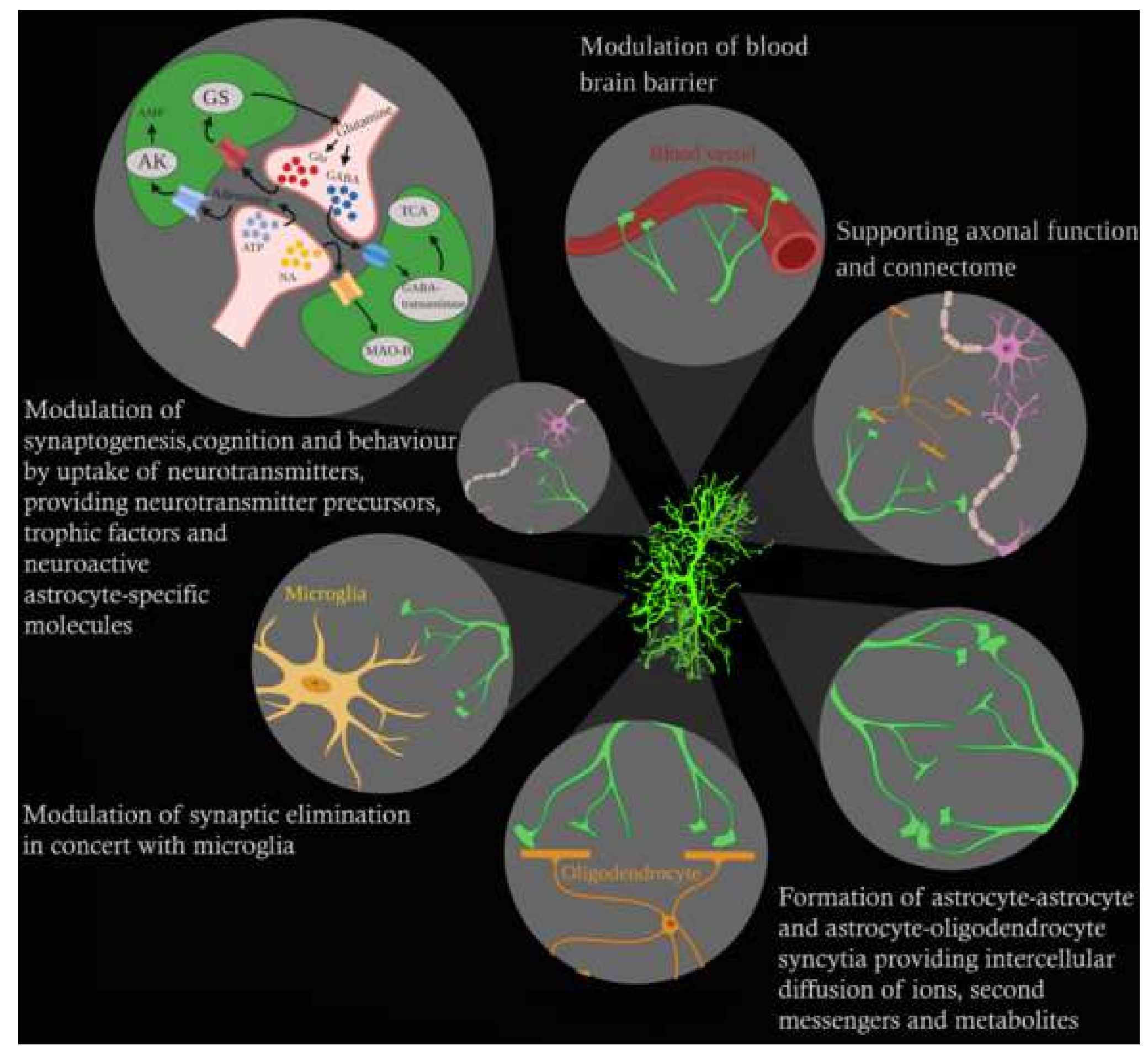




\section{Astroglia-specific contributions to the regulation of synapses, cognition and behaviour}

Marcus Augusto-Oliveira ${ }^{1,2}$, Gabriela P. Arrifano ${ }^{1,2}$, Priscila Y. Takeda ${ }^{1}$, Amanda Lopes-Araújo $^{1}$, Leticia Santos-Sacramento ${ }^{1}$, Daniel C. Anthony ${ }^{2}$, Alexei Verkhratsky $^{3,4,5^{*}}$ \& Maria Elena Crespo-Lopez ${ }^{1, *}$

${ }^{1}$ Laboratório de Farmacologia Molecular, Instituto de Ciências Biológicas, Universidade Federal do Pará, 66075-110 Belém, Brasil;

${ }^{2}$ Laboratory of Experimental Neuropathology, Department of Pharmacology, University of Oxford, Oxford OX1 3QT, UK;

${ }^{3}$ Faculty of Biology, Medicine and Health, University of Manchester, Manchester M13 9PT, UK and Achucarro Centre for Neuroscience, IKERBASQUE, Basque Foundation for Science, 48011 Bilbao, Spain.

${ }^{5}$ Sechenov First Moscow State Medical University, Moscow, Russia

* Senior authors

Correspondence:

Dr. Marcus Augusto-Oliveira

Laboratório de Farmacologia Molecular,

Instituto de Ciências Biológicas, Universidade Federal do Pará, 66075-110 Belém,

Brasil

Email: marcusoliveira@globo.com

Prof Maria Elena Crespo-Lopez

Laboratório de Farmacologia Molecular,

Instituto de Ciências Biológicas, Universidade Federal do Pará, 66075-110 Belém, Brasil

Email: maria.elena.crespo.lopez@gmail.com

Prof. Alexei Verkhratsky

Faculty of Biology, Medicine and Health

University of Manchester

Manchester, M13 9PT, UK

Email: Alexej.Verkhratsky@manchester.ac.uk 


\begin{abstract}
Astrocytes are heterogeneous population of neural cells with diverse structural, functional and molecular characteristics responsible for homeostasis and protection of the central nervous system (CNS). Unlike neurones, astrocytes do not generate action potentials, but employ fluctuations of cytosolic ions as a substrate for their excitability. Ionic signals are associated with neuronal activity and these signals initiate an array of responses ranging from the activation of plasmalemmal homeostatic transporters to the secretion of numerous signalling molecules including neuromodulators, neurotransmitter precursors, metabolic substrates, trophic factors and cytokines. Thus, astrocytes regulate the synaptic connectivity of the neuronal networks by supporting neurotransmitter metabolism, synaptogenesis, synaptic elimination and synaptic plasticity contributing to cognitive processing including learning, memory, emotions and behaviour. Astroglia-specific regulatory pathways affect the most fundamental properties of neuronal networks from their excitability to synaptic connectivity. Thus, it is the concerted action of glia and neurones, which, by employing distinct mechanisms, produce behavioural outputs of the ultimate control centre that we call the brain.
\end{abstract}

Key words: astrocyte; synaptic connectivity; synaptogenesis; synaptic plasticity; synaptic elimination; cognition; learning and memory; behaviour 


\section{Introduction: astrocytes support cognitive functions}

The neuronal doctrine, which emerged from seminal ideas of Ramon y Cajal who contemplated directional information flow through synaptically connected neuronal ensembles, assumes these neuronal constellations the primary and the only substrate of the higher cognitive functions that include emotions, learning, memory and generation of thoughts. This paradigm of neuronal pre-eminence in information processing started to be challenged almost form the moment that the neuronal doctrine emerged. In 1895, Carl Ludwig Schleich suggested that astrocytes, through swelling or contracting their processes, may mechanically block or permit communication in the synapse (Schleich, 1894). One year later, Ramon y Cajal in his book on astroglial functions entertained similar ideas of astroglial processes controlling the sleepwakefulness brain state: expansion of astroglial processes suppresses synaptic connectivity and induces sleep, whereas their retraction allows synaptic transmission thus inducing arousal (Ramón y Cajal, 1895). The concept of fundamental role of astroglia in cognition has never become extinct; it approached climax in writings of Robert Galambos who argued the supremacy of glia in brain functions: "Glia is [...] conceived as genetically charged to organize and program neuron activity so that the best interests of the organism will be served; the essential product of glia action is visualized to be what we call innate and acquired behavioural responses. In this scheme, neurones in large part merely execute the instructions glia give them" (Galambos, 1961). In supporting this unorthodox design Galambos invented the most popular misquote of Fritjof Nancen, "glia is the seat of intelligence as it increases in size from the lower to the higher forms of animal", which never occurred in Nancen's original text (Nansen, 1886).

The last decade, when in vivo studies of astroglia have become more common, new compelling data have emerged indicating that astrocytes do indeed contribute to higher brain functions, including memory and learning (Adamsky et al., 2018; Gao et al., 2016; Hertz and Gibbs, 2009; Verkhratsky et al., 2015; Zorec et al., 2015), whereas pathophysiological experimentations has revealed a more prominent role for astrocytes in disorders of mood, emotion and social integrations (Banasr and Duman, 2008; Leng et al., 2018; Li et al., 2020; Rajkowska and Stockmeier, 2013; Verkhratsky et al., 2010; Verkhratsky et al., 2014; Wang et al., 2017). Mechanisms underlying the astroglial contribution to cognition remain debatable and are in need of further investigation. The concept of a tripartite synapse that revolutionised glial research by suggesting astroglial participation in synaptic transmission through vesicular release of neurotransmitters (Araque et al., 1999), has met with criticism (Hamilton and Attwell, 2010; Nedergaard and Verkhratsky, 2012) and is yet to be characterised in vivo. At the same time a wealth of data showing that astrocytes may influence neuronal plasticity, information processing and behaviour by astrogliaspecific (i.e. distinct from neuronal) mechanisms acting though homeostatic support or regulation of synapse formation, elimination and plasticity has emerged. In this narrative, we shall review these newly discovered pathways and mechanisms that place astrocytes as indispensable elements of neural networks underlying higher brain functions.

\section{Heterogeneity of homoeostatic astroglia}


Neuroglia represent a class of cells of neuronal (macroglia) and myeloid (microglia) origin; neuroglial cells are distributed throughout the brain and spinal cord and perform the most diverse functions in the central nervous system (CNS), being mainly responsible for homeostasis and defence. The macroglia, derived from neuroectoderm, is composed of astrocytes, oligodendrocytes, and oligodendroglial precursors also known as NG2 cells, while the microglial cells, derived from the embryonic macrophages migrating from the yolk sac, represent the defensive and immunocompetent arm of the CNS (Augusto-Oliveira et al., 2019; Ginhoux et al., 2010; Kettenmann et al., 2011; Kettenmann and Verkhratsky, 2008; Reemst et al., 2016; Verkhratsky and Butt, 2013; Verkhratsky et al., 2019a).

There is a common, although erroneous, belief that glial cells outnumber neurones in the human brain by a factor of 10 (Kast, 2001). Experimental studies firmly established that overall counts of neurones and glia in the human brain are roughly equal (von Bartheld et al., 2016). The glia to neurone ratio varies between brain structures and between species (Herculano-Houzel, 2014). Astrocytes in particular account for $\sim 20-40 \%$ of all glia; astroglial cells are generally more numerous than neurones in cortical regions, and substantially less numerous in the cerebellum; of note astrocytes indeed outnumber neurones several times in the spinal cord of humans and primates (Herculano-Houzel, 2014; Sherwood et al., 2006; Sun et al., 2017; Verkhratsky and Butt, 2018; von Bartheld et al., 2016).

Astrocytes are primary homeostatic cells of the CNS (Verkhratsky and Nedergaard, 2016, 2018) which are distributed throughout the brain and the spinal cord; these cells in the nervous tissue present a remarkable morphological, molecular and functional diversity, which was generally acknowledged from the very dawn of neuroglial research (Fig. 1). According to morpho-functional criteria astrocytes are subclassified into (Fig. 2) (Verkhratsky and Nedergaard, 2018; Verkhratsky et al., 2019b): (i) radial glia, which are the pluripotent neural cells precursors that disappear at birth in mammals; (ii) protoplasmic astrocytes of grey matter; (iii) fibrous astrocytes of white matter; (iv) specialised astrocytes: (a) velate astrocytes, which are found in the brain areas densely packed with small neurones, for example in the olfactory bulb or in the granular layer of the cerebellar cortex, (b) perivascular and marginal astrocytes, localised near the pia mater, where they form endfeet with blood vessels (these astrocytes do not establish contacts with neurons and their main function is in establishing the pial and perivascular glia limitans barriers), (c) pituicytes, the astrocytes of the neurohypophysis, (d) Gomori astrocytes rich in iron and positive for Gomori's chrome alum hematoxylin staining identified in the hypothalamus and in the hippocampus and (e) surface-associated astrocytes associated with the cortical surface in the posterior prefrontal and amygdaloid cortex; (v) radial astrocytes, which include (a) Bergmann glia in the cerebellum, (b) Müller glia of the retina, (c) tanycytes of the hypothalamus, hypophysis and the raphe part of the spinal cord and (d) radial glia-like neural stem cells of the neurogenic niches; (vi) ependymocytes, choroid plexus cells and retinal pigment epithelial cells. These cells line up the ventricles and the subretinal space; the choroid plexus cells produce the cerebrospinal fluid. Ependymocytes possess small movable processes (microvilli and kinocilia), which by rhythmic movements produce a stream of cerebrospinal fluid. Additionally, the brains of humans and higher primates contain highly specialised astrocytes such as interlaminar astrocytes, polarised astrocytes and astrocytes with varicose projections (Fig. 2). 
Astrocytes make direct contact with neurones, oligodendrocytes, microglia and blood vessels interacting with all these elements (Fig. 3). In particular, in grey matter protoplasmic astrocytes create spatially segregated territorial domains; within these domains astrocytes integrate neurones, synapses, and neighbouring capillaries into the neuro-gliovascular (or neurovascular) unit (Iadecola, 2017). Perivascular processes of protoplasmic astrocytes terminate with endfeet which plaster brain blood vessels; while the release of vasoctive agents from these endfeet contribute to regulation of local blood flow at the levels of capillaries (Mulligan and MacVicar, 2004; Zonta et al., 2003). Astrocytes are also interacting with endothelial cells which form the blood-brain barrier; astroglia-derived factors control the integrity of the barrier, in particular by regulating expression of tight junctions in the endothelial layer (Sweeney et al., 2019). Astroglial asthenia, for example in neurodegenerative pathologies, may result in a loss of this regulatory support, which leads to a downregulation of tight junction expression and increase in the permeability of the bloodbrain barrier (Kriauciunaite et al., 2020).

Astrocytes possess receptors to all types of neurotransmitters and neuromodulators; although the expression of these receptors is tightly regulated by immediate neurochemical environment (Verkhratsky, 2010; Verkhratsky et al., 1998). Being equipped with all these receptors, astrocytes receive information associated with neuronal synaptic transmission, which triggers astroglial functional responses. Astrocytes are utilising specific form of intracellular "ionic" excitability, relying on fluctuations of cytosolic concentration of ions such as $\mathrm{Ca}^{2+}, \mathrm{Na}^{+}, \mathrm{K}^{+}$and $\mathrm{Cl}^{-}$ (Kirischuk et al., 1997; Kirischuk et al., 2012; Rose and Verkhratsky, 2016; Verkhratsky et al., 2019c). We shall start our narrative with an overview of astroglial functions in the healthy brain, with subsequent presentation of astroglial role in synaptic processes such as synaptogenesis, synaptic plasticity and synaptic elimination which highlight astrocytes as a target for regulating synaptic connectivity, information processing, cognition and associated behaviours.

\section{Brief on astrocyte morphology, markers and physiology}

\subsection{Morphology and markers}

The striking morphological heterogeneity of astroglial cells have been documented by numerous neuroanatomists of late $19^{\text {th }}$ and early $20^{\text {th }}$ centuries (Chvatal and Verkhratsky, 2018; Golgi, 1903; Kettenmann and Verkhratsky, 2008; Ramón y Cajal, 1909; Retzius, 1894). It remains poorly understood how astrocytes mature and reach their morphological complexity, although the field has progressed recently. To reach morphological complexity, astrocytes need to interact with other cells in the nervous tissue. Astrocyte maturation, for example, depends on astrocyte-to-astrocyte contact and is regulated by heparin-binding epidermal growth factor-like growth factor (HBEGF) and epidermal growth factor receptor (EGFR) signalling (Li et al., 2019). Astrocytic morphogenesis and complexity is regulated by fibroblast growth factor heartless signalling and astrocytic adhesion protein neuroligin (NLG) 1, 2 and 3, which interact with neuronal neurexins (NRX) (Stogsdill et al., 2017; Stork et al., 2014). There are some indications that astrocyte morphological complexity is also regulated by brain-derived neurotrophic factor (BDNF)/truncated TrkB (TrkB.T1) signalling. Deletion of astrocytic TrkB.T1 in mice resulted in appearance of 
morphologically immature astroglia associated with molecular and functional disruption (Holt et al., 2019).

Substantial morphological differences in astrocytes are also found within the same structures. Based on three-dimensional morphological reconstruction, different subgroups of astrocytes were detected in molecular layer of the dentate gyrus of rodents and in the hippocampal formation of migratory birds. These subgroups respond in a different manner to environmental changes, ageing (Diniz et al., 2016), and to physical activity in birds (long non-stop flight) (Carvalho-Paulo et al., 2017). These findings suggest that different functions are performed by astrocytic subgroups within the same brain structure.

Visualisation of morphological profiles of astrocytes in the nervous tissue relies upon immunocytochemistry of astroglia-specific markers. The oldest (Eng et al., 1971) and the most popular (Hol and Pekny, 2015) astroglial marker is the glial acidic fibrillary protein (GFAP), which is highly expressed in majority of astrocytes in vitro in culture. In healthy brain tissue, however, the majority of astrocytes do not express GFAP at the level of detection that is possible with immunohistochemistry, and hence a substantial sub-population of astrocytes are not labelled with GFAP-antibodies (Savchenko et al., 2000; Yeh et al., 2013). Other markers for astrocytes are glutamine synthetase (GS), vimentin, astroglial glutamate transporters (GLAST/EAAT1 and GLT1/EAAT2), proteins of aldehyde dehydrogenase 1 family member L1 (ALDHL1), transcriptional factor SOX9, S100B calcium binding protein, the plasma membrane protein/extracellular marker receptor CD44, etc. (Olabarria et al., 2011; Sosunov et al., 2014; Verkhratsky and Nedergaard, 2018). Some of these markers demonstrate regional specificity - for example $\mu$-crystalline was reported to be specific for striatal astrocytes (Chai et al., 2017). The expression pattern of astroglial markers changes during development and ageing, and differs between brain regions; quite often astrocytes co-express more than one marker (Ben Haim and Rowitch, 2017; Lein et al., 2007; Middeldorp and Hol, 2011; Rodriguez et al., 2014; Yeh et al., 2013). Of note, some of these astroglial markers can be expressed in other cells of the CNS: for example glutamate transporters were found in microglial cells especially in those undergoing microgliosis (Lopez-Redondo et al., 2000; Persson et al., 2005).

\subsection{Idiosyncratic human astrocytes}

Astrocytes of higher primates and humans exhibit greater volumes, larger number of branches, and higher arborisation complexity when compared to astroglial cells of rodents (Oberheim et al., 2006; Verkhratsky et al., 2018). Larger and more complex protoplasmic human astrocytes contact many more synapses compared to astroglia of the rodents. In humans, astrocytes cover about 2,000,000 synapses in the hippocampus (Oberheim et al., 2009; Verkhratsky et al., 2018) whereas the number contacted in the rodent hippocampus does not exceed 80,000 to 120,000 (Bushong et al., 2004). Moreover, human astrocytes propagate calcium waves with a speed of up to $36 \mu \mathrm{m} / \mathrm{s}$, which is many times faster than that of rodent astrocytes (Oberheim et al., 2009).

The brains of humans and of some primates also contain several types of highly specialised astrocytes, which are absent in other species (Fig. 2). The interlaminar astrocytes (observed by many neuroanatomists of $19^{\text {th }}$ century and characterised in 
detail by Jorge Colombo (Andriezen, 1893; Colombo, 2017; Martinotti, 1889; Retzius, 1894)) have small spherical cell bodies localised in the subgranular layer of the cortex; these cell bodies emanate several very long $(\sim 1 \mathrm{~mm})$ spiriform processes, which penetrate to cortical layers II to IV. The processes of interlaminar astrocytes terminate with boutons, which are also known as terminal masses or end bulbs. The interlaminar astrocytes are positive for GFAP, S100B and CD44; however they express low levels of glutamate transporters and glutamine synthetase (Oberheim et al., 2009; Sosunov et al., 2014). Human brains also contain several subtypes of astrocytes with long processes, known as polarised astrocytes or astrocytes with varicose projections; somata of these astrocytes can be found in different cortical layers; these astrocytes are immunopositive for CD44 and GFAP and often demonstrate a mixed marker phenotype between protoplasmic fibrous and interlaminar astrocytes (Sosunov et al., 2014).

\subsection{Structural plasticity of astrocytes}

Astrocytes undergo morphological changes in the course of physiological activity of the brain associated with adaptive plasticity. Such morphological plasticity of astroglia is for example observed in response to environmental stimulation, including physical activity (Salois and Smith, 2016; Saur et al., 2014). Ageing has been shown to decrease the complexity of astroglial profiles is some brain regions (Rodriguez et al., 2014), whereas environmental stimulation counteracts these age-dependent changes (Diniz et al., 2016; Jyothi et al., 2015). Exposure of aged rats to 3-months of enriched environment improved their spatial memory and increased density of GFAP positive astrocytes and enhanced their arborisation in all areas of hippocampus (Sampedro-Piquero et al., 2014). Such morphological plasticity of astrocytes is also observed in pathology: for example, physical activity and enriched environment rescues astroglial morphological atrophy in mouse models of Alzheimer's disease (Beauquis et al., 2013; Rodriguez et al., 2013). An enriched environment in combination with physical activity (but not physical activity alone) was shown to rescue failing astroglial population in the visual cortex of sensory deprived (housing in the dark) rats (Bengoetxea et al., 2013). At the sub-cellular level, synaptic plasticity is accompanied by morphological remodelling of astroglial processes and changes in peripheral processes of astrocytes determine the degree of synaptic coverage (Heller and Rusakov, 2015). These changes in peripheral astroglial processes may occur not only in response to various types of environmental stimulation but to changes of diet. For example, two months of caloric restriction provoked significant outgrowth of astroglial perisynaptic processes, which, in turn, was associated with an increase longterm potentiation (LTP) in hippocampus (Popov et al., 2020).

\subsection{Molecular heterogeneity}

Morphological heterogeneity of astrocytes is associated with substantial molecular diversity, as revealed by modern molecular profiling techniques (Cahoy et al., 2008; Chai et al., 2017; Yeh et al., 2009). Astrocytes within different brain regions as well as of different species possess distinct transcriptional profiles (Doyle et al., 2008; John Lin et al., 2017; Morel et al., 2017). For instance, the morphology, transcriptomes, and proteomes of striatal and hippocampal astrocytes are significantly different. Both types of astrocytes shared the similar proteins responsible for core astroglial functions such as $\mathrm{K}^{+}$buffering, however 2800 transcripts were significantly 
different between these two astroglial populations (Chai et al., 2017). In the cortex, molecular signatures of astrocytes appear to be layer specific with layer-dependent interactions between astrocytes and neurones (Lanjakornsiripan et al., 2018); singlecell transcriptomics of cortical astroglia revealed layered segregation of astrocytes with distinct gene expression signatures (Bayraktar et al., 2020). In the cerebellum, the astrocyte molecular profile is closely linked to the transcriptional profile of neighbouring neurones, where one determines the molecular specificity of the other (Farmer et al., 2016). This striking diversity may result in the invocation of distinct astroglial pre-programmes. For example, physical activity induces region-specific morphological and gene expression changes, suggesting differential astrocyte functionality associated with different astroglial populations (Lundquist et al., 2019).

\subsection{Functional heterogeneity}

Remarkable molecular diversity of astrocytes reflects their ability to express multiple cell-specific sets of neurotransmitter receptors, ion channels and transporters congruent with the homeostatic demands of their immediate environment, such as those associated with synaptic transmission (Hamilton and Attwell, 2010; Olsen et al., 2015; Verkhratsky, 2010; Verkhratsky and Nedergaard, 2018). Physiological stimulation of astroglial receptors trigger specific forms of glial excitability that are associated with spatio-temporally organised fluctuations of cytosolic concentration of ions. The intracellular $\mathrm{Ca}^{2+}$ and $\mathrm{Na}^{+}$excitability of astrocytes is well documented (Bazargani and Attwell, 2016; Rose and Verkhratsky, 2016; Verkhratsky et al., 1998), whereas the signalling role for $\mathrm{K}^{+}$and $\mathrm{Cl}^{-}$is yet to be properly characterised (Verkhratsky et al., 2019c). Astroglial $\mathrm{Ca}^{2+}$ signals, evoked by neuronal activity, mechanical and chemical stimuli control gene expression, trigger astroglial secretion and instigate reactive astrogliosis (Alberdi et al., 2013; Kanemaru et al., 2013; Khakh and McCarthy, 2015; Parpura et al., 2010; Stobart et al., 2018; Verkhratsky et al., 2016; Verkhratsky et al., 2012). Astroglial intracellular signalling mediated by $\mathrm{Na}^{+}$ regulates numerous plasmalemmal $\mathrm{Na}^{+}$-dependent solute carrier (SLC) transporters responsible for astroglial homeostatic capabilities. These transporters are critical for uptake of neurotransmitters (glutamate, $\gamma$-amino butyric acid, GABA, adenosine and catecholamine), for ionostasis of the interstitial fluids, for supply of neurotransmitter precursors and for buffering of reactive oxygen species (Rose et al., 2020; Verkhratsky and Rose, 2020). Astroglial ionic signalling couple astroglial functions with neuronal activity and allow astroglial cells to modulate neuronal excitability and synaptic transmission (Martin et al., 2015; Schipke et al., 2008).

The remarkable morphological and molecular heterogeneity of astrocytes underlies their contribution to fundamental functions of the CNS, from osmotic balance to cognitive processes. Astrocytes interact with other astrocytes and oligodendrocytes, with synapses (where they regulate neurotransmitter metabolism and provide energy substrates), with microglia and with blood vessels (Fig. 3). In the next sections, we shall cover several astroglia-specific mechanisms responsible for regulation of synaptic connectivity and synaptic plasticity, which underlie cognitive processes and behavioural outputs.

\section{Astroglial synaptic coverage and astroglial cradle}


Probably $\sim 50-60 \%$ of all synaptic structures in the CNS are enwrapped with membranous leaflets formed by terminal extensions of peripheral astroglial processes. The degree of astroglial coverage differs between brain regions; for example in hippocampus $60-90 \%$ of synapses are covered by astroglial leaflets (Ventura and Harris, 1999; Witcher et al., 2007); in the cerebellum, appendages emanating from Bergman glial cell processes cover $\sim 90 \%$ of synapses formed by climbing fibres and $\sim 65 \%$ of synapses formed by parallel fibres on Purkinje neurones (Grosche et al., 1999; Xu-Friedman et al., 2001), while in the neocortex 30-55\% of synapses have astroglial coverage (Bernardinelli et al., 2014). The perisynaptic astroglial leaflets are exceedingly thin $(\sim 100-200 \mathrm{~nm})$, and they do not have organelles (Patrushev et al., 2013; Peters et al., 1991; Reichenbach et al., 2010), except tiny spherical mitochondria (Derouiche et al., 2015). These perisynaptic structures are immunopositive for glutamate synthetase, astroglial glutamate transporters, ezrin and radixin while being immunonegative for GFAP (Derouiche, 2003; Derouiche et al., 2002; Reichenbach et al., 2010). Astroglial perisynaptic processes are characterised by a high surface to volume ratio $\left(\sim 25 \mu^{-1}\right)$ and they account $\sim 80 \%$ of the total surface area of an astrocyte, although occupying only $4-10 \%$ of total cell volume (Grosche et al., 2002).

Utilising these intimate contacts between astroglial membranes and synaptic structures astroglia regulate synaptic connectivity and synaptic function through numerous pathways, which include homeostatic control over the synaptic cleft, catabolism of neurotransmitters, supply of neuronal elements with neurotransmitter precursors and secretion of numerous trophic factors that influence synaptogenesis, synaptic maturation and synaptic elimination. These multiple roles for astrocytes in the regulation of synaptic transmission have been integrated in a concept of astroglial cradle (Nedergaard and Verkhratsky, 2012; Verkhratsky and Nedergaard, 2014). This concept envisages that the astroglial perisynaptic structure is a versatile instrument, regulating synaptic function through numerous complementary astroglia-specific pathways.

\section{Astrocytes regulate synaptic formation, maintenance and plasticity}

\subsection{Astrocytes and synaptogenesis}

The initial phases of the embryonic brain development are dominated by neuronogenesis; with gliogenic switch emerging at later stages with peak in astrogliogenesis occurring in postnatal period (Fig. 4), and astroglial maturation being attained around postnatal day 50 in rats (Stichel et al., 1991). In rodents neurones appear around embryonic day E12, whereas first astrocytes emerge at around E18 (Miller, 2018). Neural precursor cells (NPCs) first generate neurones and then astrocytes (Fig. 4), although the mechanisms underlying this transition are still not fully understood. Initial activation of pro-neuronal genes neurogenin 1 and neurogenin2, which promote neuronal differentiation, is associated with $\mathrm{Wnt} / \beta$ catenin signalling pathway (Hirabayashi et al., 2004). Subsequently, polycomb group complex stimulates the transition of NPCs differentiation from neuronal to astroglial cells, at the same time suppressing the promotor neurogenin1 in a developmentalstage-dependent manner (Hirabayashi et al., 2009). In addition, Mek1 and Mek2 perform critical function allowing radial glia to activate gliogenic mode in the late embryogenesis (Li et al., 2012). 
The life cycle of the synapse includes the following stages (i) formation of an initial contact between the presynaptic terminal and postsynaptic neurone; (ii) maturation; (iii) stabilisation and maintenance and (iv) elimination. For a substantial subpopulation of synapses, the progression through these stages is regulated by the astroglial cradle formed by perisynaptic processes of astrocytes (Verkhratsky and Nedergaard, 2014). The seminal observation of fundamental contribution of astrocytes to the synaptogenesis was made by Frank Pfrieger and Ben Barres (Pfrieger and Barres, 1997) on finding that the addition of astrocytes to neuronal cultures results in 7-fold increase in synaptic density. Subsequent in vivo studies demonstrated that majority of synapses are formed concurrently with astrocytes, and astrocytes are needed for synaptic maturation (Ullian et al., 2001). Rat retinal ganglion cells, for example, cannot generate synapses before embryonic day 19, when the first astrocytes begin to emerge (Barker et al., 2008). Astrocytes influence synaptogenesis by contactdependent mechanism(s) or by release of soluble factors inducing synaptic formation (Fig. 5 and Table 1 - see also (Barker et al., 2008; Hama et al., 2004)). For instance, adhesion proteins such as $\gamma$-protocadherin, localised in astrocytic perisynaptic processes, promote synaptogenesis through contact with neurones (Garrett and Weiner, 2009). However, recently it was found that $\gamma$-protocadherin contacts with neuregulin 1 (NLG-1) inhibiting its ability to bind neurorexin $1 \beta$ (NRX-1 $\beta$ ) thus preventing synaptogenesis (Molumby et al., 2017). These apparent contradictory findings may reflect different roles for $\gamma$-protocadherin in different classes of neurones at different times.

\subsubsection{Thrombospondins}

Thrombospondins (TSP), belong to a 5-member family of $\mathrm{Ca}^{2+}$-binding extracellular glycoproteins. Homotrimeric TSP-1 and TSP-2 which are necessary for generation of excitatory synapses are expressed in and are secreted by astrocytes (Christopherson et al., 2005; Hughes et al., 2010). Exposure to TSP increases the total number of synapses, but these remain functionally inactive; this silence mode reflects the lack of $\alpha$-amino-3-hydroxy-5-methyl-4-isoxazolepropionic acid receptors (AMPAR) in the postsynaptic membrane (Christopherson et al., 2005). Of note, TSPs reduce AMPAR presence also in mature neurones (Hennekinne et al., 2013). Synaptic maturation requires insertion of AMPAR into the postsynaptic membrane, and this maturation is similarly regulated by astrocytes through secretion of tumour necrosis factor- $\alpha$ (TNF$\alpha$ ), glypicans 4 and 6 and Wnt, and by extracellular matrix (Allen et al., 2012; Beattie et al., 2002; Frischknecht et al., 2009; Kerr et al., 2014; Pyka et al., 2011).

Synaptogenic effects of TSP are mediated through postsynaptic gabapentin receptors $\alpha 2 \delta 1$ (Eroglu et al., 2009), which in turn mobilise the postsynaptic Rac1, a small Rho GTPase that promotes actin reorganisation thus leading to spine reorganisation and initiation of synapse formation (Risher et al., 2018). Experiments in vitro have also demonstrated that TSPs interact with postsynaptic NLG-1, which also increases formation of excitatory synapses (Xu et al., 2010). NLG-1 acts as a synaptic partner to presynaptic adhesion protein NRX, arranging synaptic elements into the proper position for synaptic formation (Allen, 2014; Clarke and Barres, 2013). The coupling between NLG-1 and NRX is also essential for long-term potentiation (LTP), and the strengthening of synaptic connections, which results in long-lasting changes in output in response to transiently increased input, and the related-LTP spine growth (Wu et al., 
2019). The view that neuronal NLGs are solely responsible for synaptogenesis was recently challenged: it appears that astrocytic NLG-2 exerts control of synaptic formation (Stogsdill et al., 2017). The absence of NLG-2 secretion from cortical astrocytes in vivo there is a reduction in the formation of excitatory synapses and an enhancement of the formation of inhibitory synapses (Stogsdill et al., 2017). These effects may be exerted through neuronal NRXs or by affecting the astroglial release of synaptogenic factors such as TSPs or hevin. In the retina, TSP-1 secreted by Müller glia controls the genesis of excitatory synapses on retinal ganglions cells through neuronal TSP-1 receptor $\beta$-integrin (Koh et al., 2020).

\subsubsection{Hevin}

Hevin (also known as SPARC-like protein 1) and secreted protein acidic rich in cysteine (SPARC) are matricellular proteins of the extracellular matrix (Brekken and Sage, 2001). Hevin promotes maturation of silent synapses (lacking postsynaptic AMPAR) in the superior colliculus, whereas SPARC antagonises the hevin effects (Kucukdereli et al., 2011) by inhibiting postsynaptic $\beta 3$ integrins and, consequently, destabilizing AMPAR in the postsynaptic membrane (Jones et al., 2011). In mice, deletion of hevin causes a decrease in the number of synapses whereas in the absence of SPARC synaptic density increases (Kucukdereli et al., 2011). In the adulthood, a decrease in the SPARC expression occurs, but hevin remains widely expressed (Kucukdereli et al., 2011). The molecular mechanisms of hevin-induced synaptogenesis involve the synaptic adhesion molecules NRX1 $\alpha$ and NLGs; hevin promotes bridging between these two molecules (Singh et al., 2016). For example, these two proteins are crucial for the thalamocortical synaptogenesis during brain development (Singh et al., 2016).

\subsubsection{Glypicans 4 and 6}

In contrast to both TSPs and hevin, astroglia-secreted glypicans 4 and 6 trigger formation of active synapses, which is associated with clustering of GluA1 subunit of AMPAR in the postsynaptic membrane (Allen et al., 2012). This mobilisation of AMPARs results from glypican-stimulated release of the AMPAR clustering factor neuronal pentraxin 1 from the presynaptic terminal; this is mediated by receptor of protein tyrosine phosphatase type 2 (RPTP2) (Farhy-Tselnicker et al., 2017).

\subsubsection{Transforming growth factor $\beta$-1}

The transforming growth factor $\beta-1$ (TGF $\beta-1)$ also secreted by astrocytes is a cytokine related to neuronal survival (Krieglstein et al., 2002), cellular migration (Siegenthaler and Miller, 2004), gene expression (Lesne et al., 2002) and astrocyte differentiation (Gomes et al., 2005). The TGF $\beta-1$ promotes synaptogenesis of both inhibitory and excitatory synapses in rodents and humans (Diniz et al., 2012; Diniz et al., 2014). In cortical neurones TGF $\beta-1$ stimulates formation of inhibitory synapses through CaM Kinase II (CAMKII) signalling, which induces cluster formation of NLG-2 in postsynaptic terminals (Diniz et al., 2014). Blockade of CAMKII disrupt inhibitory synaptogenesis but has no effect formation of excitatory synapses (Diniz et al., 2014). The excitatory synaptogenesis induced by TGF $\beta-1$ in the cerebral cortex utilises D-serine signalling, and the disruption of this pathway blocks the effects of TGFß-1 (Diniz et al., 2012). 
Synaptogenesis in cerebellar granule neurones is similarly controlled by TGF $\beta-1$ (Araujo et al., 2016). Cerebellar granule neurones express TGF $\beta-1$ receptor T $\beta$ RII at both mRNA and protein level. Expression of TGF $\beta-1$ and T $\beta$ RII in cerebellum is developmentally regulated: is low in early postnatal days P1 to P9 and it increases after P12 and remains at high levels in adulthood (>P30), consistent with its role in synaptogenesis. Treatment with TGF $\beta-1$ led to a two-fold increase in glutamatergic synapses, which effect was inhibited by pharmacological blockage of T $\beta$ RII receptor (Araujo et al., 2016). The TGF $\beta-1$ pathway can be also operation in pathology. Recent finding demonstrated that TGF $\beta-1$ prevents synaptic loss in Parkinson's disease (PD) model (Diniz et al., 2019). Treatment with $\alpha$-synuclein (endogenous neurotoxin implicated in PD pathophysiology) triggered reactive astrogliosis, which was associated with an increased secretion of TGF $\beta-1$ and increased synaptogenesis (Diniz et al., 2019).

\subsubsection{Cholesterol}

Another astroglia-derived factor indispensable for synaptogenesis is represented by cholesterol (Mauch et al., 2001). Neuronal production of cholesterol is rather limited, and astrocytes have been found to supply extra amounts of cholesterol associated with apolipoprotein E (ApoE)-containing lipoprotein. Molecular mechanisms of cholesterol-dependent promotion of synapse formation are yet to be fully characterised, although studies of recent decade revealed several astroglia-associated pathways. The sterol regulatory element-binding protein 2 (SREBP2), the major transcription factor regulating cholesterol synthesis, tightly controls the cholesterol levels in the brain (Brown and Goldstein, 2009). Genetic ablation of astroglial SREBP2 in mice reduced the number and functionality of synapses, affected brain development and caused motor deficits (Ferris et al., 2017). Another astroglial pathway is linked to the fatty acid binding protein 7 (FABP7), a chaperon for lipophilic molecules secreted by astrocytes. The number of excitatory synapses of the medial prefrontal cortex was reduced in FABP7-knockout mice while FABP7 knockout astrocyte-conditioned medium decreased amplitude and frequency of action potential-independent miniature excitatory postsynaptic currents (Ebrahimi et al., 2016).

\subsection{6. microRNAs}

MicroRNA (miRNA) is a non-coding gene transcript widely expressed in the mammalian brains throughout the life span. Processing miRNAs precursors into mature miRNAs by endoribonuclease Dicer and subsequent fine-tuning of miRNAs contribute to several brain functions including neurogenesis ( $\mathrm{Li}$ and Jin, 2010), neuronal development (Cochella and Hobert, 2012), synaptic plasticity (Ye et al., 2016) and synaptogenesis (Kos et al., 2016). Astroglial miRNAs regulate release of cytokines and chemokines which control the ERK1/2 - CREB signalling cascade regulating synaptogenesis (Sun et al., 2019). Selective deletion of astrocytic Dicer in postnatal mice leads to disruption of the formation of dendritic spines as well as to reduction of mature spines in the cortical and hippocampal neurones. Astrocytic chemokine ligand 5 (CCL5), expression of which is suppressed by miR-324-5p, when added in neurones treated with Dicer knockout astrocyte-conditioned medium reduced number of synapses and disrupted MAPK/CREB signalling (Sun et al., 2019). 


\subsubsection{Ephrin-B1}

Ephrins are membrane-bound guidance cues acting through EphA and EphB receptors, which are tyrosine kinases. Ephrine signalling invokes bidirectional neuronalastroglial communications (Murai and Pasquale, 2011). Ephrins and ephrine receptors have been identified in perisynaptic astrocyte processes (Carmona et al., 2009; Filosa et al., 2009). Ephrin-receptor-interaction protein B1 (Ephrin-B1) belongs to a transmembrane protein family that establishes short-distance cell-cell signalling which can affect morphogenesis, cell migration and positioning, homeostasis, plasticity and synaptogenesis (Kania and Klein, 2016). Astrocyte-specific deletion of ephrin-B1 in mice leads to an increase in the density of immature dendritic spines in the CA1 hippocampal region in adult mice: this increase is, however, associated with an attenuated postsynaptic filed potentials indicating increase in a population of silent contacts. Over-expression of ephrin leads to a loss of dendritic spines associated with impaired contextual memory retention. EPhrin-B1, therefore, was suggested to restrict the formation of new synapses in the adult brain that may be involved in synaptic remodelling during learning (Koeppen et al., 2018; Nguyen et al., 2020).

\subsubsection{Specificity protein 1}

The transcription factor Specificity protein 1 (Sp1) is part of specificity protein/Kruppel-like family which contributes to several processes associated with memory (Citron et al., 2015). Astrocytes express high levels of Sp1 which modulates expression of genes involved in neurites outgrowth and synaptogenesis. Genetic deletion of $\mathrm{Sp} 1$ in mice decrease number of neurones in the cortex and hippocampus, whereas in vitro, loss of astroglial Sp1 resulted in disrupted dendritic outgrowth and synapse formation. Apparently, this synaptogenic effect relies on increased expression of complement protein C1q in the absence of astroglial Sp1 (Hung et al., 2020).

\subsubsection{Norrin}

Norrin is a protein that acts as an agonist of frizzled-4 and Leucine-rich repeatcontaining G-protein coupled receptor 4 (LGR4), which activate WNT/ $\beta$-catenin signalling cascade; in the CNS Norrin is primarily expressed in and secreted by astrocytes (Braunger and Tamm, 2012; Deng et al., 2013). Mutation of Norrin encoding gene (Norrin cystine knot growth factor gene located on the $\mathrm{X}$ chromosome) results in Norrie disease (Warburg, 1971) manifested with ocular abnormalities and conginitve deficits such as mental retardation, psychosis, and early-onset dementia. Astroglia secreted Norrin controls growth of neuronal dendrites and formation of dendritic spines; genetic deletion of Norrin led to a profound loss of dendritic spines in the cortical layer $\mathrm{V}$; this was also associated hyperactivity in behavioural tests. Transfection of astrocytes from layer $\mathrm{V}$ with Norrin under control of specific astroglial promoter rescued this loss (Miller et al., 2019).

\subsection{Astrocytes support synaptic isolation, synaptic maintenance and catabolism of neurotransmitters}

An important function of astroglia perisynaptic cover is to maintain spatial isolation of synaptic transmission, thus preserving signalling specificity. This astroglial 
isolation is achieved through direct physical fencing of synapses with the addition of another diffusional barrier, and by the activity of glutamate transporters that are present in abundance in astrocyte membrane and prevent glutamate spill-over (Verkhratsky and Nedergaard, 2018). Suppression of glutamate transport with pharmacological agents (Arnth-Jensen et al., 2002) or by gene knock-out (Marcaggi et al., 2003) permits spill-over and hence increases the duration of excitatory postsynaptic currents. Astrocytic synaptic isolation is dynamic and may change depending on physiological context, circadian cycle and developmental stage.

Membranes of perisynaptic processes carry numerous transporters and neurotransmitter receptors, thus allowing intimate regulation of astroglial homeostatic support with neuronal activity (Verkhratsky and Rose, 2020). As astroglial perisynaptic processes do not have endoplasmic reticulum, the leading role in ionic signalling belongs to ionotropic receptors and SLC transporters with particularly strong contribution from glutamate transporters (underlying bulk of $\mathrm{Na}^{+}$entry in response to glutamate (Kirischuk et al., 2007; Rose et al., 2018)) and the $\mathrm{Na}^{+} / \mathrm{Ca}^{2+}$ exchanger (which brings in $\mathrm{Ca}^{2+}$ when working in the reverse mode (Rose et al., 2020; Wade et al., 2019)). Astroglial $\mathrm{Na}^{+} / \mathrm{K}^{+}$ATPase, also present in the perisynaptic membrane, acts as a major pathway for $\mathrm{K}^{+}$buffering, while $\mathrm{K}_{\mathrm{ir}} 4.1 \mathrm{~K}^{+}$channels shuttle $\mathrm{K}^{+}$back to neurones after periods of activity to restore ionic balance (Breslin et al., 2018; Larsen et al., 2016). Thus, perisynaptic astroglial processes provide for homeostatic control in the synaptic cleft.

This homeostatic control extends to many processes; during synaptic transmission a primary function of astroglia rests in the ability to regulate the level of neurotransmitter that is present in the cleft, and to regulate neurotransmitter catabolism and the supply of neurones with neurotransmitter precursors. This function is particularly critical for glutamatergic and GABA-ergic transmission. Astrocytes represent the key element of the glutamate(GABA)-glutamine shuttle, which comprises (i) astroglial glutamate transporters; (ii) astroglia-specific enzyme glutamine synthetase, and (iii) astroglial and neuronal glutamine transporters that provide glutamine transport to neuronal terminals where the latter is converted to glutamate and, subsequently to GABA in inhibitory terminals.

Astrocytes provide the major sink for glutamate in the brain; glutamate released from the perisynaptic terminals is rapidly buffered by glutamate transporters localised in astroglial perisynaptic membranes. Within the short diffusion range of only $0.5 \mu \mathrm{m}$, glutamate is bound by $\sim 7000$ glutamate transporters, which is $\sim 300$ times larger than the number of AMPAR on neuronal postsynaptic specialisation (Marcaggi and Attwell, 2004). Thus astroglial glutamate transporters control the kinetics of the glutamate presence in the cleft, which this controls the amplitude and duration of excitatory postsynaptic currents (Asztely et al., 1997; Diamond, 2001; Mennerick and Zorumski, 1994; Tsukada et al., 2005) and degree of activation of glutamate metabotropic receptors (Brasnjo and Otis, 2001; Reichelt and Knopfel, 2002). The astroglial role in regulation of extracellular GABA may be less crucial, owing to the presence of a higher density of neuronal GABA transporters. Nonetheless, astrocytic GABA transporter type 3 (GAT-3) contributes to the regulation of tonic GABA in hippocampus (Kersante et al., 2013). In the thalamus, astroglial GABA transporter type 1 (GAT-1) modulates kinetics of inhibitory postsynaptic currents, while astrocytic GAT-3 reduces GABA spill-over (Beenhakker and Huguenard, 2010). 
Glutamate accumulated into astrocytes undergoes enzymatic conversion to glutamine; this process is catalysed by glutamine synthetase (Norenberg and Martinez-Hernandez, 1979). Glutamine in turn represents the obligatory glutamate precursor for neurones as the latter are unable to synthesise glutamate de novo and thus they completely rely on the astroglial supply of glutamine (Hertz et al., 1999). Glutamate is produced from glucose in astrocytes which specifically express pyruvate carboxylase converting glucose to $\alpha$-ketoglutarate, from which glutamate is synthesised (Schousboe et al., 2014; Shank et al., 1985; Yu et al., 1982).

Astrocytes are involved in catabolism of two other principal neurotransmitters in the CNS: monoamines and adenosine. Catabolism of monoamines occurs through deamination or methylation; deamination is catalysed by monoaminoxidases $\mathrm{A}$ and $\mathrm{B}$ (MAO-A, B); the principal enzyme MAO-B is mainly expressed in astroglia (Levitt et al., 1982; Riederer et al., 1987; Saura et al., 1992). Noradrenalin and dopamine are transported into astrocytes through $\mathrm{Na}^{+}$-dependent noradrenaline transporter (NET/SLC6A2) (Schroeter et al., 2000; Takeda et al., 2002), possibly through the $\mathrm{Na}^{+}$-dependent dopamine transporter (DAT/SLC6A3) (Karakaya et al., 2007), and the $\mathrm{Na}^{+}$-independent organic cation transporter 3 (OCT3/SLC22A3) (Petrelli et al., 2018). Metabolism of dopamine in cortical astrocytes was found to be critically dependent on the vesicular monoamine transporter 2 (VMAT2/SLC18A2), which removes cytosolic dopamine into cellular organelles; genetic deletion of this transporter significantly impairs the catabolism of dopamine, causes aberrant synaptic transmission and plasticity, and affected working memory and behavioural flexibility (Petrelli et al., 2018).

Adenosine is widely present in CNS; both neurones and glia express all types of adenosine receptors $\left(\mathrm{A}_{1} \mathrm{R}-\mathrm{A}_{4} \mathrm{R}\right)$. After being released from neurones or degraded form ATP, adenosine is taken up by astrocytes through $\mathrm{Na}^{+}$-dependent concentrating and $\mathrm{Na}^{+}$-independent equilibrative transporters (King et al., 2006; Li et al., 2013; Peng et al., 2005). In astrocytes, adenosine is phosphorylated to AMP by adenosine kinase. Adenosine kinase is the central enzyme of adenosine catabolism and it is highly expressed in astroglial cells (Boison, 2008; Studer et al., 2006).

\subsection{Astroglia secrete factors regulating synaptic transmission}

After being formed, neural circuits mature, stabilise and continuously undergo fine tuning associated with structural remodelling of exiting synapses, appearance of new ones or with synaptic elimination depending on the physiological contexts and environmental challenges (Chung et al., 2015); all these processes being substrates of synaptic plasticity. Dendritic spines, for instance, undergo maturation process during neuronal activity, or are disconnected and eliminated when involved in redundant or weakened connections (Risher et al., 2014). Astroglial homeostatic support is fundamental for this rewiring of the brain. For example, monocular enucleation, which instigates massive remodelling of visual cortex is associated with rapid increase in a subpopulation of ALDHL1-positive protoplasmic astrocytes. Transient suppression of astroglial metabolism with fluoroacetate prevents remodelling of neuronal circuitry, whereas chronic stimulation of astroglial Gi coupled metabotropic receptors potentiates cortical plasticity (Hennes et al., 2020). Astrocytes are also bona fide secretory cells, which form a gliocrine system (Vardjan et al., 2019) and release 
over 200 neuroactive substances including neuromodulators, neurohormones, trophic factors, modulators of synaptogenesis etc (Verkhratsky et al., 2016). These astrogliaderived molecules interact with the pre- and postsynaptic processes and regulate synaptic maturation, stabilisation performance (Fig. 6).

\subsubsection{Thrombospondins}

Thrombospondins appear to regulate synaptogenesis in mature brain thus modulating neuronal plasticity through the remodelling of synaptic connectivity in physiological and pathophysiological contexts. In the striatum, TSP-1 secretion from astrocytes is induced by GABA released from medium spiny neurones; TSP-1, in turn, stimulates genesis of new synapses thus potentiating cortico-striatal synaptic transmission (Nagai et al., 2019). After stroke, regeneration and plasticity require the expression of astroglial TSP-1 and -2; genetic deletion of both TSPs significantly impairs the recovery of motor function (Liauw et al., 2008). Expression of TSPs in astrocytes in pathological context was shown to be regulated through the signal transducer and activator of transcription-3 (STAT3) signalling pathway (Tyzack et al., 2014). Effects of TSP on synaptic transmission may also be mediated through acute modulation of neurotransmitter receptor presence in the postsynaptic membrane: in cultured rat spinal cord neurones TSP-1 suppressed neuronal activity by decreasing the density of AMPAR while increasing the density of glycine receptors (Hennekinne et al., 2013). In hippocampal neuronal-astroglial cultures TSP-1 released from astrocytes induces presynaptic glutamate receptor muting (decrease in the number of active presynaptic glutamatergic terminals), which is considered to be a mechanism to protect against excitotoxicity (Crawford et al., 2012).

\subsubsection{Hevin}

Hevin, in addition to its role as a synaptogenic factor, also plays a critical role in the maturation of thalamocortical connections. Genetic deletion of hevin in mice results in a smaller synapses and thinner spines (Risher et al., 2014). Hevin is critical to ocular dominance plasticity, a form of synaptic plasticity where neuronal connections undergo remodelling shaped by visual experience. The restoration of astroglial hevin during the visual development rescued ocular dominance plasticity disrupted in hevinknockout mice, indicating astrocytic control of this kind of synaptic plasticity. The action of hevin seems to be mediated through bridging between NLGs and NRXs, which recruit N-methyl-D-aspartate receptor to modulate synaptic strength (Singh et al., 2016).

\subsection{3. $T N F-\alpha$}

Astrocytes can control synaptic scaling (a form of synaptic plasticity) by releasing TNF- $\alpha$ (Stellwagen and Malenka, 2006). Synaptic scaling adjusts the strength of all the synapses of an individual neurone to stabilise the firing rate (Turrigiano, 2008). TNF- $\alpha$ is directly involved in this type of plasticity, and astrocytes together with microglial cells were identified as the principal source of this cytokine (Lewitus et al., 2016; Stellwagen and Malenka, 2006). Astrocytic TNF- $\alpha$ also controls synaptic strength by increasing surface expression of AMPAR (Beattie et al., 2002). TNF- $\alpha$ induces rapid exocytosis of AMPARs, which increases the availability of AMPAR at the post-synaptic membrane. In addition, long-term treatment with TNF- $\alpha$ modulates 
NMDA currents, suggesting an indirect action in NMDA receptors (Han and Whelan, 2010). At the same time, TNF- $\alpha$ exerts the opposite effect on GABA receptors, inducing their internalisation thus affecting synaptic plasticity (Stellwagen et al., 2005).

\subsubsection{Brain derived growth factor}

Astroglial cells are key elements of the BDNF signalling in the brain: pro-BDNF, produced and released by neurones, accumulates in astrocytes where it is converted into mature form of BDNF, and is secreted by vesicle-associated membrane protein 2 (VAMP2)-mediated exocytosis (Bergami et al., 2008). Astroglia-released BDNF modulates synaptic stabilisation by stabilising the density of clusters of synaptobrevin and their rate of addition ( $\mathrm{Hu}$ et al., 2005). Recently, it was demonstrated that astrocytic BDNF increases spines density and dendrite outgrowth, which is accompanied with cognitive improvements in the 5xTg mouse model of Alzheimer's disease (de Pins et al., 2019). Astroglia secreted BDNF induced phosphorylation of neuronal TrkB, which is instrumental for the maintenance of long-term potentiation (LTP) and memory retention (Vignoli et al., 2016). The role of TrkB receptors in stabilisation of LTP is well documented (Figurov et al., 1996; Korte et al., 1996). The disruption of astroglial processing and secretion of BDNF leads to dysfunctional synaptic transmission and disruption of memory processes such as altered object recognition memory (Vignoli et al., 2016).

\subsubsection{Cholesterol}

During synaptic activity, presynaptic terminals require proper supply of proteins and lipids, the binding of cholesterol and synaptophysin, for instance, is required for the biogenesis of synaptic microvesicles. Cholesterol depletion inhibits this biogenesis probably by interfering with the formation of synaptic-vesicle curvature, supporting the biogenesis of synaptic-like microvesicles (Thiele et al., 2000). Lipid rafts, composed mostly of cholesterol and sphingolipids, are critical to the stabilisation of plasmalemmal AMPAR (Hering et al., 2003). Depletion of cholesterol/sphingolipids from rafts results in structural dysfunction in dendritic spines, reduction of their density and increasing in their size, which all disrupt synaptic transmission (Hering et al., 2003).

Astrocyte-secreted cholesterol therefore plays a critical role in maintaining synaptic connectivity and plasticity (Pfrieger, 2003). Decreased activity of the sterol regulatory element-binding protein (SREBP) in astrocytes reduces the astrocytic release of cholesterol, which leads to a decrease in the number of synaptic vesicles, reduction in the levels of presynaptic synaptosomal-associated protein, 25kDa (SNAP-25) and increase in the number of immature or silent synapses. This in turn results in dysfunctional synaptic connectivity and deficits in short-term and long-term synaptic plasticity (van Deijk et al., 2017). Additionally, astrocytic SREBP2 is critical for neurites outgrowth, and the absence of SREBP2 causes behavioural dysfunctions, including deficits in learning and memory and aberrant social behaviour, as assessed by Stone T-maze and nest-building ability, respectively (Ferris et al., 2017). Cholesterol composition of astroglial plasma membrane is significantly modified by ketamine, which might be related to the anti-depressant activity of the latter (Lasic et al., 2019). 


\subsubsection{L- and D-Serine}

The amino acid D-serine is an endogenous positive modulator of NMDA receptors, which has been demonstrated to regulate synaptic plasticity in the CNS (Mothet et al., 2000). For some time D-serine was believed to be an astrocyte-specific "gliotransmitter" (Henneberger et al., 2010). However, it has become clear that the Dserine producing enzyme, serine racemase, is located predominantly in neurones, where the bulk of D-serine is produced (Wolosker et al., 2016, 2017). Suppression of serine racemase selectively in neurones (by using recombinant DNA technology) resulted in $65 \%$ reduction of enzyme protein in cortical and hippocampal tissue as well as impairment of LTP; analogous suppression of astroglial expression produced only marginal reduction in serine racemase protein levels (Benneyworth et al., 2012). Nonetheless astrocytes are critical for D-serine production through the supply of neurones with the obligatory precursor L-serine, which is synthesised almost exclusively in astrocytes. Enzymatic removal of L-serine from extracellular space suppressed LTP in hippocampus (Neame et al., 2019). Synthesis of L-serine is catabolised by 3-phosphoglycerate dehydrogenase (Phgdh) expressed in astroglia (Yamasaki et al., 2001); knocking this enzyme out specifically in astrocytes reduces neuronal synthesis of D-serine by $\sim 80 \%$ (Yang et al., 2010). Similarly, pharmacological inhibition of Phgdh by the selective blocker CBR-5884 decreased neuronal synthesis of D-serine by $75 \%$, significantly inhibited NMDA receptormediated field excitatory postsynaptic potentials and halved the magnitude of NMDA-receptor mediated LTP (Neame et al., 2019). Deficient function of Phgdh is associated with single nucleotide mutations result in severe neurometabolic disorder that is manifest by congenital microcephaly, psychomotor retardation, and seizures (Klomp et al., 2000). Of note, astrocytes also contain serine hydroxymethyltransferase 1, which interconverts L-serine and glycine; as a result, astroglia can release glycine through the reversed GlyT1 glycine transporter to modulate NMDA receptors (Neame et al., 2019), and thus glycine, rather than D-serine, may be the more important in regulation of glutamatergic transmission.

\subsubsection{Chordin}

Chordin-like 1 protein (Chrdl1), a bone morphogenetic protein inhibitor that was initially isolated from mouse bone marrow stromal cells (Nakayama et al., 2001) has been identified in the astrocytes secretome. Indeed, Chrdl1 appears to be a critical factor for the induction and "maturation" of AMRARs, i.e. switch form $\mathrm{Ca}^{2+}$ permeable, GluA2 lacking form, into a $\mathrm{Ca}^{2+}$-impermeable GluA2 containing form. Genetic deletion of Chrdl1 results in the enhanced synaptic plasticity (Blanco-Suarez et al., 2018). Null mutations of Chrdl1 in humans result in X-linked megalocornea, which is manifested by large cornea and increased risk of cataract (Webb et al., 2012). Incidentally, patients suffering from this disease appear to have a higher IQ, and higher verbal memory and executive skills (Webb et al., 2012). Moreover, increased expression of Chrdl1 mRNA was found in brain samples from patients with schizophrenia and bipolar disorder (Gandal et al., 2018), but whether this association indicates that these conditions are the results of an astrocytopathy remains unknown.

5.4. Dynamic remodelling of astroglial cradle in regulation of synaptic transmission 
Astroglial perisynaptic processes are dynamic structures, which can relatively rapidly extend or retract, and thus there is the potential to quickly alter the degree of synaptic coverage. This form of astroglial morphological plasticity can significantly affect synaptic transmission by changing the geometry of extrasynaptic environment, affecting diffusion of ions and neurotransmitters, modulating neurotransmitters uptake and controlling neurotransmitter spillover (Bernardinelli et al., 2014; Heller and Rusakov, 2015). Synaptic modulation through astroglial morphological plasticity was described for the first time in the lactating rats: during lactation astroglial processes retracted from synapses hence permitting spillover of glutamate, which activated presynaptic metabotropic glutamate receptors thus instigating presynaptic inhibition of neurotransmitter release (Oliet et al., 2001). A similar form of astroglial plasticity was found in Bergmann glia, which, by retracting perisynaptic processes, induced potentiation of excitatory transmission (Iino et al., 2001). Enhanced motility of astroglial processes parallels LTP induction in hippocampal slices (Perez-Alvarez et al., 2014), while sensory stimulation caused morphological plasticity of astroglial perisynaptic processes in vivo (Perez-Alvarez et al., 2014); which resulted in an increased synaptic coverage (together with an increase in expression of glutamate transporters) in the barrel cortex (Genoud et al., 2006),

\section{Astrocytes contribution to synaptic elimination}

Tailoring of neuronal ensembles in both developing and mature brain in response to environmental changes requires not only the emergence of new synaptic contacts but also elimination of weaned or redundant synapses (Lichtman and Colman, 2000). Maturation of the brain is associated with remarkable decrease in overall number of synaptic structures. In particular in the human prefrontal cortex the number of synapses in children is about 2-3 times higher than in adults (Petanjek et al., 2011). Removal of the synapses in a normal physiological context (also known as synaptic pruning or synaptic stripping) is achieved by concerted action of astrocytes and microglia (Chung et al., 2015; Kettenmann et al., 2013). Synapses are removed through phagocytosis, which is a specific function of microglial cells, although astrocytes also contribute to this process (Fig. 7). The first suggestion of astroglial phagocytosis emerged in late 1970s, which was based on electron microscopy of disappearing synaptic boutons in early postnatal spinal motoneurones (Ronnevi, 1977, 1978). These ideas of astroglial phagocytosis received some experimental support in recent years. It appears that in mouse the astroglial transcriptome has high levels of expression of genes associated with phagocytosis, including MEGF10, MERTK, AXL, INTEGRIN $\alpha 5 \beta 5$ and LRP1 (Cahoy et al., 2008). Subsequently astroglial phagocytosis was identified in vitro in cell cultures (Chung et al., 2013; Galloway et al., 2019), in vivo in the developing retinogeniculate system (Chung et al., 2013) and in human cerebral cortical spheroids derived from pluripotent stem cells (Sloan et al., 2017), although in the latter phagocytosis was predominantly associated with foetal phenotypes. Genetic deletion of phagocytic receptors MEGF10 and MERTK impaired synaptic pruning (Chung et al., 2013). Phagocytic capacity of astrocytes seems to be regulated by ApoE protein with isoforms ApoE2 enhancing and ApoE4 suppressing phagocytosis (Chung et al., 2016). Astroglial phagocytosis of large synapses also seems to be enhanced by acute sleep deprivation, whereas chronic sleep deprivation promotes microglia-associated synaptic pruning (Bellesi et al., 2017). 
The major role of astrocytes in synaptic elimination is, however, associated with their regulation of microglial synaptic stripping through tagging the unwanted synapses by using complement system components (Bialas and Stevens, 2013; Stevens et al., 2007). For example, astrocytes promote up-regulation of C1q, the protein triggering the complement cascade, in retinal ganglion cells (RGC), which leads to binding of downstream complement protein $\mathrm{C} 3$ and subsequent synaptic pruning through $\mathrm{C} 3$ receptors expressed by microglia (Stevens et al., 2007). Thus, by releasing TGF- $\beta$, astrocytes modulate $\mathrm{C} 1 \mathrm{q}$ neuronal expression and, consequently, the synaptic elimination (Bialas and Stevens, 2013). Mice deficient in C1q or C3 showed disrupted synaptic pruning and supernumerary synapses in the geniculate circuit (Stevens et al., 2007), while mice deficient in neuronal TGF- $\beta$ receptor II showed both reduced expression of $\mathrm{C} 1 \mathrm{q}$ in RGC and impaired synaptic elimination (Bialas and Stevens, 2013). These findings implicate TGF- $\beta$ signalling in the synaptic elimination mediated through complement system proteins and microglia. The ApoE isoforms, apart from controlling astroglial phagocytosis, also regulate the expression of C1q: it appears that in ApoE2 knockout mice C1q accumulation was significantly reduced, whereas in ApoE4 transgenic mice it was markedly increased (Chung et al., 2016). In addition, astrocytes can promote microglial synaptic pruning through secretion of interleukin-33 (IL-33), a cytokine from interleukin-1 family that induces microglia to engulf synapses (Vainchtein et al., 2018). Astroglial derived IL-33 seems to be critical for synapse homeostasis during CNS development, by controlling the appropriate density of synapses (Vainchtein et al., 2018). The mechanisms regulating astrocytic IL-33 expression, release and downstream effects on microglia remain, however, unknown.

\section{Astrocytes support long-term potentiation and depression}

The wide range of astroglial responses to the activity of neuronal circuits and the elaborate signalling pathways between astroglia and neurones have provoked a growing interest in the potential role played by astrocytes in cognitive processes. The learning process is known to affect astrocytes by increasing their complexity, and, by extension, results in an increase in synaptic coverage and more astroglial homeostatic support (Allen and Messier, 2013; Anderson et al., 1994; Jones and Greenough, 1996; Rodriguez et al., 2013). The most widely recognised electrophysiological correlate of learning and memory is represented by LTP and LTD of synaptic strength, which have been characterised for various synaptically connected neuronal circuits (Bliss and Lomo, 1973; Nicoll, 2017). Astrocytes are known to influence LTP and LTD through several mechanisms outlined below.

\subsection{Cannabinoids}

Endocannabinoid retrograde neurotransmitter system has been discovered in 1980s (Devane et al., 1988). Cannabinoid receptors type $1\left(\mathrm{CB}_{1} \mathrm{R}\right)$ are arguably the most abundant metabotropic receptors in the brain (Ronan et al., 2016); they have been detected at both mRNA and protein levels in many brain areas including hippocampus (Herkenham et al., 1991) and are expressed in astrocytes (Stella, 2010). Activation of $\mathrm{CB}_{1} \mathrm{R}$ modulates astroglial morphology and molecular profiling, increasing for example expression of GFAP or TNF- $\alpha$, and evokes InsP $_{3}$-mediated $\mathrm{Ca}^{2+}$ release from the endoplasmic reticulum store (Navarrete and Araque, 2008). Stimulation of astrocytes with cannabinoids may result in depression or potentiation of synaptic 
transmission. Mice lacking astrocytic $\mathrm{CB}_{1} \mathrm{R}$ displayed induction of LTD and impaired spatial working memory (Han et al., 2012). At the same time, $\mathrm{CB}_{1} \mathrm{R}$ seems to control hippocampal LTP possibly through interacting with D-serine production (Robin et al., 2018).

\subsection{Astrocytes-derived chemokines and cytokines}

The expression of chemokines and cytokines is crucial for cognitive processes (McAfoose and Baune, 2009). Interleukin 6 (IL-6), for example, is predominantly expressed by reactive astrocytes and is involved in inflammation as well as in neurotrophic and neuroprotective signalling (Van Wagoner and Benveniste, 1999). It has been reported to also modulate memory and cognition. Increased IL-6 gene expression accompanies LTP suggesting its role involvement in synaptic plasticity (Balschun et al., 2004). Specific disruption of astrocytic IL-6 and its receptors (IL-6R) induced behavioural deficits. Astroglia-specific IL-6 and IL-6R knockout mice present deficits related to anxiety and exploratory behaviours as assessed by holeboard and elevated plus-maze tests (Quintana et al., 2013). In the same, astroglial IL-6 knockout results in deficits in spatial learning in Morris water-maze test and in social behaviour as assessed by dominance tube and resident intruder tests (Erta et al., 2015). Electrophysiological and activation/expression studies using transgenic mice overexpressing astrocytic IL-6 have indicated that this cytokine contributes to GABAergic transmission in the amygdala and hippocampus, which transmission drives emotional alterations such as anxiety and depressive-like behaviour (Roberts, Khom et al. 2019).

For many years, interleukin-1 (IL-1) has been known to play a role in learning and memory. However, a compelling study from Raz Yirmiya's group highlights the central role of the IL-1R1 receptor on astrocytes in fear-conditioning and water maze paradigms (Ben Menachem-Zidon et al., 2011). When NPCs from wild type or IL1R1 knockout animals are transplanted into hippocampus of wild type or IL-1R1 knockout host mice, the NPCs were found to differentiate into astrocytes, but not to neurones or oligodendrocytes. The IL-1R1 knockout mice engrafted with IL-1R1 knockout cells exhibited strong memory deficits in the fear-conditioning and water maze tests as well as impaired in LTP. In contrast IL-1R1 knockout mice transplanted with wild type NPCs displayed complete memory recovery and partial restoration of LTP (Ben Menachem-Zidon et al., 2011).

\subsection{Lactate}

Lactate, a by-product of aerobic glycolysis, is an energy substrate readily used by neurones for ATP production; it is synthesised and secreted by astrocytes and contributes to brain energy metabolism (Pellerin and Magistretti, 2012). Learning process is accompanied with an increase in extracellular lactate in the rodent hippocampus (Suzuki et al., 2011). Inhibition of astroglial monocarboxylate transporters MCT1 and MCT4 (transporters responsible for export of lactate) or neuronal transporter MCT2 (responsible for neuronal lactate import), inhibited LTP and induced amnesia, both of which were rescued by L-lactate (Suzuki et al., 2011). Inhibition of astroglial glycogenolysis causes memory impairment, which can be rescued by lactate as well as by Krebs cycle substrates pyruvate and ketone body B3HB (Descalzi et al., 2019). Similarly, astroglial production of lactate regulated through $\beta_{2}$-adrenoceptors is needed for memory consolidation (Gao et al., 2016). At 
the ultrastructural level, inhibition of astroglial glycose metabolism and lactate production suppressed the learning-associated increases in spine volume and postsynaptic density surface both being the substrates of long-term memory (Vezzoli et al., 2019). Astroglia-derived lactate is essential for induction of molecular processes associated to memory formation such as learning-induced mRNA translation (Descalzi et al., 2019), induction of phosphor-CREB and phosphor-cofilin (Suzuki et al., 2011), and for expression of neuronal genes related to synaptic plasticity such as Arc, c-Fos, and Zif268 through modulation of NMDAR and downstream Erk1/2 cascade (Yang et al., 2014). These and other findings clearly indicated that astrocyte-neurone lactate shuttle is necessary to support memory processes (Alberini et al., 2018).

There is growing evidence indicating that lactate may also act as a signalling molecule for astrocyte-neurone communications (Bergersen, 2015; DiNuzzo, 2016). Lactate was reported to inhibit electrical activity of neurones in culture (Bozzo et al., 2013) and in vivo (Gilbert et al., 2006). In locus coeruleus, secretion of lactate following optogenetic activation of astrocytes led to excitation of neurones and release of noradrenaline release both in slices and in vivo (Tang et al., 2014). Signalling function of lactate is arguably mediated through dedicated receptor(s); such as the hydroxycarboxylic acid (HCA)/GRP81 G-protein coupled receptor coupled with cAMP signalling cascade, which are expressed in many neurones and in astroglial endfeet (Lauritzen et al., 2014).

\subsection{Astrocytes and brain gamma- and theta- oscillations}

Astrocytes modulate neuronal activity and regulate memory processes through maintenance of functional gamma-oscillations; inhibition of astroglial secretion impaired upon novel object recognition behaviour together with disruption of gammaoscillations (Lee et al., 2014). Similarly, interfering with astroglial soluble Nethylmaleimide-sensitive fusion protein attachment protein receptors (SNARE proteins) impairs neural theta-oscillations between dorsal hippocampus and prefrontal areas. This leads to remarkable cognitive deficits as assessed by behavioural tests including the Morris water maze, novel object recognition, and hole board tests; all these abnormalities could be rescued by the exogenous administration of D-serine (Sardinha et al., 2017). Astroglia-derived protein S100B has been shown to coordinate theta and gamma oscillations and improve cognitive flexibility. Chemical ablation of astrocytes with L- $\alpha$-aminoadipic acid reduced cognitive flexibility and decreased power of delta, alpha and gamma oscillations; whereas infusion of S100B or optogenetic stimulation of astroglial $\mathrm{Ca}^{2+}$ signalling enhanced cognitive flexibility (Brockett et al., 2018).

\section{Astrocytes in higher brain functions}

Studying, analysing and interpreting the role of astroglia in regulation of animal cognition, memory, emotions and behaviours is a strenuous challenge that requires specific experimental models in which stimulation of astrocytes can be done with precision and within a normal physiological context. These experimental models range from astroglial ablation (by gliotoxins such as L- $\alpha$-aminoadipic acid or glial metabolism inhibitors such as fluorocitrate) to the use of pharmacological agents to just block/inhibit astrocytes function momentarily (such the inhibitor of mitochondrial 
fission, Mdivi-1, that markedly reduced the expression of GFAP) and genetically modified animals. Many of these approaches have been comprehensively reviewed in 2015 (Oliveira et al., 2015), and thus here we have focussed on more recent discoveries, summarised in Table 2. We need only to note that new state-of-the- art technologies such as optogenetics or designer receptors that can be exclusively activated by designer drugs require care in the interpretation of the results as they are not as straightforward as they might seem. Adding a new channel or a receptor allows cell-specific stimulation, but it also adds new signalling cascades, which may not reflect the mechanisms employed by the cells in their native state.

\subsection{Astrocytes in memory and cognition}

Cognition comprises complex abilities such as learning, memory, attention, reasoning, language and decision-making. Although many aspects are involved in cognitive processes, in animal models, cognition is investigated by testing learning and memory and, to a smaller extent, by employing attention paradigms. Many studies have shed light on the astrocytic involvement in cognitive processes by demonstrating that manipulating with astrocyte-specific molecules and processes does affect cognitive processes, although the question of astrocytes as substrates of information processing remains, hitherto, unanswered.

Conceptually, manipulations with astroglial signalling (transcription factors, clock genes, neurotransmitters and neuromodulators receptors, molecular cascades associated with $\mathrm{Ca}^{2+}$ signalling, synaptogenic factors and secretion-related molecules) and metabolic factors (lactate, mitochondrial enzymatic cascades) affect learning and memory and have been assessed in a number of well-established behavioural tests. These tests include fear conditioning, novel object location test, spatial object location, hole-board test, the Morris water maze, open field test, contextual and auditory fear conditioning and inhibitory avoidance test (Table 2), which all reflect changes in short and long-term memory. These data have, collectively, corroborate an importance of astroglial homeostatic pathways to support and maintain higher cognitive function.

\subsection{Astrocytes and motor behaviour}

The ultimate output of the brain information processing that underlie all types of behaviours, conscious or sub-conspicuous is manifested in the muscle contraction and motor activity. "The infinite diversity of the external manifestations of cerebral activities can be reduced ultimately to one phenomenon - muscular movement. Does a child laugh at the sight of its toy, does Garibaldi smile when they expel him for excessive love of the fatherland, does a girl tremble at the first thought of love, does Newton create world-governing laws and inscribe them on paper - everywhere, in every case the ultimate fact is muscular movement." ${ }^{1}$ Disruption or manipulation with astroglia-specific pathways has been demonstrated to modify motor behaviour in several animal models.

\footnotetext{
${ }^{1}$ Сеченов И. М. Рефлексы головного мозга, 1866, СПб: Типография А. Гончарова, pp. 186; English translation Sechenov, I. Reflexes of the Brain, 1965, MIT Press
} 
Although the ultimate step in initiation of motor behaviours belongs to motoneurones, astrocytes were recently found to influence motor behaviour through numerous astroglial-specific mechanisms. Alterations of astroglial $\mathrm{Ca}^{2+}$ signalling, for example, are sufficient to alter motor behaviour in mice. Acute enhancement of locomotion produced by amphetamine is reduced in mice with astroglia-specific deletion of $\mathrm{InsP}_{3}$ receptors type 2, which generate global astroglial $\mathrm{Ca}^{2+}$ signals (Corkrum et al., 2020). Similarly, astroglia-specific $\mathrm{Ins}_{3}$ receptor type 2 knockout mice displayed impaired motor skills learning (Padmashri et al., 2015). Motor learning was likewise impaired in animals with genetic deletion of astroglial transcription factor specificity protein 1 or Sp1 (Hung et al., 2020).

Motor behaviours are also regulated by astroglia-derived IL-6. Impairments of astroglial IL-6 production by deletion of IL-6 or IL-6R (Erta et al., 2015), or by overexpression of IL-6 (Roberts et al., 2019) resulted in aberrant motor behaviour and emotional alterations in various contexts. Astroglial energy metabolism also seems to link to regulation of motor behaviour. Astrocytes produce several times more reactive oxygen species (ROS) than neurones (Lopez-Fabuel et al., 2016); these astrogliaderived ROS seem to regulate brain metabolism and a reduction of astroglia ROS production decreased motor activity (Vicente-Gutierrez et al., 2019). Motor functions are also affected by manipulations with astrocytic receptors. Adenosine $\mathrm{A}_{2 \mathrm{~A}}$ receptors contribute to regulation of motor activity (Svenningsson et al., 1999) and, very recently, it was found that selective astrocytic deletion of $\mathrm{A}_{2 \mathrm{~A}} \mathrm{R}$ resulted in aberrant glutamatergic transmission and altered motor activity (Matos et al., 2015). Genetic deletion of astroglial histamine receptor $1\left(\mathrm{H}_{1} \mathrm{R}\right)$ caused reduced motor activity and this abnormal motor behaviour led to alterations in circadian cycle (Karpati et al., 2019).

\subsection{Astrocytes and avoidance behaviour}

In the ventral tegmental area, astrocytes modulate (through glutamate uptake) glutamate availability to regulate GABAergic inhibition of dopamine neurones, thus affecting avoidance and approach behaviour. Optogenetic stimulation of astrocytes expressing channel rhodopsin 2, which triggers an increase in cytoplasmic $\mathrm{Na}^{+}$thus modulating glutamate neurotransmission, induced real-time avoidance in mice as assessed by a real-time place preference test. This astroglia-driven pathway ultimately relied upon expression of glutamate transporter GLT-1 (Gomez et al., 2019). These experiments demonstrate that astrocytes can trigger complex behavioural paradigm using astroglia-specific homeostatic mechanisms.

\subsection{Astrocytes and emotional behaviour}

Emotional behaviours such as fear and anxiety are strongly related to amygdala and its functionally different subnuclei (LeDoux, 2000). Among them the medial nuclei from central amygdala contributes to emotional information processing (Duvarci and Pare, 2014). Stimulation of astrocytes with endogenously mobilised endocannabioids acting through CB1 receptors potentiated inhibitory transmission between lateral and medial nuclei of amygdala and regulated excitatory transmission between basolateral and central amygdala. The former effect was mediated by $\mathrm{A}_{2 \mathrm{~A}}$ adenosine receptors whereas the latter was mediated by $\mathrm{A}_{1}$ adenosine receptors. Activation of an astroglial 
pathway in amygdala led to a decrease of firing rate of neurones in medial nuclei and reduced fear expression in a fear-conditioning paradigm (Martin-Fernandez et al., 2017).

\subsection{Astrocytes and pathological behaviours}

The role of astroglia in controlling behavioural patterns is often revealed by instigating and analysing specific pathological behaviours. Astrocytes in striatum, for example, contribute to development of hyperactivity with disrupted attention through the release of TSP-1 that boosts synaptogenesis in striatal medium spiny neurones (Nagai et al., 2019). Suppression of calcium signalling in astrocytes in striatum by over-expression of the plasmalemmal $\mathrm{Ca}^{2+}$ pump alters firing patterns of striatal medium spiny neurones and instigates repetitive self-grooming behaviour. These changes were directly linked to astroglia homeostatic GABA uptake; inhibition of glial GABA transporter GAT-3/SLC6A11 rectified this pathological behaviour (Yu et al., 2018). Astroglial cells are associated with mood disorders; significant reduction in astroglial densities and atrophy of astroglial profiles has been identified in postmortem tissues from patients with major depressive disorder (Bowley et al., 2002; Ongur et al., 1998; Rajkowska et al., 2018; Rajkowska et al., 1999; Rajkowska and Stockmeier, 2013; Verkhratsky et al., 2014). Ablation of astrocytes in prefrontal cortex of rats with L- $\alpha$-aminoadipic acid was sufficient to trigger depressive-like behaviours, while classical anti-depressants have been shown to target astroglial cascades (Czeh and Di Benedetto, 2013; Lasic et al., 2019; Peng et al., 2015; Rivera and Butt, 2019). Chronic unpredicted stress, which is used to induce depressive-like behaviour in rodents, results in astroglial atrophy and a decrease in the number of GFAP-positive astrocytes (Ardalan et al., 2017; Tynan et al., 2013). These astroglial changes are reversed by anti-depressant drugs (Ardalan et al., 2017; Machado-Santos et al., 2019). However, it has been claimed that exposure of repeated chronic stress results in increased astroglial complexity (Machado-Santos et al., 2019). Furthermore, depressive behaviours are seemingly associated with compromised astroglial homeostatic capacity: selective inhibition of the expression of glutamate transporters by the regional injection of silencing mRNAs precipitates depressive-like behaviours in mice (Fullana et al., 2019). Depression has been linked to aberrant astroglial secretion of ATP (Cao et al., 2013), while astroglia-associated epoxyeicosatrienoic acid, and the enzyme that produces it -soluble epoxide hydrolase - were increased in mouse depression model as well as in post-mortem human tissues. Impaired epoxyeicosatrienoic acid signalling is thought to provoke depressive behaviour through altered astroglial ATP secretion (Xiong et al., 2019). In summary, compromised astroglial homeostasis and the morphological atrophy of astrocytes results in reduced synaptic coverage may be responsible for the initiation of mood disorders and depressive-like behaviours in animal models.

\subsection{Astrocytes and food intake behaviour}

Regulation of the body energy requirements and the downstream food intake behaviour is provided by a complex cellular network of the hypothalamic nuclei comprised of the arcuate nucleus, the ventromedial hypothalamic nucleus, and the paraventricular nucleus. Hypothalamic protoplasmic astrocytes as well as specialised tanycytes contribute to all aspects of hypothalamic function: they are involved in chemoception, and in the control of appetite by the regulation of the hormones leptin, 
ghrelin, and insulin (Garcia-Caceres et al., 2019; Morton et al., 2006). Changes in glucose concentration in the blood regulate appetite and satiation, which was established more than a century ago (Carlson, 1919). In hypothalamus glucosesensing cells are involve several sub-populations of neurones and the tanycytes (Burdakov et al., 2005; Garcia-Caceres et al., 2019). Tanycytes of $\beta 2$ subtype form the blood-brain barrier in the medial eminence; the barrier is sealed by tight junctions formed between somata of tanycytes. The processes of tanycytes contact fenestrated vessels of the pituitary portal blood system and thus directly monitor blood composition (Mullier et al., 2010; Schaeffer et al., 2013). Glucose triggers $\mathrm{Ca}^{2+}$ signalling and propagating $\mathrm{Ca}^{2+}$ waves in tanycytes, which, arguably, then signal to hypothalamic neurones (Bolborea and Dale, 2015; Orellana et al., 2012). Tanycytes also express leptin receptors (LepR) that are localised in tanycyte processes contacting the fenestrated capillaries (Balland et al., 2014). Tanycytes are known to take up leptin and ghrelin and transport them to hypothalamic neurones (Balland et al., 2014; Cabral et al., 2014; Collden et al., 2015; Schaeffer et al., 2013).

Specific deletion of LepRs from astrocytes reduced density and morphological complexity of hypothalamic astrocytes (without any effect on astroglial cells in hippocampus), which resulted in reduced synaptic coverage of appetite controlling agouti-related protein expressing neurones and pro-opiomelanocortin-expressing neurones. This impaired synaptic transmission and triggered aberrant feeding behaviour: feeding was abnormally increased after fasting and ghrelin administration whereas leptin-depended feeding was decreased (Kim et al., 2014). In a further study, chemogenetic stimulation of medial basal hypothalamic astrocytes suppressed basal feeding as well as feeding evoked by ghrelin (Yang et al., 2015).

\subsection{Astrocytes in regulation of circadian rhythms and sleep}

Unexpectedly, astrocytes have been found to control motor behaviours associated with circadian rhythms. For a long time, the rhythms have been considered to stem solely from neuronal activity and inter-neuronal connections in suprachiasmatic nucleus of hypothalamus. It appears, however, that astrocytes express the transcription-translation negative feedback loop mechanism (TTFL) that requires the Clock/Bmal1-dependent daytime expression of Period (Per) and Cryptochrome (Cry) genes (Menet et al., 2014). Astrocytes express this transcription factor, and genetic deletion of it from astrocytes instigates abnormal motor behaviour linked to the circadian cycle (Barca-Mayo et al., 2017; Tso et al., 2017). Moreover, when neuronal Cry was deleted, astroglial cell-autonomous TTFL was able to drive both molecular oscillations in the CNS and circadian behaviour in mice (Brancaccio et al., 2019).

The role of astrocytes in regulation of sleep was suggested by Ramon y Cajal (Ramón y Cajal, 1895). The fundamental states of the brain, wakefulness and sleep, are regulated by two systems, by the circadian clock and by neurotransmitters, which control sleep homeostat and arousal. Astrocytes contribute to both sleep regulatory systems. Sleep affects astroglial transcriptome, with $1.4 \%$ of all transcripts undergoing changes in expression in sleep when compare to wakefulness; incidentally sleep does not affect transcriptome of oligodendrocytes (Bellesi et al., 2015; Bellesi et al., 2013). Sleep also indices the morphological plasticity of astrocytes which leads to an increase in extracellular volume (Xie et al., 2013) and increase in synaptic coverage by astroglial processes (Bellesi et al., 2015). The urge to sleep or sleep 
homeostat is seemingly associated with accumulation of adenosine in the brain during wake state; this accumulation of adenosine originates from astroglial ATP secretion; secreted ATP is rapidly degraded to adenosine by ectonucleotidases, adenosine in turn inhibits neuronal activity acting through $\mathrm{A}_{1}$ presynaptic receptors (Halassa et al., 2009; Haydon, 2017).

Arousal is triggered by the release of monoamines, which is paralleled by changes in the interstitial ion composition: extracellular $\mathrm{K}^{+}$is increased, whereas extracellular concentrations of $\mathrm{Ca}^{2+}, \mathrm{Mg}^{2+}$ and $\mathrm{H}^{+}$are diminished (Bazargani and Attwell, 2017; Ding et al., 2016). These perturbations are directly linked to astroglial function: astrocytes are main receivers of noradrenergic transmission in the brain and astrocytes are primarily responsible for controlling the ionic composition of the interstitial fluid providing for the tissue "ionostasis" (Ding et al., 2013; Ding et al., 2016; Verkhratsky and Nedergaard, 2018). Astrocytes seem to regulate various aspects of sleep: for example, expression of astroglia-specific fatty acid binding protein Fapb7 oscillates with the sleep-wake cycle. Missense mutation of this protein results in fragmented sleep in humans, whereas genetic deletion or expression of missense mutation in astrocytes of mice triggers very same sleep abnormality (Gerstner et al., 2017). Astroglial $\mathrm{Ca}^{2+}$ signalling similarly shows associations with sleep- wake cycle; $\mathrm{Ca}^{+}$ signalling seems to be reduced during sleep and is maximal at the moment of awakening. Deletion of astroglial $\mathrm{InsP}_{3}$ receptors type II which suppresses global astroglial $\mathrm{Ca}^{2+}$ signalling results in sleep fragmentation (Bojarskaite et al., 2019).

\subsection{Human astrocytes in rodent brain - do they add some intelligence?}

As we have discussed, human astrocytes differ considerably from astrocytes in rodents; human astrocytes are larger, are more complex, and there are human specific sub-types of astroglia which are not present in other mammals. This, of course, makes the extrapolation of rodent-derived data to understand the contribution of human astrocytes to brain physiology and behaviour problematic. Thus the "humanisation" of neuroglial research is of paramount importance. This is of particular importance for studies in neuropathology as many human diseases do not occur in animals and the value of animal models is dubious (Verkhratsky et al., 2017). Astrocytes are considered by many to be part of a "computing unit", in which they contribute to the integration of numerous inputs and are then able to alter signalling in any thousand, if not millions, of synapses, that lie within astrocytic territorial domains. In this way they have the potential to add significantly to the modulation and computing power of neural networks (Mitterauer, 2013; Porto-Pazos et al., 2011; Tang et al., 2019). Following this logic, human astrocytes may provide an essential cellular element of human intelligence. Intra-brain grafting of foetal human astroglia into mouse pups at postnatal day 1 created a mice-human chimeric brain (Han et al., 2013; Windrem et al., 2014). The human astrocytes, engrafted in the mouse, were larger than the host astrocytes, preserving the characteristics of human astrocytes, and they populated substantial parts of the host brain and replaced mouse glial progenitor cells. The presence of the human astrocytes in the mouse brain was accompanied with a decrease in the threshold for LTP in hippocampus, in enhanced memory and learning ability in cognitive tests, such as novel object recognition or auditory fear conditioning (Han et al., 2013). Whether this finding indicates that human astrocytes intrinsically contribute to cognitive function or whether the increased homeostatic power of the human astroglial cells was responsible for the elevated performance of 
neuronal networks is unknown. However, what is certain is that these experiments have catapulted interest in astrocyte function and cognition into the mainstream of neuroscience research.

\section{Conclusion}

Astrocytes are primary homeostatic cells of the CNS, and as such they are endowed with extended repertoire of molecular programmes and signalling pathways that are responsible for maintenance of neural tissue. By employing these programmes, astrocytes influence and regulate synaptic transmission and functional activity of neuronal ensembles responsible for the functional output of the CNS. Astrogliaspecific regulatory pathways affect the most fundamental properties of neuronal networks from their excitability to synaptic connectivity. Thus, it is the concerted action of glia and neurones, which, by engaging distinct mechanisms, produce behavioural outputs of the ultimate control centre that we call the brain.

Authors' contributions: Conceptualisation: MAO, GPA, AV and MECL; resources: MAO, GPA, AV and MECL; writing - original draft preparation: MAO, GPA and MECL; literature review, tables and figures: PYT, ALA, LSS; writing - review and editing: MAO, GPA, DCA, AV and MECL; supervision: AV and MECL

Acknowledgements: This work was supported by Conselho Nacional de Desenvolvimento Científico e Tecnológico (CNPq, grant numbers 27724/2018-2 and 307564/2017-7), Coordenação de Aperfeiçoamento de Pessoal de Nível Superior (CAPES, grant number 88887.200500/2018-00) and Pró-reitoria de Pesquisa da Universidade Federal do Pará (PROPESP-UFPA, s/n). Figures 3-7 were made with Biorender software. MAO thanks CAPES for his post-doctoral fellowship. MECL thanks CNPq for its recognition as a highly productive researcher. 


\section{References}

Adamsky, A., Kol, A., Kreisel, T., Doron, A., Ozeri-Engelhard, N., Melcer, T., Refaeli, R., Horn, H., Regev, L., Groysman, M., et al. (2018). Astrocytic Activation Generates De Novo Neuronal Potentiation and Memory Enhancement. Cell 174, 5971 e14.Doi: 10.1016/j.cell.2018.05.002.

Aida, T., Yoshida, J., Nomura, M., Tanimura, A., Iino, Y., Soma, M., Bai, N., Ito, Y., Cui, W., Aizawa, H., et al. (2015). Astroglial glutamate transporter deficiency increases synaptic excitability and leads to pathological repetitive behaviors in mice. Neuropsychopharmacology 40, 1569-1579.Doi: 10.1038/npp.2015.26.

Alberdi, E., Wyssenbach, A., Alberdi, M., Sanchez-Gomez, M.V., Cavaliere, F., Rodriguez, J.J., Verkhratsky, A., and Matute, C. (2013). $\mathrm{Ca}^{2+}$-dependent endoplasmic reticulum stress correlates with astrogliosis in oligomeric amyloid $\beta$-treated astrocytes and in a model of Alzheimer's disease. Aging Cell 12, 292-302.Doi:

10.1111/acel.12054.

Alberini, C.M., Cruz, E., Descalzi, G., Bessieres, B., and Gao, V. (2018). Astrocyte glycogen and lactate: New insights into learning and memory mechanisms. Glia 66, 1244-1262.Doi: 10.1002/glia.23250.

Allen, A., and Messier, C. (2013). Plastic changes in the astrocyte GLUT1 glucose transporter and beta-tubulin microtubule protein following voluntary exercise in mice. Behav Brain Res 240, 95-102.Doi: 10.1016/j.bbr.2012.11.025.

Allen, N.J. (2014). Astrocyte regulation of synaptic behavior. Annu Rev Cell Dev Biol 30, 439-463.Doi: 10.1146/annurev-cellbio-100913-013053.

Allen, N.J., Bennett, M.L., Foo, L.C., Wang, G.X., Chakraborty, C., Smith, S.J., and Barres, B.A. (2012). Astrocyte glypicans 4 and 6 promote formation of excitatory synapses via GluA1 AMPA receptors. Nature 486, 410-414.Doi: 10.1038/nature11059.

Anderson, B.J., Li, X., Alcantara, A.A., Isaacs, K.R., Black, J.E., and Greenough, W.T. (1994). Glial hypertrophy is associated with synaptogenesis following motorskill learning, but not with angiogenesis following exercise. Glia 11, 73-80.Doi: 10.1002/glia.440110110.

Andriezen, W.L. (1893). The Neuroglia Elements in the Human Brain. Br Med J 2, 227-230.Doi: 10.1136/bmj.2.1700.227.

Araque, A., Parpura, V., Sanzgiri, R.P., and Haydon, P.G. (1999). Tripartite synapses: glia, the unacknowledged partner. Trends Neurosci 22, 208-215.

Araujo, A.P., Diniz, L.P., Eller, C.M., de Matos, B.G., Martinez, R., and Gomes, F.C. (2016). Effects of Transforming Growth Factor $\beta 1$ in Cerebellar Development: Role in Synapse Formation. Front Cell Neurosci 10, 104.Doi: 10.3389/fncel.2016.00104. Ardalan, M., Rafati, A.H., Nyengaard, J.R., and Wegener, G. (2017). Rapid antidepressant effect of ketamine correlates with astroglial plasticity in the hippocampus. Br J Pharmacol 174, 483-492.Doi: 10.1111/bph.13714.

Arnth-Jensen, N., Jabaudon, D., and Scanziani, M. (2002). Cooperation between independent hippocampal synapses is controlled by glutamate uptake. Nat Neurosci 5, 325-331.Doi: 10.1038/nn825.

Asztely, F., Erdemli, G., and Kullmann, D.M. (1997). Extrasynaptic glutamate spillover in the hippocampus: dependence on temperature and the role of active glutamate uptake. Neuron 18, 281-293. 
Augusto-Oliveira, M., Arrifano, G.P., Lopes-Araujo, A., Santos-Sacramento, L., Takeda, P.Y., Anthony, D.C., Malva, J.O., and Crespo-Lopez, M.E. (2019). What Do Microglia Really Do in Healthy Adult Brain? Cells 8, E1293.Doi: 10.3390/cells8101293.

Balland, E., Dam, J., Langlet, F., Caron, E., Steculorum, S., Messina, A., Rasika, S., Falluel-Morel, A., Anouar, Y., Dehouck, B., et al. (2014). Hypothalamic tanycytes are an ERK-gated conduit for leptin into the brain. Cell Metab 19, 293-301.Doi: 10.1016/j.cmet.2013.12.015.

Balschun, D., Wetzel, W., Del Rey, A., Pitossi, F., Schneider, H., Zuschratter, W., and Besedovsky, H.O. (2004). Interleukin-6: a cytokine to forget. FASEB J 18, 17881790.Doi: 10.1096/fj.04-1625fje.

Banasr, M., and Duman, R.S. (2008). Glial loss in the prefrontal cortex is sufficient to induce depressive-like behaviors. Biol Psychiatry 64, 863-870.Doi:

10.1016/j.biopsych.2008.06.008.

Barca-Mayo, O., Pons-Espinal, M., Follert, P., Armirotti, A., Berdondini, L., and De Pietri Tonelli, D. (2017). Astrocyte deletion of Bmall alters daily locomotor activity and cognitive functions via GABA signalling. Nat Commun 8, 14336.Doi: 10.1038/ncomms14336.

Barker, A.J., Koch, S.M., Reed, J., Barres, B.A., and Ullian, E.M. (2008).

Developmental control of synaptic receptivity. J Neurosci 28, 8150-8160.Doi: 10.1523/JNEUROSCI.1744-08.2008.

Bayraktar, O.A., Bartels, T., Holmqvist, S., Kleshchevnikov, V., Martirosyan, A., Polioudakis, D., Ben Haim, L., Young, A.M.H., Batiuk, M.Y., Prakash, K., et al. (2020). Astrocyte layers in the mammalian cerebral cortex revealed by a single-cell in situ transcriptomic map. Nat Neurosci.Doi: 10.1038/s41593-020-0602-1.

Bazargani, N., and Attwell, D. (2016). Astrocyte calcium signaling: the third wave. Nat Neurosci 19, 182-189.Doi: 10.1038/nn.4201.

Bazargani, N., and Attwell, D. (2017). Amines, Astrocytes, and Arousal. Neuron 94, 228-231.Doi: 10.1016/j.neuron.2017.03.035.

Beattie, E.C., Stellwagen, D., Morishita, W., Bresnahan, J.C., Ha, B.K., Von Zastrow, M., Beattie, M.S., and Malenka, R.C. (2002). Control of synaptic strength by glial TNF- $\alpha$. Science 295, 2282-2285.Doi: 10.1126/science.1067859.

Beauquis, J., Pavia, P., Pomilio, C., Vinuesa, A., Podlutskaya, N., Galvan, V., and Saravia, F. (2013). Environmental enrichment prevents astroglial pathological changes in the hippocampus of APP transgenic mice, model of Alzheimer's disease. Exp Neurol 239, 28-37.Doi: 10.1016/j.expneurol.2012.09.009.

Beenhakker, M.P., and Huguenard, J.R. (2010). Astrocytes as gatekeepers of GABA receptor function. J Neurosci 30, 15262-15276.Doi: 10.1523/JNEUROSCI.324310.2010.

Bellesi, M., de Vivo, L., Chini, M., Gilli, F., Tononi, G., and Cirelli, C. (2017). Sleep Loss Promotes Astrocytic Phagocytosis and Microglial Activation in Mouse Cerebral Cortex. J Neurosci 37, 5263-5273.Doi: 10.1523/JNEUROSCI.3981-16.2017.

Bellesi, M., de Vivo, L., Tononi, G., and Cirelli, C. (2015). Effects of sleep and wake on astrocytes: clues from molecular and ultrastructural studies. BMC Biol 13, 66.Doi: 10.1186/s12915-015-0176-7.

Bellesi, M., Pfister-Genskow, M., Maret, S., Keles, S., Tononi, G., and Cirelli, C. (2013). Effects of sleep and wake on oligodendrocytes and their precursors. J Neurosci 33, 14288-14300.Doi: 10.1523/JNEUROSCI.5102-12.2013. Ben Haim, L., and Rowitch, D.H. (2017). Functional diversity of astrocytes in neural circuit regulation. Nat Rev Neurosci 18, 31-41.Doi: 10.1038/nrn.2016.159. 
Ben Menachem-Zidon, O., Avital, A., Ben-Menahem, Y., Goshen, I., Kreisel, T., Shmueli, E.M., Segal, M., Ben Hur, T., and Yirmiya, R. (2011). Astrocytes support hippocampal-dependent memory and long-term potentiation via interleukin-1 signaling. Brain Behav Immun 25, 1008-1016.Doi: 10.1016/j.bbi.2010.11.007. Bengoetxea, H., Ortuzar, N., Rico-Barrio, I., Lafuente, J.V., and Argandoña, E.G. (2013). Increased physical activity is not enough to recover astrocytic population from dark-rearing. Synergy with multisensory enrichment is required. Frontiers in cellular neuroscience 7, 170-170.Doi: 10.3389/fncel.2013.00170.

Benneyworth, M.A., Li, Y., Basu, A.C., Bolshakov, V.Y., and Coyle, J.T. (2012). Cell selective conditional null mutations of serine racemase demonstrate a predominate localization in cortical glutamatergic neurons. Cell Mol Neurobiol 32, 613-624.Doi: 10.1007/s10571-012-9808-4.

Bergami, M., Santi, S., Formaggio, E., Cagnoli, C., Verderio, C., Blum, R., Berninger, B., Matteoli, M., and Canossa, M. (2008). Uptake and recycling of pro-BDNF for transmitter-induced secretion by cortical astrocytes. J Cell Biol 183, 213-221.Doi: $10.1083 /$ jcb.200806137.

Bergersen, L.H. (2015). Lactate transport and signaling in the brain: potential therapeutic targets and roles in body-brain interaction. J Cereb Blood Flow Metab 35, 176-185.Doi: 10.1038/jcbfm.2014.206.

Bernardinelli, Y., Muller, D., and Nikonenko, I. (2014). Astrocyte-synapse structural plasticity. Neural Plast 2014, 232105.Doi: 10.1155/2014/232105.

Bialas, A.R., and Stevens, B. (2013). TGF- $\beta$ signaling regulates neuronal C1q expression and developmental synaptic refinement. Nat Neurosci 16, 1773-1782.Doi: 10.1038/nn.3560.

Blanco-Suarez, E., Liu, T.F., Kopelevich, A., and Allen, N.J. (2018). AstrocyteSecreted Chordin-like 1 Drives Synapse Maturation and Limits Plasticity by Increasing Synaptic GluA2 AMPA Receptors. Neuron 100, 1116-1132 e1113.Doi: 10.1016/j.neuron.2018.09.043.

Bliss, T.V., and Lomo, T. (1973). Long-lasting potentiation of synaptic transmission in the dentate area of the anaesthetized rabbit following stimulation of the perforant path. J Physiol 232, 331-356.Doi: 10.1113/jphysiol.1973.sp010273.

Boison, D. (2008). Adenosine as a neuromodulator in neurological diseases. Curr Opin Pharmacol 8, 2-7.

Bojarskaite, L., Bjørnstad, D.M., Pettersen, K.H., Cunen, C., Hermansen, G.H., Åbjørsbråten, K.S., Sprengel, R., Vervaeke, K., Tang, W., Enger, R., et al. (2019). $\mathrm{Ca}^{2+}$ signaling in astrocytes is sleep-wake state specific and modulates sleep. bioRxiv preprint.Doi: 10.1101/75028.

Bolborea, M., and Dale, N. (2015). Tanycytes excite neurons of the hypothalamic arcuate nucleus in mice. Proc Physiol Soc 34, SA049 (Abstract).

Boury-Jamot, B., Carrard, A., Martin, J.L., Halfon, O., Magistretti, P.J., and Boutrel, B. (2016). Disrupting astrocyte-neuron lactate transfer persistently reduces conditioned responses to cocaine. Mol Psychiatry 21, 1070-1076.Doi: 10.1038/mp.2015.157.

Bowley, M.P., Drevets, W.C., Ongur, D., and Price, J.L. (2002). Low glial numbers in the amygdala in major depressive disorder. Biol Psychiatry 52, 404-412.Doi: 10.1016/s0006-3223(02)01404-X.

Bozzo, L., Puyal, J., and Chatton, J.Y. (2013). Lactate modulates the activity of primary cortical neurons through a receptor-mediated pathway. PLoS One 8, e71721.Doi: 10.1371/journal.pone.0071721. 
Brancaccio, M., Edwards, M.D., Patton, A.P., Smyllie, N.J., Chesham, J.E., Maywood, E.S., and Hastings, M.H. (2019). Cell-autonomous clock of astrocytes drives circadian behavior in mammals. Science 363, 187-192.Doi: 10.1126/science.aat4104. Brasnjo, G., and Otis, T.S. (2001). Neuronal glutamate transporters control activation of postsynaptic metabotropic glutamate receptors and influence cerebellar long-term depression. Neuron 31, 607-616.

Braunger, B.M., and Tamm, E.R. (2012). The different functions of Norrin. Adv Exp Med Biol 723, 679-683.Doi: 10.1007/978-1-4614-0631-0_86.

Brekken, R.A., and Sage, E.H. (2001). SPARC, a matricellular protein: at the crossroads of cell-matrix communication. Matrix Biol 19, 816-827.

Breslin, K., Wade, J.J., Wong-Lin, K., Harkin, J., Flanagan, B., Van Zalinge, H., Hall, S., Walker, M., Verkhratsky, A., and McDaid, L. (2018). Potassium and sodium microdomains in thin astroglial processes: A computational model study. PLoS Comput Biol 14, e1006151.Doi: 10.1371/journal.pcbi.1006151.

Brockett, A.T., Kane, G.A., Monari, P.K., Briones, B.A., Vigneron, P.A., Barber, G.A., Bermudez, A., Dieffenbach, U., Kloth, A.D., Buschman, T.J., et al. (2018). Evidence supporting a role for astrocytes in the regulation of cognitive flexibility and neuronal oscillations through the $\mathrm{Ca}^{2+}$ binding protein S100ß. PLoS One 13, e0195726.Doi: 10.1371/journal.pone.0195726.

Brown, M.S., and Goldstein, J.L. (2009). Cholesterol feedback: from Schoenheimer's bottle to Scap's MELADL. J Lipid Res 50 Suppl, S15-27.Doi: 10.1194/jlr.R800054JLR200.

Buckman, L.B., Thompson, M.M., Lippert, R.N., Blackwell, T.S., Yull, F.E., and Ellacott, K.L. (2015). Evidence for a novel functional role of astrocytes in the acute homeostatic response to high-fat diet intake in mice. Mol Metab 4, 58-63.Doi: 10.1016/j.molmet.2014.10.001.

Burdakov, D., Gerasimenko, O., and Verkhratsky, A. (2005). Physiological changes in glucose differentially modulate the excitability of hypothalamic melaninconcentrating hormone and orexin neurons in situ. J Neurosci 25, 2429-2433.Doi: 10.1523/JNEUROSCI.4925-04.2005.

Bushong, E.A., Martone, M.E., and Ellisman, M.H. (2004). Maturation of astrocyte morphology and the establishment of astrocyte domains during postnatal hippocampal development. Int J Dev Neurosci 22, 73-86.Doi: 10.1016/j.ijdevneu.2003.12.008. Butzke, V. (1872). Studien uber den feineren Bau der Grosshirnrinde. Archiv für Psychiatrie und Nervenkrankheiten 3, 575-600.

Cabral, A., Valdivia, S., Fernandez, G., Reynaldo, M., and Perello, M. (2014). Divergent neuronal circuitries underlying acute orexigenic effects of peripheral or central ghrelin: critical role of brain accessibility. J Neuroendocrinol 26, 542-554.Doi: 10.1111/jne.12168.

Cahoy, J.D., Emery, B., Kaushal, A., Foo, L.C., Zamanian, J.L., Christopherson, K.S., Xing, Y., Lubischer, J.L., Krieg, P.A., Krupenko, S.A., et al. (2008). A transcriptome database for astrocytes, neurons, and oligodendrocytes: a new resource for understanding brain development and function. J Neurosci 28, 264-278.Doi: 10.1523/JNEUROSCI.4178-07.2008.

Cao, X., Li, L.P., Wang, Q., Wu, Q., Hu, H.H., Zhang, M., Fang, Y.Y., Zhang, J., Li, S.J., Xiong, W.C., et al. (2013). Astrocyte-derived ATP modulates depressive-like behaviors. Nat Med 19, 773-777.Doi: 10.1038/nm.3162.

Carlson, A.J. (1919). The control of hunger in health and disease (Chicago, IL: The University of Chicago Press). 
Carmona, M.A., Murai, K.K., Wang, L., Roberts, A.J., and Pasquale, E.B. (2009). Glial ephrin-A3 regulates hippocampal dendritic spine morphology and glutamate transport. Proc Natl Acad Sci U S A 106, 12524-12529.Doi: 10.1073/pnas.0903328106.

Carvalho-Paulo, D., de Morais Magalhaes, N.G., de Almeida Miranda, D., Diniz, D.G., Henrique, E.P., Moraes, I.A.M., Pereira, P.D.C., de Melo, M.A.D., de Lima, C.M., de Oliveira, M.A., et al. (2017). Hippocampal Astrocytes in Migrating and Wintering Semipalmated Sandpiper Calidris pusilla. Front Neuroanat 11, 126.Doi: 10.3389/fnana.2017.00126.

Chai, H., Diaz-Castro, B., Shigetomi, E., Monte, E., Octeau, J.C., Yu, X., Cohn, W., Rajendran, P.S., Vondriska, T.M., Whitelegge, J.P., et al. (2017). Neural CircuitSpecialized Astrocytes: Transcriptomic, Proteomic, Morphological, and Functional Evidence. Neuron 95, 531-549 e539.Doi: 10.1016/j.neuron.2017.06.029.

Chen, N., Sugihara, H., Kim, J., Fu, Z., Barak, B., Sur, M., Feng, G., and Han, W. (2016). Direct modulation of GFAP-expressing glia in the arcuate nucleus bidirectionally regulates feeding. Elife 5.Doi: 10.7554/eLife.18716.

Christopherson, K.S., Ullian, E.M., Stokes, C.C., Mullowney, C.E., Hell, J.W., Agah, A., Lawler, J., Mosher, D.F., Bornstein, P., and Barres, B.A. (2005).

Thrombospondins are astrocyte-secreted proteins that promote CNS synaptogenesis. Cell 120, 421-433.Doi: 10.1016/j.cell.2004.12.020.

Chung, W.S., Allen, N.J., and Eroglu, C. (2015). Astrocytes Control Synapse Formation, Function, and Elimination. Cold Spring Harb Perspect Biol 7, a020370.Doi: 10.1101/cshperspect.a020370.

Chung, W.S., Clarke, L.E., Wang, G.X., Stafford, B.K., Sher, A., Chakraborty, C., Joung, J., Foo, L.C., Thompson, A., Chen, C., et al. (2013). Astrocytes mediate synapse elimination through MEGF10 and MERTK pathways. Nature 504, 394400.Doi: 10.1038/nature12776.

Chung, W.S., Verghese, P.B., Chakraborty, C., Joung, J., Hyman, B.T., Ulrich, J.D., Holtzman, D.M., and Barres, B.A. (2016). Novel allele-dependent role for APOE in controlling the rate of synapse pruning by astrocytes. Proc Natl Acad Sci U S A 113, 10186-10191.Doi: 10.1073/pnas.1609896113.

Chvatal, A., and Verkhratsky, A. (2018). Early history of neuroglial research: Personalities. . Neuroglia 1, 245 - 281.Doi: 10.3390/neuroglia1010016.

Citron, B.A., Saykally, J.N., Cao, C., Dennis, J.S., Runfeldt, M., and Arendash, G.W. (2015). Transcription factor $\mathrm{Sp} 1$ inhibition, memory, and cytokines in a mouse model of Alzheimer's disease. Am J Neurodegener Dis 4, 40-48.Doi:

Clarke, L.E., and Barres, B.A. (2013). Emerging roles of astrocytes in neural circuit development. Nat Rev Neurosci 14, 311-321.Doi: 10.1038/nrn3484.

Cochella, L., and Hobert, O. (2012). Diverse functions of microRNAs in nervous system development. Curr Top Dev Biol 99, 115-143.Doi: 10.1016/B978-0-12387038-4.00005-7.

Collden, G., Balland, E., Parkash, J., Caron, E., Langlet, F., Prevot, V., and Bouret, S.G. (2015). Neonatal overnutrition causes early alterations in the central response to peripheral ghrelin. Mol Metab 4, 15-24.Doi: 10.1016/j.molmet.2014.10.003.

Colombo, J.A. (2017). The interlaminar glia: from serendipity to hypothesis. Brain Struct Funct 222, 1109-1129.Doi: 10.1007/s00429-016-1332-8.

Corkrum, M., Covelo, A., Lines, J., Bellocchio, L., Pisansky, M., Loke, K., Quintana, R., Rothwell, P.E., Lujan, R., Marsicano, G., et al. (2020). Dopamine-Evoked Synaptic Regulation in the Nucleus Accumbens Requires Astrocyte Activity. Neuron 105, 1036-1047 e1035.Doi: 10.1016/j.neuron.2019.12.026. 
Crawford, D.C., Jiang, X., Taylor, A., and Mennerick, S. (2012). Astrocyte-derived thrombospondins mediate the development of hippocampal presynaptic plasticity in vitro. J Neurosci 32, 13100-13110.Doi: 10.1523/JNEUROSCI.2604-12.2012.

Czeh, B., and Di Benedetto, B. (2013). Antidepressants act directly on astrocytes: evidences and functional consequences. Eur Neuropsychopharmacol 23, 171-185.Doi: 10.1016/j.euroneuro.2012.04.017.

de Pins, B., Cifuentes-Diaz, C., Farah, A.T., Lopez-Molina, L., Montalban, E., Sancho-Balsells, A., Lopez, A., Gines, S., Delgado-Garcia, J.M., Alberch, J., et al. (2019). Conditional BDNF Delivery from Astrocytes Rescues Memory Deficits, Spine Density, and Synaptic Properties in the 5xFAD Mouse Model of Alzheimer Disease. J Neurosci 39, 2441-2458.Doi: 10.1523/JNEUROSCI.2121-18.2019. Deiters, O. (1865). Untersuchungen über Gehirn und Rückenmark des Menschen und der Säugethiere (Braunschweig: Vieweg).

Deng, C., Reddy, P., Cheng, Y., Luo, C.W., Hsiao, C.L., and Hsueh, A.J. (2013). Multi-functional norrin is a ligand for the LGR4 receptor. J Cell Sci 126, 20602068.Doi: $10.1242 /$ jcs.123471.

Derouiche, A. (2003). The perisynaptic astrocyte process as a glial compartmentimmunolabeling for glutamine synthetase and other glial markers. Advances in Molecular and Cell Biology 31, 147-163.

Derouiche, A., Anlauf, E., Aumann, G., Muhlstadt, B., and Lavialle, M. (2002). Anatomical aspects of glia-synapse interaction: the perisynaptic glial sheath consists of a specialized astrocyte compartment. J Physiol Paris 96, 177-182.

Derouiche, A., Haseleu, J., and Korf, H.W. (2015). Fine astrocyte processes contain very small mitochondria: Glial oxidative capability may fuel transmitter metabolism. Neurochem Res 40, 2402-2413.Doi: 10.1007/s11064-015-1563-8.

Descalzi, G., Gao, V., Steinman, M.Q., Suzuki, A., and Alberini, C.M. (2019). Lactate from astrocytes fuels learning-induced mRNA translation in excitatory and inhibitory neurons. Commun Biol 2, 247.Doi: 10.1038/s42003-019-0495-2.

Devane, W.A., Dysarz, F.A., 3rd, Johnson, M.R., Melvin, L.S., and Howlett, A.C. (1988). Determination and characterization of a cannabinoid receptor in rat brain. Mol Pharmacol 34, 605-613.

Diamond, J.S. (2001). Neuronal glutamate transporters limit activation of NMDA receptors by neurotransmitter spillover on CA1 pyramidal cells. J Neurosci 21, 83288338 .

Ding, F., O'Donnell, J., Thrane, A.S., Zeppenfeld, D., Kang, H., Xie, L., Wang, F., and Nedergaard, M. (2013). $\alpha 1$-Adrenergic receptors mediate coordinated $\mathrm{Ca}^{2+}$ signaling of cortical astrocytes in awake, behaving mice. Cell Calcium 54, 387394.Doi: 10.1016/j.ceca.2013.09.001.

Ding, F., O'Donnell, J., Xu, Q., Kang, N., Goldman, N., and Nedergaard, M. (2016). Changes in the composition of brain interstitial ions control the sleep-wake cycle. Science 352, 550-555.Doi: 10.1126/science.aad4821. Diniz, D.G., de Oliveira, M.A., de Lima, C.M., Foro, C.A., Sosthenes, M.C., BentoTorres, J., da Costa Vasconcelos, P.F., Anthony, D.C., and Diniz, C.W. (2016). Age, environment, object recognition and morphological diversity of GFAPimmunolabeled astrocytes. Behav Brain Funct 12, 28.Doi: 10.1186/s12993-016-01112.

Diniz, L.P., Almeida, J.C., Tortelli, V., Vargas Lopes, C., Setti-Perdigao, P., Stipursky, J., Kahn, S.A., Romao, L.F., de Miranda, J., Alves-Leon, S.V., et al. (2012). Astrocyte-induced synaptogenesis is mediated by transforming growth factor 
$\beta$ signaling through modulation of $\mathrm{D}$-serine levels in cerebral cortex neurons. J Biol Chem 287, 41432-41445.Doi: 10.1074/jbc.M112.380824.

Diniz, L.P., Matias, I., Araujo, A.P.B., Garcia, M.N., Barros Aragao, F., Alves-Leon, S.V., de Souza, J.M., Foguel, D., Figueiredo, C.P., Braga, C., et al. (2019). $\alpha-$ synuclein oligomers enhance astrocyte-induced synapse formation through TGF-beta1 signaling in a Parkinson's disease model. J Neurochem.Doi: 10.1111/jnc.14710. Diniz, L.P., Tortelli, V., Garcia, M.N., Araujo, A.P., Melo, H.M., Silva, G.S., Felice, F.G., Alves-Leon, S.V., Souza, J.M., Romao, L.F., et al. (2014). Astrocyte transforming growth factor $\beta 1$ promotes inhibitory synapse formation via $\mathrm{CaM}$ kinase II signaling. Glia 62, 1917-1931.Doi: 10.1002/glia.22713.

DiNuzzo, M. (2016). Astrocyte-neuron interactions during learning may occur by lactate signaling rather than metabolism. Front Integr Neurosci 10, 2.Doi: 10.3389/fnint.2016.00002.

Dowling, C., and Allen, N.J. (2018). Mice Lacking Glypican 4 Display Juvenile Hyperactivity and Adult Social Interaction Deficits. Brain Plast 4, 197-209.Doi: 10.3233/BPL-180079.

Doyle, J.P., Dougherty, J.D., Heiman, M., Schmidt, E.F., Stevens, T.R., Ma, G., Bupp, S., Shrestha, P., Shah, R.D., Doughty, M.L., et al. (2008). Application of a translational profiling approach for the comparative analysis of CNS cell types. Cell 135, 749-762.Doi: 10.1016/j.cell.2008.10.029.

Duvarci, S., and Pare, D. (2014). Amygdala microcircuits controlling learned fear. Neuron 82, 966-980.Doi: 10.1016/j.neuron.2014.04.042.

Ebrahimi, M., Yamamoto, Y., Sharifi, K., Kida, H., Kagawa, Y., Yasumoto, Y., Islam, A., Miyazaki, H., Shimamoto, C., Maekawa, M., et al. (2016). Astrocyte-expressed FABP7 regulates dendritic morphology and excitatory synaptic function of cortical neurons. Glia 64, 48-62.Doi: 10.1002/glia.22902.

Eng, L.F., Vanderhaeghen, J.J., Bignami, A., and Gerstl, B. (1971). An acidic protein isolated from fibrous astrocytes. Brain Res 28, 351-354.Doi: 10.1016/00068993(71)90668-8.

Eroglu, C., Allen, N.J., Susman, M.W., O'Rourke, N.A., Park, C.Y., Ozkan, E., Chakraborty, C., Mulinyawe, S.B., Annis, D.S., Huberman, A.D., et al. (2009). Gabapentin receptor $\alpha 2 \delta-1$ is a neuronal thrombospondin receptor responsible for excitatory CNS synaptogenesis. Cell 139, 380-392.Doi: 10.1016/j.cell.2009.09.025. Erta, M., Giralt, M., Esposito, F.L., Fernandez-Gayol, O., and Hidalgo, J. (2015). Astrocytic IL-6 mediates locomotor activity, exploration, anxiety, learning and social behavior. Horm Behav 73, 64-74.Doi: 10.1016/j.yhbeh.2015.06.016.

Farhy-Tselnicker, I., van Casteren, A.C.M., Lee, A., Chang, V.T., Aricescu, A.R., and Allen, N.J. (2017). Astrocyte-Secreted Glypican 4 Regulates Release of Neuronal Pentraxin 1 from Axons to Induce Functional Synapse Formation. Neuron 96, 428445 e413.Doi: 10.1016/j.neuron.2017.09.053.

Farmer, W.T., Abrahamsson, T., Chierzi, S., Lui, C., Zaelzer, C., Jones, E.V., Bally, B.P., Chen, G.G., Theroux, J.F., Peng, J., et al. (2016). Neurons diversify astrocytes in the adult brain through sonic hedgehog signaling. Science 351, 849-854.Doi:

10.1126/science.aab3103.

Ferris, H.A., Perry, R.J., Moreira, G.V., Shulman, G.I., Horton, J.D., and Kahn, C.R. (2017). Loss of astrocyte cholesterol synthesis disrupts neuronal function and alters whole-body metabolism. Proc Natl Acad Sci U S A 114, 1189-1194.Doi: $10.1073 /$ pnas. 1620506114. 
Figurov, A., Pozzo-Miller, L.D., Olafsson, P., Wang, T., and Lu, B. (1996). Regulation of synaptic responses to high-frequency stimulation and LTP by neurotrophins in the hippocampus. Nature 381, 706-709.Doi: 10.1038/381706a0. Filosa, A., Paixao, S., Honsek, S.D., Carmona, M.A., Becker, L., Feddersen, B., Gaitanos, L., Rudhard, Y., Schoepfer, R., Klopstock, T., et al. (2009). Neuron-glia communication via EphA4/ephrin-A3 modulates LTP through glial glutamate transport. Nat Neurosci 12, 1285-1292.Doi: 10.1038/nn.2394.

Frischknecht, R., Heine, M., Perrais, D., Seidenbecher, C.I., Choquet, D., and Gundelfinger, E.D. (2009). Brain extracellular matrix affects AMPA receptor lateral mobility and short-term synaptic plasticity. Nat Neurosci 12, 897-904.Doi: 10.1038/nn.2338.

Fullana, M.N., Ruiz-Bronchal, E., Ferres-Coy, A., Juarez-Escoto, E., Artigas, F., and Bortolozzi, A. (2019). Regionally selective knockdown of astroglial glutamate transporters in infralimbic cortex induces a depressive phenotype in mice. Glia 67, 1122-1137.Doi: 10.1002/glia.23593.

Galambos, R. (1961). A glia-neural theory of brain function. Proc Natl Acad Sci U S A 47, 129-136.

Galloway, D.A., Phillips, A.E.M., Owen, D.R.J., and Moore, C.S. (2019).

Phagocytosis in the Brain: Homeostasis and Disease. Front Immunol 10, 790.Doi: 10.3389/fimmu.2019.00790.

Gandal, M.J., Haney, J.R., Parikshak, N.N., Leppa, V., Ramaswami, G., Hartl, C., Schork, A.J., Appadurai, V., Buil, A., Werge, T.M., et al. (2018). Shared molecular neuropathology across major psychiatric disorders parallels polygenic overlap. Science 359, 693-697.Doi: 10.1126/science.aad6469.

Gao, V., Suzuki, A., Magistretti, P.J., Lengacher, S., Pollonini, G., Steinman, M.Q., and Alberini, C.M. (2016). Astrocytic $\beta_{2}$-adrenergic receptors mediate hippocampal long-term memory consolidation. Proc Natl Acad Sci U S A 113, 8526-8531.Doi: 10.1073/pnas.1605063113.

Garcia-Caceres, C., Balland, E., Prevot, V., Luquet, S., Woods, S.C., Koch, M., Horvath, T.L., Yi, C.X., Chowen, J.A., Verkhratsky, A., et al. (2019). Role of astrocytes, microglia, and tanycytes in brain control of systemic metabolism. Nat Neurosci 22, 7-14.Doi: 10.1038/s41593-018-0286-y.

Garrett, A.M., and Weiner, J.A. (2009). Control of CNS synapse development by $\gamma$ protocadherin-mediated astrocyte-neuron contact. J Neurosci 29, 11723-11731.Doi: 10.1523/JNEUROSCI.2818-09.2009.

Gasull-Camos, J., Tarres-Gatius, M., Artigas, F., and Castane, A. (2017). Glial GLT-1 blockade in infralimbic cortex as a new strategy to evoke rapid antidepressant-like effects in rats. Transl Psychiatry 7, e1038.Doi: 10.1038/tp.2017.7.

Genoud, C., Quairiaux, C., Steiner, P., Hirling, H., Welker, E., and Knott, G.W. (2006). Plasticity of astrocytic coverage and glutamate transporter expression in adult mouse cortex. PLoS Biol 4, e343.Doi: 10.1371/journal.pbio.0040343.

Gerstner, J.R., Perron, I.J., Riedy, S.M., Yoshikawa, T., Kadotani, H., Owada, Y., Van Dongen, H.P.A., Galante, R.J., Dickinson, K., Yin, J.C.P., et al. (2017). Normal sleep requires the astrocyte brain-type fatty acid binding protein FABP7. Sci Adv 3, e1602663.Doi: 10.1126/sciadv.1602663.

Gilbert, E., Tang, J.M., Ludvig, N., and Bergold, P.J. (2006). Elevated lactate suppresses neuronal firing in vivo and inhibits glucose metabolism in hippocampal slice cultures. Brain Res 1117, 213-223.Doi: 10.1016/j.brainres.2006.07.107. Ginhoux, F., Greter, M., Leboeuf, M., Nandi, S., See, P., Gokhan, S., Mehler, M.F., Conway, S.J., Ng, L.G., Stanley, E.R., et al. (2010). Fate mapping analysis reveals 
that adult microglia derive from primitive macrophages. Science 330, 841-845.Doi: 10.1126/science. 1194637.

Golgi, C. (1903). Opera omnia (Milano: Ulrico Hoepli).

Gomes, F.C., Sousa Vde, O., and Romao, L. (2005). Emerging roles for TGF- $\beta 1$ in nervous system development. Int J Dev Neurosci 23, 413-424.Doi:

10.1016/j.ijdevneu.2005.04.001.

Gomez, J.A., Perkins, J.M., Beaudoin, G.M., Cook, N.B., Quraishi, S.A., Szoeke, E.A., Thangamani, K., Tschumi, C.W., Wanat, M.J., Maroof, A.M., et al. (2019). Ventral tegmental area astrocytes orchestrate avoidance and approach behavior. Nat Commun 10, 1455.Doi: 10.1038/s41467-019-09131-y.

Grosche, J., Kettenmann, H., and Reichenbach, A. (2002). Bergmann glial cells form distinct morphological structures to interact with cerebellar neurons. J Neurosci Res 68, 138-149.Doi:

Grosche, J., Matyash, V., Moller, T., Verkhratsky, A., Reichenbach, A., and Kettenmann, H. (1999). Microdomains for neuron-glia interaction: parallel fiber signaling to Bergmann glial cells. Nat Neurosci 2, 139-143.Doi: 10.1038/5692. Halassa, M.M., Florian, C., Fellin, T., Munoz, J.R., Lee, S.Y., Abel, T., Haydon, P.G., and Frank, M.G. (2009). Astrocytic modulation of sleep homeostasis and cognitive consequences of sleep loss. Neuron 61, 213-219.Doi: 10.1016/j.neuron.2008.11.024. Hama, H., Hara, C., Yamaguchi, K., and Miyawaki, A. (2004). PKC signaling mediates global enhancement of excitatory synaptogenesis in neurons triggered by local contact with astrocytes. Neuron 41, 405-415.

Hamilton, N.B., and Attwell, D. (2010). Do astrocytes really exocytose neurotransmitters? Nat Rev Neurosci 11, 227-238.Doi: 10.1038/nrn2803. Han, J., Kesner, P., Metna-Laurent, M., Duan, T., Xu, L., Georges, F., Koehl, M., Abrous, D.N., Mendizabal-Zubiaga, J., Grandes, P., et al. (2012). Acute cannabinoids impair working memory through astroglial CB1 receptor modulation of hippocampal LTD. Cell 148, 1039-1050.Doi: 10.1016/j.cell.2012.01.037.

Han, P., and Whelan, P.J. (2010). Tumor necrosis factor $\alpha$ enhances glutamatergic transmission onto spinal motoneurons. J Neurotrauma 27, 287-292.Doi:

10.1089/neu.2009.1016.

Han, X., Chen, M., Wang, F., Windrem, M., Wang, S., Shanz, S., Xu, Q., Oberheim, N.A., Bekar, L., Betstadt, S., et al. (2013). Forebrain engraftment by human glial progenitor cells enhances synaptic plasticity and learning in adult mice. Cell Stem Cell 12, 342-353.Doi: 10.1016/j.stem.2012.12.015.

Harris, R.A., Lone, A., Lim, H., Martinez, F., Frame, A.K., Scholl, T.J., and Cumming, R.C. (2019). Aerobic Glycolysis Is Required for Spatial Memory Acquisition But Not Memory Retrieval in Mice. eNeuro 6.Doi:

10.1523/ENEURO.0389-18.2019.

Haydon, P.G. (2017). Astrocytes and the modulation of sleep. Curr Opin Neurobiol 44, 28-33.Doi: 10.1016/j.conb.2017.02.008.

Heller, J.P., and Rusakov, D.A. (2015). Morphological plasticity of astroglia: Understanding synaptic microenvironment. Glia 63, 2133-2151.Doi:

10.1002/glia.22821.

Henneberger, C., Papouin, T., Oliet, S.H., and Rusakov, D.A. (2010). Long-term potentiation depends on release of D-serine from astrocytes. Nature 463, 232236.Doi: 10.1038/nature08673.

Hennekinne, L., Colasse, S., Triller, A., and Renner, M. (2013). Differential control of thrombospondin over synaptic glycine and AMPA receptors in spinal cord neurons. J Neurosci 33, 11432-11439.Doi: 10.1523/JNEUROSCI.5247-12.2013. 
Hennes, M., Lombaert, N., Wahis, J., Van den Haute, C., Holt, M.G., and Arckens, L. (2020). Astrocytes shape the plastic response of adult cortical neurons to vision loss. Glia.Doi: 10.1002/glia.23830.

Herculano-Houzel, S. (2014). The glia/neuron ratio: how it varies uniformly across brain structures and species and what that means for brain physiology and evolution. Glia 62, 1377-1391.Doi: 10.1002/glia.22683.

Hering, H., Lin, C.C., and Sheng, M. (2003). Lipid rafts in the maintenance of synapses, dendritic spines, and surface AMPA receptor stability. J Neurosci 23, 32623271.Doi:

Herkenham, M., Lynn, A.B., Johnson, M.R., Melvin, L.S., de Costa, B.R., and Rice, K.C. (1991). Characterization and localization of cannabinoid receptors in rat brain: a quantitative in vitro autoradiographic study. J Neurosci 11, 563-583.Doi:

Hertz, L., Dringen, R., Schousboe, A., and Robinson, S.R. (1999). Astrocytes: glutamate producers for neurons. J Neurosci Res 57, 417-428.

Hertz, L., and Gibbs, M.E. (2009). What learning in day-old chickens can teach a neurochemist: focus on astrocyte metabolism. J Neurochem 109 Suppl 1, 10-16.Doi: 10.1111/j.1471-4159.2009.05939.x.

Hirabayashi, Y., Itoh, Y., Tabata, H., Nakajima, K., Akiyama, T., Masuyama, N., and Gotoh, Y. (2004). The Wnt/beta-catenin pathway directs neuronal differentiation of cortical neural precursor cells. Development 131, 2791-2801.Doi: 10.1242/dev.01165. Hirabayashi, Y., Suzki, N., Tsuboi, M., Endo, T.A., Toyoda, T., Shinga, J., Koseki, H., Vidal, M., and Gotoh, Y. (2009). Polycomb limits the neurogenic competence of neural precursor cells to promote astrogenic fate transition. Neuron 63, 600-613.Doi: 10.1016/j.neuron.2009.08.021.

Hol, E.M., and Pekny, M. (2015). Glial fibrillary acidic protein (GFAP) and the astrocyte intermediate filament system in diseases of the central nervous system. Curr Opin Cell Biol 32, 121-130.Doi: 10.1016/j.ceb.2015.02.004.

Holt, L.M., Hernandez, R.D., Pacheco, N.L., Torres Ceja, B., Hossain, M., and Olsen, M.L. (2019). Astrocyte morphogenesis is dependent on BDNF signaling via astrocytic TrkB.T1. Elife 8.Doi: 10.7554/eLife.44667.

$\mathrm{Hu}$, B., Nikolakopoulou, A.M., and Cohen-Cory, S. (2005). BDNF stabilizes synapses and maintains the structural complexity of optic axons in vivo. Development 132, 4285-4298.Doi: 10.1242/dev.02017.

Hughes, E.G., Elmariah, S.B., and Balice-Gordon, R.J. (2010). Astrocyte secreted proteins selectively increase hippocampal GABAergic axon length, branching, and synaptogenesis. Mol Cell Neurosci 43, 136-145.Doi: 10.1016/j.mcn.2009.10.004. Hung, C.Y., Hsu, T.I., Chuang, J.Y., Su, T.P., Chang, W.C., and Hung, J.J. (2020). Sp1 in Astrocyte Is Important for Neurite Outgrowth and Synaptogenesis. Mol Neurobiol 57, 261-277.Doi: 10.1007/s12035-019-01694-7.

Iadecola, C. (2017). The Neurovascular Unit Coming of Age: A Journey through Neurovascular Coupling in Health and Disease. Neuron 96, 17-42.Doi: 10.1016/j.neuron.2017.07.030.

Iino, M., Goto, K., Kakegawa, W., Okado, H., Sudo, M., Ishiuchi, S., Miwa, A., Takayasu, Y., Saito, I., Tsuzuki, K., et al. (2001). Glia-synapse interaction through $\mathrm{Ca}^{2+}$-permeable AMPA receptors in Bergmann glia. Science 292, 926-929.Doi: 10.1126/science. 1058827 .

Jastrowitz, M. (1871). Studien über die Encephalitis und Myelitis des ersten Kindesalters. Arch f Psychiat 3, 162-213.

John Lin, C.C., Yu, K., Hatcher, A., Huang, T.W., Lee, H.K., Carlson, J., Weston, M.C., Chen, F., Zhang, Y., Zhu, W., et al. (2017). Identification of diverse astrocyte 
populations and their malignant analogs. Nat Neurosci 20, 396-405.Doi:

10.1038/nn.4493.

Jones, E.V., Bernardinelli, Y., Tse, Y.C., Chierzi, S., Wong, T.P., and Murai, K.K. (2011). Astrocytes control glutamate receptor levels at developing synapses through SPARC-beta-integrin interactions. J Neurosci 31, 4154-4165.Doi:

10.1523/JNEUROSCI.4757-10.2011.

Jones, T.A., and Greenough, W.T. (1996). Ultrastructural evidence for increased contact between astrocytes and synapses in rats reared in a complex environment. Neurobiology of learning and memory 65, 48-56.Doi: 10.1006/nlme.1996.0005. Jyothi, H.J., Vidyadhara, D.J., Mahadevan, A., Philip, M., Parmar, S.K., Manohari, S.G., Shankar, S.K., Raju, T.R., and Alladi, P.A. (2015). Aging causes morphological alterations in astrocytes and microglia in human substantia nigra pars compacta. Neurobiol Aging 36, 3321-3333.Doi: 10.1016/j.neurobiolaging.2015.08.024. Kanemaru, K., Kubota, J., Sekiya, H., Hirose, K., Okubo, Y., and Iino, M. (2013). Calcium-dependent $\mathrm{N}$-cadherin up-regulation mediates reactive astrogliosis and neuroprotection after brain injury. Proc Natl Acad Sci U S A 110, 11612-11617.Doi: 10.1073/pnas.1300378110.

Kania, A., and Klein, R. (2016). Mechanisms of ephrin-Eph signalling in development, physiology and disease. Nat Rev Mol Cell Biol 17, 240-256.Doi: 10.1038/nrm.2015.16.

Karakaya, S., Kipp, M., and Beyer, C. (2007). Oestrogen regulates the expression and function of dopamine transporters in astrocytes of the nigrostriatal system. J Neuroendocrinol 19, 682-690.Doi: 10.1111/j.1365-2826.2007.01575.x.

Karpati, A., Yoshikawa, T., Naganuma, F., Matsuzawa, T., Kitano, H., Yamada, Y., Yokoyama, M., Futatsugi, A., Mikoshiba, K., and Yanai, K. (2019). Histamine $\mathrm{H}_{1}$ receptor on astrocytes and neurons controls distinct aspects of mouse behaviour. Sci Rep 9, 16451.Doi: 10.1038/s41598-019-52623-6.

Kast, B. (2001). The best supporting actors. Nature 412, 674-676.Doi: $10.1038 / 35089223$.

Kerr, K.S., Fuentes-Medel, Y., Brewer, C., Barria, R., Ashley, J., Abruzzi, K.C., Sheehan, A., Tasdemir-Yilmaz, O.E., Freeman, M.R., and Budnik, V. (2014). Glial wingless/Wnt regulates glutamate receptor clustering and synaptic physiology at the Drosophila neuromuscular junction. J Neurosci 34, 2910-2920.Doi:

10.1523/JNEUROSCI.3714-13.2014.

Kersante, F., Rowley, S.C., Pavlov, I., Gutierrez-Mecinas, M., Semyanov, A., Reul, J.M., Walker, M.C., and Linthorst, A.C. (2013). A functional role for both aminobutyric acid (GABA) transporter-1 and GABA transporter-3 in the modulation of extracellular GABA and GABAergic tonic conductances in the rat hippocampus. J Physiol 591, 2429-2441.Doi: 10.1113/jphysiol.2012.246298.

Kettenmann, H., Hanisch, U.K., Noda, M., and Verkhratsky, A. (2011). Physiology of microglia. Physiol Rev 91, 461-553.Doi: 10.1152/physrev.00011.2010.

Kettenmann, H., Kirchhoff, F., and Verkhratsky, A. (2013). Microglia: new roles for the synaptic stripper. Neuron 77, 10-18.Doi: 10.1016/j.neuron.2012.12.023.

Kettenmann, H., and Verkhratsky, A. (2008). Neuroglia: the 150 years after. Trends Neurosci 31, 653-659.Doi: 10.1016/j.tins.2008.09.003.

Khakh, B.S., and McCarthy, K.D. (2015). Astrocyte calcium signaling: from observations to functions and the challenges therein. Cold Spring Harb Perspect Biol 7, a020404.Doi: 10.1101/cshperspect.a020404.

Kim, J.G., Suyama, S., Koch, M., Jin, S., Argente-Arizon, P., Argente, J., Liu, Z.W., Zimmer, M.R., Jeong, J.K., Szigeti-Buck, K., et al. (2014). Leptin signaling in 
astrocytes regulates hypothalamic neuronal circuits and feeding. Nat Neurosci 17, 908-910.Doi: 10.1038/nn.3725.

King, A.E., Ackley, M.A., Cass, C.E., Young, J.D., and Baldwin, S.A. (2006). Nucleoside transporters: from scavengers to novel therapeutic targets. Trends Pharmacol Sci 27, 416-425.Doi: 10.1016/j.tips.2006.06.004.

Kirischuk, S., Kettenmann, H., and Verkhratsky, A. (1997). $\mathrm{Na}^{+} / \mathrm{Ca}^{2+}$ exchanger modulates kainate-triggered $\mathrm{Ca}^{2+}$ signaling in Bergmann glial cells in situ. FASEB J 11, 566-572.Doi: 10.1096/fasebj.11.7.9212080.

Kirischuk, S., Kettenmann, H., and Verkhratsky, A. (2007). Membrane currents and cytoplasmic sodium transients generated by glutamate transport in Bergmann glial cells. Pflugers Arch 454, 245-252.Doi: 10.1007/s00424-007-0207-5.

Kirischuk, S., Parpura, V., and Verkhratsky, A. (2012). Sodium dynamics: another key to astroglial excitability? Trends Neurosci 35, 497-506.Doi:

10.1016/j.tins.2012.04.003.

Klomp, L.W., de Koning, T.J., Malingre, H.E., van Beurden, E.A., Brink, M., Opdam, F.L., Duran, M., Jaeken, J., Pineda, M., Van Maldergem, L., et al. (2000). Molecular characterization of 3-phosphoglycerate dehydrogenase deficiency - a neurometabolic disorder associated with reduced L-serine biosynthesis. Am J Hum Genet 67, 13891399.Doi: 10.1086/316886.

Koeppen, J., Nguyen, A.Q., Nikolakopoulou, A.M., Garcia, M., Hanna, S., Woodruff, S., Figueroa, Z., Obenaus, A., and Ethell, I.M. (2018). Functional Consequences of Synapse Remodeling Following Astrocyte-Specific Regulation of Ephrin-B1 in the Adult Hippocampus. J Neurosci 38, 5710-5726.Doi: 10.1523/JNEUROSCI.361817.2018.

Koh, S., Roy, S., Eroglu, O., Strader, S., Chen, W.J., Kay, J.N., Field, G.D., and Eroglu, C. (2020). Thrombospondin-1 Promotes Circuit-Specific Synapse Formation Via $\beta 1$-Integrin. NEURON-D-19-01864 (preprint) https://ssrn.com/abstract=3497027.Doi:

Kol, K., Adamsky, A., Groysman, M., Kreisel, T., London, M., and Goshen, I. (2019). Astrocytes Contribute to Remote Memory Formation by Modulating HippocampalCortical Communication During Learning. BioRxiv, preprint, doi: 101101/682344.Doi:

Kölliker, A. (1867). Handbuch der Gewebelehre des Menschen für Ärtze und Studirende. 5th Edition. (Leipzig: Engelmann).

Korte, M., Staiger, V., Griesbeck, O., Thoenen, H., and Bonhoeffer, T. (1996). The involvement of brain-derived neurotrophic factor in hippocampal long-term potentiation revealed by gene targeting experiments. J Physiol Paris 90, 157-164.Doi: Kos, A., Olde Loohuis, N., Meinhardt, J., van Bokhoven, H., Kaplan, B.B., Martens, G.J., and Aschrafi, A. (2016). MicroRNA-181 promotes synaptogenesis and attenuates axonal outgrowth in cortical neurons. Cell Mol Life Sci 73, 3555-3567.Doi: 10.1007/s00018-016-2179-0.

Kriauciunaite, K., Kausyle, A., Pajarskiene, J., Tunaitis, V., Lim, D., Verkhratsky, A., and Pivoriunas, A. (2020). Immortalised Hippocampal Astrocytes from 3xTG-AD Mice Fail to Support BBB Integrity In Vitro: Role of Extracellular Vesicles in GlialEndothelial Communication. Cell Mol Neurobiol.Doi: 10.1007/s10571-020-00871-w. Krieglstein, K., Strelau, J., Schober, A., Sullivan, A., and Unsicker, K. (2002). TGF- $\beta$ and the regulation of neuron survival and death. J Physiol Paris 96, 25-30.Doi: Kucukdereli, H., Allen, N.J., Lee, A.T., Feng, A., Ozlu, M.I., Conatser, L.M., Chakraborty, C., Workman, G., Weaver, M., Sage, E.H., et al. (2011). Control of 
excitatory CNS synaptogenesis by astrocyte-secreted proteins Hevin and SPARC. Proc Natl Acad Sci U S A 108, E440-449.Doi: 10.1073/pnas.1104977108.

Lanjakornsiripan, D., Pior, B.J., Kawaguchi, D., Furutachi, S., Tahara, T., Katsuyama, Y., Suzuki, Y., Fukazawa, Y., and Gotoh, Y. (2018). Layer-specific morphological and molecular differences in neocortical astrocytes and their dependence on neuronal layers. Nat Commun 9, 1623.Doi: 10.1038/s41467-018-03940-3.

Larsen, B.R., Holm, R., Vilsen, B., and MacAulay, N. (2016). Glutamate transporter activity promotes enhanced $\mathrm{Na}^{+} / \mathrm{K}^{+}$-ATPase-mediated extracellular $\mathrm{K}^{+}$management during neuronal activity. J Physiol 594, 6627-6641.Doi: 10.1113/JP272531.

Lasic, E., Lisjak, M., Horvat, A., Bozic, M., Sakanovic, A., Anderluh, G., Verkhratsky, A., Vardjan, N., Jorgacevski, J., Stenovec, M., et al. (2019). Astrocyte Specific Remodeling of Plasmalemmal Cholesterol Composition by Ketamine Indicates a New Mechanism of Antidepressant Action. Sci Rep 9, 10957.Doi: 10.1038/s41598-019-47459-z.

Lauritzen, K.H., Morland, C., Puchades, M., Holm-Hansen, S., Hagelin, E.M., Lauritzen, F., Attramadal, H., Storm-Mathisen, J., Gjedde, A., and Bergersen, L.H. (2014). Lactate receptor sites link neurotransmission, neurovascular coupling, and brain energy metabolism. Cereb Cortex 24, 2784-2795.Doi: 10.1093/cercor/bht136. LeDoux, J.E. (2000). Emotion circuits in the brain. Annu Rev Neurosci 23, 155184.Doi: 10.1146/annurev.neuro.23.1.155.

Lee, H.S., Ghetti, A., Pinto-Duarte, A., Wang, X., Dziewczapolski, G., Galimi, F., Huitron-Resendiz, S., Pina-Crespo, J.C., Roberts, A.J., Verma, I.M., et al. (2014). Astrocytes contribute to gamma oscillations and recognition memory. Proc Natl Acad Sci U S A 111, E3343-3352.Doi: 10.1073/pnas.1410893111.

Lein, E.S., Hawrylycz, M.J., Ao, N., Ayres, M., Bensinger, A., Bernard, A., Boe, A.F., Boguski, M.S., Brockway, K.S., Byrnes, E.J., et al. (2007). Genome-wide atlas of gene expression in the adult mouse brain. Nature 445, 168-176.Doi:

10.1038/nature05453.

Leng, L., Zhuang, K., Liu, Z., Huang, C., Gao, Y., Chen, G., Lin, H., Hu, Y., Wu, D., Shi, M., et al. (2018). Menin Deficiency Leads to Depressive-like Behaviors in Mice by Modulating Astrocyte-Mediated Neuroinflammation. Neuron 100, 551-563 e557.Doi: 10.1016/j.neuron.2018.08.031.

Lesne, S., Blanchet, S., Docagne, F., Liot, G., Plawinski, L., MacKenzie, E.T., Auffray, C., Buisson, A., Pietu, G., and Vivien, D. (2002). Transforming growth factor- $\beta 1$-modulated cerebral gene expression. J Cereb Blood Flow Metab 22, 11141123.Doi: 10.1097/00004647-200209000-00009.

Levitt, P., Pintar, J.E., and Breakefield, X.O. (1982). Immunocytochemical demonstration of monoamine oxidase $\mathrm{B}$ in brain astrocytes and serotonergic neurons. Proc Natl Acad Sci U S A 79, 6385-6389.Doi:

Lewitus, G.M., Konefal, S.C., Greenhalgh, A.D., Pribiag, H., Augereau, K., and Stellwagen, D. (2016). Microglial TNF- $\alpha$ Suppresses Cocaine-Induced Plasticity and Behavioral Sensitization. Neuron 90, 483-491.Doi: 10.1016/j.neuron.2016.03.030. Li, B., Gu, L., Hertz, L., and Peng, L. (2013). Expression of nucleoside transporter in freshly isolated neurons and astrocytes from mouse brain. Neurochem Res 38, 23512358.Doi: 10.1007/s11064-013-1146-5.

Li, J., Khankan, R.R., Caneda, C., Godoy, M.I., Haney, M.S., Krawczyk, M.C., Bassik, M.C., Sloan, S.A., and Zhang, Y. (2019). Astrocyte-to-astrocyte contact and a positive feedback loop of growth factor signaling regulate astrocyte maturation. Glia 67, 1571-1597.Doi: 10.1002/glia.23630. 
Li, X., and Jin, P. (2010). Roles of small regulatory RNAs in determining neuronal identity. Nat Rev Neurosci 11, 329-338.Doi: 10.1038/nrn2739.

Li, X., Newbern, J.M., Wu, Y., Morgan-Smith, M., Zhong, J., Charron, J., and Snider, W.D. (2012). MEK Is a Key Regulator of Gliogenesis in the Developing Brain.

Neuron 75, 1035-1050.Doi: 10.1016/j.neuron.2012.08.031.

Li, Z., Lu, Y., Liang, S., Li, S., Chen, B., Zhang, M., Xia, M., Guan, D., Verkhratsky, A., and Li, B. (2020). Fluoxetine improves behavioural deficits induced by chronic alcohol treatment by alleviating RNA editing of 5-HT2C receptors. Neurochem Int 134, 104689.Doi: 10.1016/j.neuint.2020.104689.

Liauw, J., Hoang, S., Choi, M., Eroglu, C., Choi, M., Sun, G.H., Percy, M., WildmanTobriner, B., Bliss, T., Guzman, R.G., et al. (2008). Thrombospondins 1 and 2 are necessary for synaptic plasticity and functional recovery after stroke. J Cereb Blood Flow Metab 28, 1722-1732.Doi: 10.1038/jcbfm.2008.65.

Lichtman, J.W., and Colman, H. (2000). Synapse elimination and indelible memory. Neuron 25, 269-278.

Lopez-Fabuel, I., Le Douce, J., Logan, A., James, A.M., Bonvento, G., Murphy, M.P., Almeida, A., and Bolanos, J.P. (2016). Complex I assembly into supercomplexes determines differential mitochondrial ROS production in neurons and astrocytes. Proc Natl Acad Sci U S A 113, 13063-13068.Doi: 10.1073/pnas.1613701113.

Lopez-Redondo, F., Nakajima, K., Honda, S., and Kohsaka, S. (2000). Glutamate transporter GLT-1 is highly expressed in activated microglia following facial nerve axotomy. Brain Res Mol Brain Res 76, 429-435.Doi: 10.1016/s0169-328x(00)00022$\mathrm{x}$.

Lundquist, A.J., Parizher, J., Petzinger, G.M., and Jakowec, M.W. (2019). Exercise induces region-specific remodeling of astrocyte morphology and reactive astrocyte gene expression patterns in male mice. J Neurosci Res 97, 1081-1094.Doi:

10.1002/jnr.24430.

MacDonald, A.J., Holmes, F.E., Beall, C., Pickering, A.E., and Ellacott, K.L.J. (2020). Regulation of food intake by astrocytes in the brainstem dorsal vagal complex. Glia 68, 1241-1254.Doi: 10.1002/glia.23774.

Machado-Santos, A.R., Alves, N.D., Araujo, B., Correia, J.S., Patricio, P., MateusPinheiro, A., Loureiro-Campos, E., Bessa, J.M., Sousa, N., and Pinto, L. (2019). Astrocytic plasticity at the dorsal dentate gyrus on an animal model of recurrent depression. Neuroscience.Doi: 10.1016/j.neuroscience.2019.10.032.

Marcaggi, P., and Attwell, D. (2004). Role of glial amino acid transporters in synaptic transmission and brain energetics. Glia 47, 217-225.Doi: 10.1002/glia.20027. Marcaggi, P., Billups, D., and Attwell, D. (2003). The role of glial glutamate transporters in maintaining the independent operation of juvenile mouse cerebellar parallel fibre synapses. J Physiol 552, 89-107.Doi: 10.1113/jphysiol.2003.044263. Martin-Fernandez, M., Jamison, S., Robin, L.M., Zhao, Z., Martin, E.D., Aguilar, J., Benneyworth, M.A., Marsicano, G., and Araque, A. (2017). Synapse-specific astrocyte gating of amygdala-related behavior. Nat Neurosci 20, 1540-1548.Doi: 10.1038/nn.4649.

Martin, R., Bajo-Graneras, R., Moratalla, R., Perea, G., and Araque, A. (2015). Circuit-specific signaling in astrocyte-neuron networks in basal ganglia pathways. Science 349, 730-734.Doi: 10.1126/science.aaa7945.

Martinotti, C. (1889). Contributo allo studio della corteccia cerebrale, ed all' origine centrale dei nervi (Fratelli Bocca).

Matos, M., Shen, H.Y., Augusto, E., Wang, Y., Wei, C.J., Wang, Y.T., Agostinho, P., Boison, D., Cunha, R.A., and Chen, J.F. (2015). Deletion of adenosine $\mathrm{A}_{2 \mathrm{~A}}$ receptors 
from astrocytes disrupts glutamate homeostasis leading to psychomotor and cognitive impairment: relevance to schizophrenia. Biol Psychiatry 78, 763-774.Doi: 10.1016/j.biopsych.2015.02.026.

Mauch, D.H., Nagler, K., Schumacher, S., Goritz, C., Muller, E.C., Otto, A., and Pfrieger, F.W. (2001). CNS synaptogenesis promoted by glia-derived cholesterol. Science 294, 1354-1357.Doi: 10.1126/science.294.5545.1354.

McAfoose, J., and Baune, B.T. (2009). Evidence for a cytokine model of cognitive function. Neurosci Biobehav Rev 33, 355-366.Doi: 10.1016/j.neubiorev.2008.10.005.

Menet, J.S., Pescatore, S., and Rosbash, M. (2014). CLOCK:BMAL1 is a pioneer-like transcription factor. Genes Dev 28, 8-13.Doi: 10.1101/gad.228536.113.

Mennerick, S., and Zorumski, C.F. (1994). Glial contributions to excitatory neurotransmission in cultured hippocampal cells. Nature 368, 59-62.Doi: 10.1038/368059a0.

Middeldorp, J., and Hol, E.M. (2011). GFAP in health and disease. Prog Neurobiol 93, 421-443.Doi: 10.1016/j.pneurobio.2011.01.005.

Miller, S.J. (2018). Astrocyte Heterogeneity in the Adult Central Nervous System. Front Cell Neurosci 12, 401.Doi: 10.3389/fncel.2018.00401.

Miller, S.J., Philips, T., Kim, N., Dastgheyb, R., Chen, Z., Hsieh, Y.C., Daigle, J.G., Datta, M., Chew, J., Vidensky, S., et al. (2019). Molecularly defined cortical astroglia subpopulation modulates neurons via secretion of Norrin. Nat Neurosci 22, 741752.Doi: 10.1038/s41593-019-0366-7.

Mitterauer, B. (2013). The proemial synapse: Consciousness-generating glialneuronal units. In The Unity of Mind, Brain and World: Current Perspectives on a Science of Consciousness, A. APereira, Jr , and D. Lehmann, eds. (Cambridge: Cambridge University Press), pp. 233-264.

Molumby, M.J., Anderson, R.M., Newbold, D.J., Koblesky, N.K., Garrett, A.M., Schreiner, D., Radley, J.J., and Weiner, J.A. (2017). $\gamma$-Protocadherins Interact with Neuroligin-1 and Negatively Regulate Dendritic Spine Morphogenesis. Cell Rep 18, 2702-2714.Doi: 10.1016/j.celrep.2017.02.060.

Morel, L., Chiang, M.S.R., Higashimori, H., Shoneye, T., Iyer, L.K., Yelick, J., Tai, A., and Yang, Y. (2017). Molecular and Functional Properties of Regional Astrocytes in the Adult Brain. J Neurosci 37, 8706-8717.Doi: 10.1523/JNEUROSCI.395616.2017.

Morton, G.J., Cummings, D.E., Baskin, D.G., Barsh, G.S., and Schwartz, M.W. (2006). Central nervous system control of food intake and body weight. Nature 443, 289-295.Doi: 10.1038/nature05026.

Mothet, J.P., Parent, A.T., Wolosker, H., Brady, R.O., Jr., Linden, D.J., Ferris, C.D., Rogawski, M.A., and Snyder, S.H. (2000). D-serine is an endogenous ligand for the glycine site of the N-methyl-D-aspartate receptor. Proc Natl Acad Sci U S A 97, 4926-4931.Doi: 10.1073/pnas.97.9.4926.

Mullier, A., Bouret, S.G., Prevot, V., and Dehouck, B. (2010). Differential distribution of tight junction proteins suggests a role for tanycytes in bloodhypothalamus barrier regulation in the adult mouse brain. J Comp Neurol 518, 943962.Doi: 10.1002/cne.22273.

Mulligan, S.J., and MacVicar, B.A. (2004). Calcium transients in astrocyte endfeet cause cerebrovascular constrictions. Nature 431, 195-199.Doi: 10.1038/nature02827 nature02827 [pii].

Murai, K.K., and Pasquale, E.B. (2011). Eph receptors and ephrins in neuronastrocyte communication at synapses. Glia 59, 1567-1578.Doi: 10.1002/glia.21226. 
Nagai, J., Rajbhandari, A.K., Gangwani, M.R., Hachisuka, A., Coppola, G., Masmanidis, S.C., Fanselow, M.S., and Khakh, B.S. (2019). Hyperactivity with Disrupted Attention by Activation of an Astrocyte Synaptogenic Cue. Cell 177, 12801292 e1220.Doi: 10.1016/j.cell.2019.03.019.

Nakayama, N., Han, C.E., Scully, S., Nishinakamura, R., He, C., Zeni, L., Yamane, H., Chang, D., Yu, D., Yokota, T., et al. (2001). A novel chordin-like protein inhibitor for bone morphogenetic proteins expressed preferentially in mesenchymal cell lineages. Dev Biol 232, 372-387.Doi: 10.1006/dbio.2001.0200.

Nansen, F. (1886). The Structure and Combination of teh Histological Elements of teh Central Nervous System (Bergen: John Grieg).

Navarrete, M., and Araque, A. (2008). Endocannabinoids mediate neuron-astrocyte communication. Neuron 57, 883-893.Doi: 10.1016/j.neuron.2008.01.029.

Neame, S., Safory, H., Radzishevsky, I., Touitou, A., Marchesani, F., Marchetti, M., Kellner, S., Berlin, S., Foltyn, V.N., Engelender, S., et al. (2019). The NMDA receptor activation by d-serine and glycine is controlled by an astrocytic Phgdhdependent serine shuttle. Proc Natl Acad Sci U S A 116, 20736-20742.Doi: 10.1073/pnas.1909458116.

Nedergaard, M., and Verkhratsky, A. (2012). Artifact versus reality--how astrocytes contribute to synaptic events. Glia 60, 1013-1023.Doi: 10.1002/glia.22288.

Nguyen, A.Q., Koeppen, J., Woodruff, S., Mina, K., Figueroa, Z., and Ethell, I.M. (2020). Astrocytic Ephrin-B1 Controls Synapse Formation in the Hippocampus During Learning and Memory. Front Synaptic Neurosci 12, 10.Doi: 10.3389/fnsyn.2020.00010.

Nicoll, R.A. (2017). A Brief History of Long-Term Potentiation. Neuron 93, 281290.Doi: 10.1016/j.neuron.2016.12.015.

Norenberg, M.D., and Martinez-Hernandez, A. (1979). Fine structural localization of glutamine synthetase in astrocytes of rat brain. Brain Res 161, 303-310.Doi:

Oberheim, N.A., Takano, T., Han, X., He, W., Lin, J.H., Wang, F., Xu, Q., Wyatt, J.D., Pilcher, W., Ojemann, J.G., et al. (2009). Uniquely hominid features of adult human astrocytes. J Neurosci 29, 3276-3287.Doi: 10.1523/JNEUROSCI.470708.2009 .

Oberheim, N.A., Wang, X., Goldman, S., and Nedergaard, M. (2006). Astrocytic complexity distinguishes the human brain. Trends Neurosci 29, 547-553.Doi: 10.1016/j.tins.2006.08.004.

Oe, Y., Wang, X., Patriarchi, T., Konno, A., Ozawa, K., Yahagi, K., Hirai, H., Tian, L., McHugh, T.J., and Hirase, H. (2020). Distinct temporal integration of noradrenaline signaling by astrocytic second messengers during vigilance. Nat Commun 11, 471.Doi: 10.1038/s41467-020-14378-x.

Olabarria, M., Noristani, H.N., Verkhratsky, A., and Rodriguez, J.J. (2011). Agedependent decrease in glutamine synthetase expression in the hippocampal astroglia of the triple transgenic Alzheimer's disease mouse model: mechanism for deficient glutamatergic transmission? Mol Neurodegener 6, 55.Doi: 10.1186/1750-1326-6-55. Oliet, S.H., Piet, R., and Poulain, D.A. (2001). Control of glutamate clearance and synaptic efficacy by glial coverage of neurons. Science 292, 923-926.Doi: 10.1126/science.1059162.

Oliveira, J.F., Sardinha, V.M., Guerra-Gomes, S., Araque, A., and Sousa, N. (2015). Do stars govern our actions? Astrocyte involvement in rodent behavior. Trends Neurosci 38, 535-549.Doi: 10.1016/j.tins.2015.07.006.

Olsen, M.L., Khakh, B.S., Skatchkov, S.N., Zhou, M., Lee, C.J., and Rouach, N. (2015). New Insights on Astrocyte Ion Channels: Critical for Homeostasis and 
Neuron-Glia Signaling. J Neurosci 35, 13827-13835.Doi:

10.1523/JNEUROSCI.2603-15.2015.

Ongur, D., Drevets, W.C., and Price, J.L. (1998). Glial reduction in the subgenual prefrontal cortex in mood disorders. Proc Natl Acad Sci U S A 95, 13290-13295.Doi: 10.1073/pnas.95.22.13290.

Orellana, J.A., Saez, P.J., Cortes-Campos, C., Elizondo, R.J., Shoji, K.F., ContrerasDuarte, S., Figueroa, V., Velarde, V., Jiang, J.X., Nualart, F., et al. (2012). Glucose increases intracellular free $\mathrm{Ca}^{2+}$ in tanycytes via ATP released through connexin 43 hemichannels. Glia 60, 53-68.Doi: 10.1002/glia.21246.

Orr, A.G., Hsiao, E.C., Wang, M.M., Ho, K., Kim, D.H., Wang, X., Guo, W., Kang, J., Yu, G.Q., Adame, A., et al. (2015). Astrocytic adenosine receptor $\mathrm{A}_{2 \mathrm{~A}}$ and $\mathrm{G}_{\mathrm{s}}$-coupled signaling regulate memory. Nat Neurosci 18, 423-434.Doi: 10.1038/nn.3930.

Padmashri, R., Suresh, A., Boska, M.D., and Dunaevsky, A. (2015). Motor-Skill Learning Is Dependent on Astrocytic Activity. Neural Plast 2015, 938023.Doi: 10.1155/2015/938023.

Parpura, V., Baker, B.J., Jeras, M., and Zorec, R. (2010). Regulated exocytosis in astrocytic signal integration. Neurochem Int 57, 451-459.Doi:

10.1016/j.neuint.2010.02.007.

Patrushev, I., Gavrilov, N., Turlapov, V., and Semyanov, A. (2013). Subcellular location of astrocytic calcium stores favors extrasynaptic neuron-astrocyte communication. Cell Calcium 54, 343-349.Doi: 10.1016/j.ceca.2013.08.003. Pellerin, L., and Magistretti, P.J. (2012). Sweet sixteen for ANLS. J Cereb Blood Flow Metab 32, 1152-1166.Doi: 10.1038/jcbfm.2011.149.

Pelluru, D., Konadhode, R.R., Bhat, N.R., and Shiromani, P.J. (2016). Optogenetic stimulation of astrocytes in the posterior hypothalamus increases sleep at night in C57BL/6J mice. Eur J Neurosci 43, 1298-1306.Doi: 10.1111/ejn.13074.

Peng, L., Huang, R., Yu, A.C., Fung, K.Y., Rathbone, M.P., and Hertz, L. (2005). Nucleoside transporter expression and function in cultured mouse astrocytes. Glia 52, 25-35.Doi: 10.1002/glia.20216.

Peng, L., Verkhratsky, A., Gu, L., and Li, B. (2015). Targeting astrocytes in major depression. Expert Rev Neurother 15, 1299-1306.Doi:

10.1586/14737175.2015.1095094.

Perez-Alvarez, A., Navarrete, M., Covelo, A., Martin, E.D., and Araque, A. (2014). Structural and functional plasticity of astrocyte processes and dendritic spine interactions. J Neurosci 34, 12738-12744.Doi: 10.1523/JNEUROSCI.2401-14.2014. Persson, M., Brantefjord, M., Hansson, E., and Ronnback, L. (2005).

Lipopolysaccharide increases microglial GLT-1 expression and glutamate uptake capacity in vitro by a mechanism dependent on TNF-alpha. Glia 51, 111-120.Doi: 10.1002/glia.20191.

Petanjek, Z., Judas, M., Simic, G., Rasin, M.R., Uylings, H.B., Rakic, P., and Kostovic, I. (2011). Extraordinary neoteny of synaptic spines in the human prefrontal cortex. Proc Natl Acad Sci U S A 108, 13281-13286.Doi: 10.1073/pnas.1105108108. Peters, A., Palay, S.L., and Webster, H.F. (1991). The Fine Structure of the Nervous System: The Neurons and Supporting Cells, 3rd Ed. (New York, Oxford: Oxford University Press).

Petrelli, F., Dallerac, G., Pucci, L., Cali, C., Zehnder, T., Sultan, S., Lecca, S., Chicca, A., Ivanov, A., Asensio, C.S., et al. (2018). Dysfunction of homeostatic control of dopamine by astrocytes in the developing prefrontal cortex leads to cognitive impairments. Mol Psychiatry.Doi: 10.1038/s41380-018-0226-y. 
Pfrieger, F.W. (2003). Role of cholesterol in synapse formation and function. Biochim Biophys Acta 1610, 271-280.

Pfrieger, F.W., and Barres, B.A. (1997). Synaptic efficacy enhanced by glial cells in vitro. Science 277, 1684-1687.Doi:

Pinto-Duarte, A., Roberts, A.J., Ouyang, K., and Sejnowski, T.J. (2019). Impairments in remote memory caused by the lack of Type $2 \mathrm{IP}_{3}$ receptors. Glia 67, 19761989.Doi: 10.1002/glia.23679.

Popov, A., Denisov, P., Bychkov, M., Brazhe, A., Lyukmanova, E., Shenkarev, Z., Lazareva, N., Verkhratsky, A., and Semyanov, A. (2020). Caloric restriction triggers morphofunctional remodeling of astrocytes and enhances synaptic plasticity in the mouse hippocampus. Cell Death Dis, 11, 208. Doi: 10.1038/s41419-020-2406-3. Porto-Pazos, A.B., Veiguela, N., Mesejo, P., Navarrete, M., Alvarellos, A., Ibanez, O., Pazos, A., and Araque, A. (2011). Artificial astrocytes improve neural network performance. PLoS One 6, e19109.Doi: 10.1371/journal.pone.0019109.

Pyka, M., Wetzel, C., Aguado, A., Geissler, M., Hatt, H., and Faissner, A. (2011). Chondroitin sulfate proteoglycans regulate astrocyte-dependent synaptogenesis and modulate synaptic activity in primary embryonic hippocampal neurons. Eur J Neurosci 33, 2187-2202.Doi: 10.1111/j.1460-9568.2011.07690.x.

Quintana, A., Erta, M., Ferrer, B., Comes, G., Giralt, M., and Hidalgo, J. (2013). Astrocyte-specific deficiency of interleukin-6 and its receptor reveal specific roles in survival, body weight and behavior. Brain Behav Immun 27, 162-173.Doi: 10.1016/j.bbi.2012.10.011.

Rajkowska, G., Legutko, B., Moulana, M., Syed, M., Romero, D.G., Stockmeier, C.A., and Miguel-Hidalgo, J.J. (2018). Astrocyte pathology in the ventral prefrontal white matter in depression. J Psychiatr Res 102, 150-158.Doi:

10.1016/j.jpsychires.2018.04.005.

Rajkowska, G., Miguel-Hidalgo, J.J., Wei, J., Dilley, G., Pittman, S.D., Meltzer, H.Y., Overholser, J.C., Roth, B.L., and Stockmeier, C.A. (1999). Morphometric evidence for neuronal and glial prefrontal cell pathology in major depression. Biol Psychiatry 45, 1085-1098.Doi: 10.1016/s0006-3223(99)00041-4.

Rajkowska, G., and Stockmeier, C.A. (2013). Astrocyte pathology in major depressive disorder: insights from human postmortem brain tissue. Curr Drug Targets 14, 1225-1236.Doi: 10.2174/13894501113149990156.

Ramón y Cajal, S. (1895). Algunas conjeturas sobre el mechanismoanatomico de la ideacion, asociacion y atencion (Imprenta y Libreria de Nicolas Moya).

Ramón y Cajal, S. (1909). Histologie du système nerveux de l'homme \& des vertébrés, Vol v. 1, Ed. française rev. \& mise à jour par l'auteur, tr. de l'espagnol par L. Azoulay. edn (Paris :: Maloine).

Reemst, K., Noctor, S.C., Lucassen, P.J., and Hol, E.M. (2016). The Indispensable Roles of Microglia and Astrocytes during Brain Development. Front Hum Neurosci 10, 566.Doi: 10.3389/fnhum.2016.00566.

Reichelt, W., and Knopfel, T. (2002). Glutamate uptake controls expression of a slow postsynaptic current mediated by mGluRs in cerebellar Purkinje cells. J Neurophysiol 87, 1974-1980.Doi: 10.1152/jn.00704.2001.

Reichenbach, A., Derouiche, A., and Kirchhoff, F. (2010). Morphology and dynamics of perisynaptic glia. Brain Res Rev 63, 11-25.Doi: 10.1016/j.brainresrev.2010.02.003. Retzius, G. (1894). Biologishe Untersuchungen. Neue Folge, Vol VI. Mit 32 Tafeln (Jena - Stockholm: Von Gustav Fischer). 
Riederer, P., Konradi, C., Schay, V., Kienzl, E., Birkmayer, G., Danielczyk, W., Sofic, E., and Youdim, M.B. (1987). Localization of MAO-A and MAO-B in human brain: a step in understanding the therapeutic action of L-deprenyl. Adv Neurol 45, 111-118. Rindfleisch, E. (1873). Lehrbuch der pathologischen Gewebelehre zur Eeinführung in das Studium der pathologischen Anatomie (Leipzig: Wilhelm Engelmann).

Risher, W.C., Kim, N., Koh, S., Choi, J.E., Mitev, P., Spence, E.F., Pilaz, L.J., Wang, D., Feng, G., Silver, D.L., et al. (2018). Thrombospondin receptor $\alpha 2 \delta-1$ promotes synaptogenesis and spinogenesis via postsynaptic Rac1. J Cell Biol 217, 37473765.Doi: 10.1083/jcb.201802057.

Risher, W.C., Patel, S., Kim, I.H., Uezu, A., Bhagat, S., Wilton, D.K., Pilaz, L.J., Singh Alvarado, J., Calhan, O.Y., Silver, D.L., et al. (2014). Astrocytes refine cortical connectivity at dendritic spines. Elife 3.Doi: 10.7554/eLife.04047.

Rivera, A.D., and Butt, A.M. (2019). Astrocytes are direct cellular targets of lithium treatment: novel roles for lysyl oxidase and peroxisome-proliferator activated receptor-gamma as astroglial targets of lithium. Transl Psychiatry 9, 211.Doi: 10.1038/s41398-019-0542-2.

Roberts, A.J., Khom, S., Bajo, M., Vlkolinsky, R., Polis, I., Cates-Gatto, C., Roberto, M., and Gruol, D.L. (2019). Increased IL-6 expression in astrocytes is associated with emotionality, alterations in central amygdala GABAergic transmission, and excitability during alcohol withdrawal. Brain Behav Immun.Doi:

10.1016/j.bbi.2019.08.185.

Robin, L.M., Oliveira da Cruz, J.F., Langlais, V.C., Martin-Fernandez, M., MetnaLaurent, M., Busquets-Garcia, A., Bellocchio, L., Soria-Gomez, E., Papouin, T., Varilh, M., et al. (2018). Astroglial CB1 Receptors Determine Synaptic D-Serine Availability to Enable Recognition Memory. Neuron 98, 935-944 e935.Doi: 10.1016/j.neuron.2018.04.034.

Rodriguez, J.J., Terzieva, S., Olabarria, M., Lanza, R.G., and Verkhratsky, A. (2013). Enriched environment and physical activity reverse astrogliodegeneration in the hippocampus of AD transgenic mice. Cell Death Dis 4, e678.Doi:

10.1038/cddis.2013.194.

Rodriguez, J.J., Yeh, C.Y., Terzieva, S., Olabarria, M., Kulijewicz-Nawrot, M., and Verkhratsky, A. (2014). Complex and region-specific changes in astroglial markers in the aging brain. Neurobiol Aging 35, 15-23.Doi:

10.1016/j.neurobiolaging.2013.07.002.

Ronan, P.J., Wongngamnit, N., and Beresford, T.P. (2016). Molecular Mechanisms of Cannabis Signaling in the Brain. Prog Mol Biol Transl Sci 137, 123-147.Doi:

10.1016/bs.pmbts.2015.10.002.

Ronnevi, L.O. (1977). Spontaneous phagocytosis of boutons on spinal motoneurons during early postnatal development. An electron microscopical study in the cat. J Neurocytol 6, 487-504.

Ronnevi, L.O. (1978). Origin of the glial processes responsible for the spontaneous postnatal phagocytosis of boutons on cat spinal motoneurons. Cell Tissue Res 189, 203-217.

Rose, C.R., and Verkhratsky, A. (2016). Principles of sodium homeostasis and sodium signalling in astroglia. Glia 64, 1611-1627.Doi: 10.1002/glia.22964. Rose, C.R., Ziemens, D., Untiet, V., and Fahlke, C. (2018). Molecular and cellular physiology of sodium-dependent glutamate transporters. Brain Res Bull 136, 316.Doi: 10.1016/j.brainresbull.2016.12.013. 
Rose, C.R., Ziemens, D., and Verkhratsky, A. (2020). On the special role of NCX in astrocytes: Translating $\mathrm{Na}^{+}$-transients into intracellular $\mathrm{Ca}^{2+}$ signals. Cell Calcium 86, 102154.Doi: 10.1016/j.ceca.2019.102154.

Salois, G., and Smith, J.S. (2016). Housing Complexity Alters GFAPImmunoreactive Astrocyte Morphology in the Rat Dentate Gyrus. Neural Plast 2016, 3928726.Doi: 10.1155/2016/3928726.

Sampedro-Piquero, P., De Bartolo, P., Petrosini, L., Zancada-Menendez, C., Arias, J.L., and Begega, A. (2014). Astrocytic plasticity as a possible mediator of the cognitive improvements after environmental enrichment in aged rats. Neurobiology of learning and memory 114, 16-25.Doi: 10.1016/j.nlm.2014.04.002.

Sardinha, V.M., Guerra-Gomes, S., Caetano, I., Tavares, G., Martins, M., Reis, J.S., Correia, J.S., Teixeira-Castro, A., Pinto, L., Sousa, N., et al. (2017). Astrocytic signaling supports hippocampal-prefrontal theta synchronization and cognitive function. Glia 65, 1944-1960.Doi: 10.1002/glia.23205.

Saur, L., Baptista, P.P., de Senna, P.N., Paim, M.F., do Nascimento, P., Ilha, J., Bagatini, P.B., Achaval, M., and Xavier, L.L. (2014). Physical exercise increases GFAP expression and induces morphological changes in hippocampal astrocytes. Brain Struct Funct 219, 293-302.Doi: 10.1007/s00429-012-0500-8.

Saura, J., Kettler, R., Da Prada, M., and Richards, J.G. (1992). Quantitative enzyme radioautography with 3H-Ro 41-1049 and 3H-Ro 19-6327 in vitro: localization and abundance of MAO-A and MAO-B in rat CNS, peripheral organs, and human brain. J Neurosci 12, 1977-1999.

Savchenko, V.L., McKanna, J.A., Nikonenko, I.R., and Skibo, G.G. (2000). Microglia and astrocytes in the adult rat brain: comparative immunocytochemical analysis demonstrates the efficacy of lipocortin 1 immunoreactivity. Neuroscience 96, 195203.Doi: 10.1016/s0306-4522(99)00538-2.

Schaeffer, M., Langlet, F., Lafont, C., Molino, F., Hodson, D.J., Roux, T., Lamarque, L., Verdie, P., Bourrier, E., Dehouck, B., et al. (2013). Rapid sensing of circulating ghrelin by hypothalamic appetite-modifying neurons. Proc Natl Acad Sci U S A 110, 1512-1517.Doi: 10.1073/pnas.1212137110.

Schipke, C.G., Haas, B., and Kettenmann, H. (2008). Astrocytes discriminate and selectively respond to the activity of a subpopulation of neurons within the barrel cortex. Cereb Cortex 18, 2450-2459.Doi: 10.1093/cercor/bhn009.

Schleich, C.L. (1894). Schmerzlose Operationen: Örtliche Betäubung mit indiffrenten Flüssigkeiten. Psychophysik des natürlichen und künstlichen Schlafes. (Berlin: Julius Springer).

Schousboe, A., Scafidi, S., Bak, L.K., Waagepetersen, H.S., and McKenna, M.C. (2014). Glutamate metabolism in the brain focusing on astrocytes. Adv Neurobiol 11, 13-30.Doi: 10.1007/978-3-319-08894-5_2.

Schroeter, S., Apparsundaram, S., Wiley, R.G., Miner, L.H., Sesack, S.R., and Blakely, R.D. (2000). Immunolocalization of the cocaine- and antidepressantsensitive 1-norepinephrine transporter. J Comp Neurol 420, 211-232.Doi:

Shank, R.P., Bennett, G.S., Freytag, S.O., and Campbell, G.L. (1985). Pyruvate carboxylase: an astrocyte-specific enzyme implicated in the replenishment of amino acid neurotransmitter pools. Brain Res 329, 364-367.

Sherwood, C.C., Stimpson, C.D., Raghanti, M.A., Wildman, D.E., Uddin, M., Grossman, L.I., Goodman, M., Redmond, J.C., Bonar, C.J., Erwin, J.M., et al. (2006). Evolution of increased glia-neuron ratios in the human frontal cortex. Proc Natl Acad Sci U S A 103, 13606-13611.Doi: 10.1073/pnas.0605843103. 
Siegenthaler, J.A., and Miller, M.W. (2004). Transforming growth factor $\beta 1$ modulates cell migration in rat cortex: effects of ethanol. Cereb Cortex 14, 791802.Doi: 10.1093/cercor/bhh039.

Singh, S.K., Stogsdill, J.A., Pulimood, N.S., Dingsdale, H., Kim, Y.H., Pilaz, L.J., Kim, I.H., Manhaes, A.C., Rodrigues, W.S., Jr., Pamukcu, A., et al. (2016). Astrocytes Assemble Thalamocortical Synapses by Bridging NRX1 $\alpha$ and NL1 via Hevin. Cell 164, 183-196.Doi: 10.1016/j.cell.2015.11.034.

Sloan, S.A., Darmanis, S., Huber, N., Khan, T.A., Birey, F., Caneda, C., Reimer, R., Quake, S.R., Barres, B.A., and Pasca, S.P. (2017). Human Astrocyte Maturation Captured in 3D Cerebral Cortical Spheroids Derived from Pluripotent Stem Cells. Neuron 95, 779-790 e776.Doi: 10.1016/j.neuron.2017.07.035.

Sosunov, A.A., Wu, X., Tsankova, N.M., Guilfoyle, E., McKhann, G.M., 2nd, and Goldman, J.E. (2014). Phenotypic heterogeneity and plasticity of isocortical and hippocampal astrocytes in the human brain. J Neurosci 34, 2285-2298.Doi: 10.1523/JNEUROSCI.4037-13.2014.

Stella, N. (2010). Cannabinoid and cannabinoid-like receptors in microglia, astrocytes, and astrocytomas. Glia 58, 1017-1030.Doi: 10.1002/glia.20983.

Stellwagen, D., Beattie, E.C., Seo, J.Y., and Malenka, R.C. (2005). Differential regulation of AMPA receptor and GABA receptor trafficking by tumor necrosis factor-alpha. J Neurosci 25, 3219-3228.Doi: 10.1523/JNEUROSCI.4486-04.2005. Stellwagen, D., and Malenka, R.C. (2006). Synaptic scaling mediated by glial TNF- $\alpha$. Nature 440, 1054-1059.Doi: 10.1038/nature04671.

Stevens, B., Allen, N.J., Vazquez, L.E., Howell, G.R., Christopherson, K.S., Nouri, N., Micheva, K.D., Mehalow, A.K., Huberman, A.D., Stafford, B., et al. (2007). The classical complement cascade mediates CNS synapse elimination. Cell 131, 11641178.Doi: 10.1016/j.cell.2007.10.036.

Stichel, C.C., Muller, C.M., and Zilles, K. (1991). Distribution of glial fibrillary acidic protein and vimentin immunoreactivity during rat visual cortex development. $\mathrm{J}$ Neurocytol 20, 97-108.

Stobart, J.L., Ferrari, K.D., Barrett, M.J.P., Gluck, C., Stobart, M.J., Zuend, M., and Weber, B. (2018). Cortical Circuit Activity Evokes Rapid Astrocyte Calcium Signals on a Similar Timescale to Neurons. Neuron 98, 726-735 e724.Doi:

10.1016/j.neuron.2018.03.050.

Stogsdill, J.A., Ramirez, J., Liu, D., Kim, Y.H., Baldwin, K.T., Enustun, E., Ejikeme, T., Ji, R.R., and Eroglu, C. (2017). Astrocytic neuroligins control astrocyte morphogenesis and synaptogenesis. Nature 551, 192-197.Doi: 10.1038/nature24638. Stork, T., Sheehan, A., Tasdemir-Yilmaz, O.E., and Freeman, M.R. (2014). Neuronglia interactions through the Heartless FGF receptor signaling pathway mediate morphogenesis of Drosophila astrocytes. Neuron 83, 388-403.Doi:

10.1016/j.neuron.2014.06.026.

Studer, F.E., Fedele, D.E., Marowsky, A., Schwerdel, C., Wernli, K., Vogt, K., Fritschy, J.M., and Boison, D. (2006). Shift of adenosine kinase expression from neurons to astrocytes during postnatal development suggests dual functionality of the enzyme. Neuroscience 142, 125-137.Doi: 10.1016/j.neuroscience.2006.06.016. Sun, C., Zhu, L., Ma, R., Ren, J., Wang, J., Gao, S., Yang, D., Ning, K., Ling, B., Lu, B., et al. (2019). Astrocytic miR-324-5p is essential for synaptic formation by suppressing the secretion of CCL5 from astrocytes. Cell Death Dis 10, 141.Doi: 10.1038/s41419-019-1329-3.

Sun, W., Cornwell, A., Li, J., Peng, S., Osorio, M.J., Aalling, N., Wang, S., Benraiss, A., Lou, N., Goldman, S.A., et al. (2017). SOX9 Is an Astrocyte-Specific Nuclear 
Marker in the Adult Brain Outside the Neurogenic Regions. J Neurosci 37, 44934507.Doi: 10.1523/JNEUROSCI.3199-16.2017.

Suzuki, A., Stern, S.A., Bozdagi, O., Huntley, G.W., Walker, R.H., Magistretti, P.J., and Alberini, C.M. (2011). Astrocyte-neuron lactate transport is required for longterm memory formation. Cell 144, 810-823.Doi: 10.1016/j.cell.2011.02.018.

Svenningsson, P., Le Moine, C., Fisone, G., and Fredholm, B.B. (1999). Distribution, biochemistry and function of striatal adenosine A2A receptors. Prog Neurobiol 59, 355-396.Doi: 10.1016/s0301-0082(99)00011-8.

Sweeney, M.D., Zhao, Z., Montagne, A., Nelson, A.R., and Zlokovic, B.V. (2019). Blood-Brain Barrier: From Physiology to Disease and Back. Physiol Rev 99, 2178.Doi: 10.1152/physrev.00050.2017.

Sweeney, P., Qi, Y., Xu, Z., and Yang, Y. (2016). Activation of hypothalamic astrocytes suppresses feeding without altering emotional states. Glia 64, 22632273.Doi: 10.1002/glia.23073.

Tadi, M., Allaman, I., Lengacher, S., Grenningloh, G., and Magistretti, P.J. (2015). Learning-Induced Gene Expression in the Hippocampus Reveals a Role of Neuron Astrocyte Metabolic Coupling in Long Term Memory. PLoS One 10, e0141568.Doi: 10.1371/journal.pone.0141568.

Takeda, H., Inazu, M., and Matsumiya, T. (2002). Astroglial dopamine transport is mediated by norepinephrine transporter. Naunyn Schmiedebergs Arch Pharmacol 366, 620-623.Doi: 10.1007/s00210-002-0640-0.

Tang, F., Lane, S., Korsak, A., Paton, J.F., Gourine, A.V., Kasparov, S., and Teschemacher, A.G. (2014). Lactate-mediated glia-neuronal signalling in the mammalian brain. Nat Commun 5, 3284.Doi: 10.1038/ncomms4284.

Tang, G., Polykretis, I.E., Ivanov, V.A., Shah, A., and Michmizos, K.P. (2019). Introducing Astrocytes on a Neuromorphic Processor: Synchronization, Local Plasticity and Edge of Chaos. arXiv:190701620.Doi:

Tertil, M., Skupio, U., Barut, J., Dubovyk, V., Wawrzczak-Bargiela, A., Soltys, Z., Golda, S., Kudla, L., Wiktorowska, L., Szklarczyk, K., et al. (2018). Glucocorticoid receptor signaling in astrocytes is required for aversive memory formation. Transl Psychiatry 8, 255.Doi: 10.1038/s41398-018-0300-x.

Thiele, C., Hannah, M.J., Fahrenholz, F., and Huttner, W.B. (2000). Cholesterol binds to synaptophysin and is required for biogenesis of synaptic vesicles. Nat Cell Biol 2, 42-49.Doi: $10.1038 / 71366$.

Tso, C.F., Simon, T., Greenlaw, A.C., Puri, T., Mieda, M., and Herzog, E.D. (2017). Astrocytes Regulate Daily Rhythms in the Suprachiasmatic Nucleus and Behavior. Curr Biol 27, 1055-1061.Doi: 10.1016/j.cub.2017.02.037.

Tsukada, S., Iino, M., Takayasu, Y., Shimamoto, K., and Ozawa, S. (2005). Effects of a novel glutamate transporter blocker, $(2 \mathrm{~S}, 3 \mathrm{~S})-3-[3-[4-$ (trifluoromethyl)benzoylamino]benzyloxy]aspartate (TFB-TBOA), on activities of hippocampal neurons. Neuropharmacology 48, 479-491.Doi:

10.1016/j.neuropharm.2004.11.006.

Turrigiano, G.G. (2008). The self-tuning neuron: synaptic scaling of excitatory synapses. Cell 135, 422-435.Doi: 10.1016/j.cell.2008.10.008.

Tynan, R.J., Beynon, S.B., Hinwood, M., Johnson, S.J., Nilsson, M., Woods, J.J., and Walker, F.R. (2013). Chronic stress-induced disruption of the astrocyte network is driven by structural atrophy and not loss of astrocytes. Acta Neuropathol 126, 7591.Doi: 10.1007/s00401-013-1102-0.

Tyzack, G.E., Sitnikov, S., Barson, D., Adams-Carr, K.L., Lau, N.K., Kwok, J.C., Zhao, C., Franklin, R.J., Karadottir, R.T., Fawcett, J.W., et al. (2014). Astrocyte 
response to motor neuron injury promotes structural synaptic plasticity via STAT3regulated TSP-1 expression. Nat Commun 5, 4294.Doi: 10.1038/ncomms5294. Ullian, E.M., Sapperstein, S.K., Christopherson, K.S., and Barres, B.A. (2001). Control of synapse number by glia. Science 291, 657-661.Doi:

10.1126/science.291.5504.657.

Vainchtein, I.D., Chin, G., Cho, F.S., Kelley, K.W., Miller, J.G., Chien, E.C., Liddelow, S.A., Nguyen, P.T., Nakao-Inoue, H., Dorman, L.C., et al. (2018). Astrocyte-derived interleukin-33 promotes microglial synapse engulfment and neural circuit development. Science 359, 1269-1273.Doi: 10.1126/science.aal3589.

van Deijk, A.F., Camargo, N., Timmerman, J., Heistek, T., Brouwers, J.F., Mogavero, F., Mansvelder, H.D., Smit, A.B., and Verheijen, M.H. (2017). Astrocyte lipid metabolism is critical for synapse development and function in vivo. Glia 65, 670682.Doi: 10.1002/glia.23120.

Van Wagoner, N.J., and Benveniste, E.N. (1999). Interleukin-6 expression and regulation in astrocytes. J Neuroimmunol 100, 124-139.Doi: 10.1016/s01655728(99)00187-3.

Vardjan, N., Parpura, V., Verkhratsky, A., and Zorec, R. (2019). Gliocrine System: Astroglia as Secretory Cells of the CNS. Adv Exp Med Biol 1175, 93-115.Doi: 10.1007/978-981-13-9913-8_4.

Ventura, R., and Harris, K.M. (1999). Three-dimensional relationships between hippocampal synapses and astrocytes. J Neurosci 19, 6897-6906.

Verkhratsky, A. (2010). Physiology of neuronal-glial networking. Neurochem Int 57, 332-343.Doi: 10.1016/j.neuint.2010.02.002.

Verkhratsky, A., Bush, N.A.O., Nedergaard, M., and Butt, A. (2018). The Special Case of Human Astrocytes. Neuroglia 1, 21-29. Doi: 0.3390/neuroglia1010004. Verkhratsky, A., and Butt, A.M. (2013). Glial Physiology and Pathophysiology (Chichester: Wiley-Blackwell).

Verkhratsky, A., and Butt, A.M. (2018). The History of the Decline and Fall of the Glial Numbers Legend. Neuroglia 1, 188-192. 10.3390/neuroglia1010013.

Verkhratsky, A., Ho, M.S., Zorec, R., and Parpura, V. (2019a). The Concept of Neuroglia. Adv Exp Med Biol 1175, 1-13.Doi: 10.1007/978-981-13-9913-8_1. Verkhratsky, A., Matteoli, M., Parpura, V., Mothet, J.P., and Zorec, R. (2016). Astrocytes as secretory cells of the central nervous system: idiosyncrasies of vesicular secretion. EMBO J 35, 239-257.Doi: 10.15252/embj.201592705.

Verkhratsky, A., and Nedergaard, M. (2014). Astroglial cradle in the life of the synapse. Philos Trans R Soc Lond B Biol Sci 369, 20130595.Doi:

10.1098/rstb.2013.0595.

Verkhratsky, A., and Nedergaard, M. (2016). The homeostatic astroglia emerges from evolutionary specialization of neural cells. Philos Trans R Soc Lond B Biol Sci 371.Doi: 10.1098/rstb.2015.0428.

Verkhratsky, A., and Nedergaard, M. (2018). Physiology of Astroglia. Physiol Rev 98, 239-389.Doi: 10.1152/physrev.00042.2016.

Verkhratsky, A., Nedergaard, M., and Hertz, L. (2015). Why are astrocytes important? Neurochem Res 40, 389-401.Doi: 10.1007/s11064-014-1403-2.

Verkhratsky, A., Olabarria, M., Noristani, H.N., Yeh, C.Y., and Rodriguez, J.J. (2010). Astrocytes in Alzheimer's disease. Neurotherapeutics 7, 399-412.Doi:

10.1016/j.nurt.2010.05.017.

Verkhratsky, A., Orkand, R.K., and Kettenmann, H. (1998). Glial calcium: homeostasis and signaling function. Physiol Rev 78, 99-141.Doi:

10.1152/physrev.1998.78.1.99. 
Verkhratsky, A., Rodrigues, J.J., Pivoriunas, A., Zorec, R., and Semyanov, A. (2019b). Astroglial atrophy in Alzheimer's disease. Pflugers Arch 471, 1247-1261.Doi: 10.1007/s00424-019-02310-2.

Verkhratsky, A., Rodriguez, J.J., and Parpura, V. (2012). Calcium signalling in astroglia. Mol Cell Endocrinol 353, 45-56.Doi: 10.1016/j.mce.2011.08.039.

Verkhratsky, A., Rodriguez, J.J., and Steardo, L. (2014). Astrogliopathology: a central element of neuropsychiatric diseases? Neuroscientist 20, 576-588.Doi:

$10.1177 / 1073858413510208$.

Verkhratsky, A., and Rose, C.R. (2020). $\mathrm{Na}^{+}$-dependent transporters: The backbone of astroglial homeostatic function. Cell Calcium 85, 102136.Doi:

10.1016/j.ceca.2019.102136.

Verkhratsky, A., Untiet, V., and Rose, C.R. (2019c). Ionic signalling in astroglia beyond calcium. J Physiol.Doi: 10.1113/JP277478.

Verkhratsky, A., Zorec, R., and Parpura, V. (2017). Stratification of astrocytes in healthy and diseased brain. Brain Pathol 27, 629-644.Doi: 10.1111/bpa.12537.

Vezzoli, E., Cali, C., De Roo, M., Ponzoni, L., Sogne, E., Gagnon, N., Francolini, M., Braida, D., Sala, M., Muller, D., et al. (2019). Ultrastructural Evidence for a Role of Astrocytes and Glycogen-Derived Lactate in Learning-Dependent Synaptic

Stabilization. Cereb Cortex.Doi: 10.1093/cercor/bhz226.

Vicente-Gutierrez, C., Bonora, N., Bobo-Jimenez, V., Jimenez-Blasco, D., Lopez-

Fabuel, I., Fernandez, E., Josephine, C., Bonvento, G., Enriquez, J.A., A., A., et al. (2019). Astrocytic mitochondrial ROS modulate brain metabolism and mouse behaviour. . Nat Metab 1, 201-211.Doi: 10.1038/s42255-018-0031-6.

Vignoli, B., Battistini, G., Melani, R., Blum, R., Santi, S., Berardi, N., and Canossa, M. (2016). Peri-Synaptic Glia Recycles Brain-Derived Neurotrophic Factor for LTP Stabilization and Memory Retention. Neuron 92, 873-887.Doi:

10.1016/j.neuron.2016.09.031.

von Bartheld, C.S., Bahney, J., and Herculano-Houzel, S. (2016). The search for true numbers of neurons and glial cells in the human brain: A review of 150 years of cell counting. J Comp Neurol 524, 3865-3895.Doi: 10.1002/cne.24040.

Wade, J.J., Breslin, K., Wong-Lin, K., Harkin, J., Flanagan, B., Van Zalinge, H., Hall, S., Dallas, M., Bithell, A., Verkhratsky, A., et al. (2019). Calcium Microdomain Formation at the Perisynaptic Cradle Due to NCX Reversal: A Computational Study. Front Cell Neurosci 13, 185.Doi: 10.3389/fncel.2019.00185.

Wang, Q., Jie, W., Liu, J.H., Yang, J.M., and Gao, T.M. (2017). An astroglial basis of major depressive disorder? An overview. Glia 65, 1227-1250.Doi: 10.1002/glia.23143. Warburg, M. (1971). Norrie's disease. Birth Defects Orig Artic Ser 7, 117-124.Doi:

Webb, T.R., Matarin, M., Gardner, J.C., Kelberman, D., Hassan, H., Ang, W., Michaelides, M., Ruddle, J.B., Pennell, C.E., Yazar, S., et al. (2012). X-linked megalocornea caused by mutations in CHRDL1 identifies an essential role for ventroptin in anterior segment development. Am J Hum Genet 90, 247-259.Doi: 10.1016/j.ajhg.2011.12.019.

Windrem, M.S., Schanz, S.J., Morrow, C., Munir, J., Chandler-Militello, D., Wang, S., and Goldman, S.A. (2014). A competitive advantage by neonatally engrafted human glial progenitors yields mice whose brains are chimeric for human glia. J Neurosci 34, 16153-16161.Doi: 10.1523/JNEUROSCI.1510-14.2014.

Witcher, M.R., Kirov, S.A., and Harris, K.M. (2007). Plasticity of perisynaptic astroglia during synaptogenesis in the mature rat hippocampus. Glia 55, 13-23.Doi: 10.1002/glia.20415. 
Wolosker, H., Balu, D.T., and Coyle, J.T. (2016). The rise and fall of the d-serinemediated gliotransmission hypothesis. Trends Neurosci 39, 712-721.Doi:

10.1016/j.tins.2016.09.007.

Wolosker, H., Balu, D.T., and Coyle, J.T. (2017). Astroglial Versus Neuronal DSerine: Check Your Controls! Trends Neurosci 40, 520-522.Doi:

10.1016/j.tins.2017.06.010.

Wu, X., Morishita, W.K., Riley, A.M., Hale, W.D., Sudhof, T.C., and Malenka, R.C. (2019). Neuroligin-1 Signaling Controls LTP and NMDA Receptors by Distinct Molecular Pathways. Neuron 102, 621-635 e623.Doi: 10.1016/j.neuron.2019.02.013. Xie, L., Kang, H., Xu, Q., Chen, M.J., Liao, Y., Thiyagarajan, M., O'Donnell, J., Christensen, D.J., Nicholson, C., Iliff, J.J., et al. (2013). Sleep drives metabolite clearance from the adult brain. Science 342, 373-377.Doi: 10.1126/science.1241224. Xiong, W., Cao, X., Zeng, Y., Qin, X., Zhu, M., Ren, J., Wu, Z., Huang, Q., Zhang, Y., Wang, M., et al. (2019). Astrocytic Epoxyeicosatrienoic Acid Signaling in the Medial Prefrontal Cortex Modulates Depressive-like Behaviors. J Neurosci 39, 46064623.Doi: 10.1523/JNEUROSCI.3069-18.2019.

Xu-Friedman, M.A., Harris, K.M., and Regehr, W.G. (2001). Three-dimensional comparison of ultrastructural characteristics at depressing and facilitating synapses onto cerebellar Purkinje cells. J Neurosci 21, 6666-6672.

Xu, J., Xiao, N., and Xia, J. (2010). Thrombospondin 1 accelerates synaptogenesis in hippocampal neurons through neuroligin 1. Nat Neurosci 13, 22-24.Doi: 10.1038/nn.2459.

Yamasaki, M., Yamada, K., Furuya, S., Mitoma, J., Hirabayashi, Y., and Watanabe, M. (2001). 3-Phosphoglycerate dehydrogenase, a key enzyme for 1-serine biosynthesis, is preferentially expressed in the radial glia/astrocyte lineage and olfactory ensheathing glia in the mouse brain. J Neurosci 21, 7691-7704.Doi:

Yang, J., Ruchti, E., Petit, J.M., Jourdain, P., Grenningloh, G., Allaman, I., and Magistretti, P.J. (2014). Lactate promotes plasticity gene expression by potentiating NMDA signaling in neurons. Proc Natl Acad Sci U S A 111, 12228-12233.Doi: 10.1073/pnas.1322912111.

Yang, J.H., Wada, A., Yoshida, K., Miyoshi, Y., Sayano, T., Esaki, K., Kinoshita, M.O., Tomonaga, S., Azuma, N., Watanabe, M., et al. (2010). Brain-specific Phgdh deletion reveals a pivotal role for L-serine biosynthesis in controlling the level of Dserine, an N-methyl-D-aspartate receptor co-agonist, in adult brain. J Biol Chem 285, 41380-41390.Doi: 10.1074/jbc.M110.187443.

Yang, L., Qi, Y., and Yang, Y. (2015). Astrocytes control food intake by inhibiting AGRP neuron activity via adenosine $A_{1}$ receptors. Cell Rep 11, 798-807.Doi: 10.1016/j.celrep.2015.04.002.

Ye, Y., Xu, H., Su, X., and He, X. (2016). Role of MicroRNA in Governing Synaptic Plasticity. Neural Plast 2016, 4959523.Doi: 10.1155/2016/4959523.

Yeh, C.Y., Verkhratsky, A., Terzieva, S., and Rodriguez, J.J. (2013). Glutamine synthetase in astrocytes from entorhinal cortex of the triple transgenic animal model of Alzheimer's disease is not affected by pathological progression. Biogerontology 14, 777-787.Doi: 10.1007/s10522-013-9456-1.

Yeh, T.H., Lee, D.Y., Gianino, S.M., and Gutmann, D.H. (2009). Microarray analyses reveal regional astrocyte heterogeneity with implications for neurofibromatosis type 1 (NF1)-regulated glial proliferation. Glia 57, 1239-1249.Doi: 10.1002/glia.20845. $\mathrm{Yu}$, A.C., Schousboe, A., and Hertz, L. (1982). Metabolic fate of ${ }^{14} \mathrm{C}$-labeled glutamate in astrocytes in primary cultures. J Neurochem 39, 954-960.Doi: 
Yu, X., Taylor, A.M.W., Nagai, J., Golshani, P., Evans, C.J., Coppola, G., and Khakh, B.S. (2018). Reducing Astrocyte Calcium Signaling In Vivo Alters Striatal Microcircuits and Causes Repetitive Behavior. Neuron 99, 1170-1187 e1179.Doi: 10.1016/j.neuron.2018.08.015.

Zonta, M., Angulo, M.C., Gobbo, S., Rosengarten, B., Hossmann, K.A., Pozzan, T., and Carmignoto, G. (2003). Neuron-to-astrocyte signaling is central to the dynamic control of brain microcirculation. Nat Neurosci 6, 43-50.Doi: 10.1038/nn980 nn980 [pii].

Zorec, R., Horvat, A., Vardjan, N., and Verkhratsky, A. (2015). Memory Formation Shaped by Astroglia. Front Integr Neurosci 9, 56.Doi: 10.3389/fnint.2015.00056. 


\section{Figure legends}

Figure 1. Morphological diversity of astrocytes as seen in early neuroanatomic studies.

A: Images of astroglia drawn by Santiago Ramon y Cajal showing Golgi impregnated glia from human cortex (two months old child). These images are part of the collection of the Cajal Legacy at the Cajal Institute of the Spanish Research Council (CSIC). "®CAJAL INSTITUTE, CSIC". Madrid, Spain. Images have been kindly provided by Professor Ricardo Martínez Murillo

B: Images of Golgi-stained parenchymal glia (astrocytes) from human foetal brain as seen by Gustav Retzius (Retzius, 1894).

C: Parenchymal glia drawn by Otto Deiters, showing greay matter glial cell on the right and white matter glial cell on the left (Deiters, 1865).

D: Astroglial syncytium drawn by Abert von Kölliker (Kölliker, 1867).

E: Pair of spider-like glial cells (Spinnezellen) from the vicinity of the human brain ventricle ependyma as seen by Moritz Jastrowitz (Jastrowitz, 1871).

F: Glial cells (glial corpuscles - Gliakörperchen) with prominent arborisation drawn by Victor Butzke (Butzke, 1872).

G: Image of two star-like parenchymal glial cells made by Eduard Rindfleisch (Rindfleisch, 1873).

For more details on early history of glial research see also (Chvatal and Verkhratsky, 2018).

Figure 2. Classification of astrocytes.

Astrocytes can be subdivided into distinct subtypes according to morphology, brain region and function. The brains of high primates and humans additionally contain highly specialised astroglial cells.

Figure 3. Astrocytes interact with diverse cellular structures including blood vessels, oligodendrocytes, neurones, microglia and other astrocytes, contributing to various functions (clockwise from the top) such as regulation of the blood brain barrier, supporting axons, myelination and connectome, forming astrocyte-astrocyte and astrocyte-oligodendrocyte syncytia, controlling (in concert with microglia) synaptic elimination and modulating synaptogenesis, cognition and behaviour by the neurochemical dialogue with synapses.

Figure 4. In mammals, early development of the nervous system is dominated by neuronogenesis from neuronal precursors, which originate by asymmetric division of radial glia. The peak of astrogliogenesis coincides with postnatal massive synaptogenesis.

Figure 5. Astrocytes regulate synpatogenesis.

Astrocyte-secreted molecules regulate synapse formation through different pathways (clockwise from the top left): astrocyte-released thrombospondins (TSP) acts by bridging NLG-1 $\beta$ and NRX-1 $\alpha$, reorganizing postsynaptic density through $\alpha 2 \delta 1$ receptors and through $\beta$-integrin receptors; hevin, similarly to TSP, acts by bridging NLG-1 $\beta$ and NRX-1 $\alpha$; glypicans 4 and 6 mobilise AMPAR to postsynaptic terminal 
by stimulating pentraxin release and clustering through RPTP2 activation; cholesterol promotes synapses formation through SREBP2 and FABP7 signalling;. Sp1 regulates synapse formation by reducing $\mathrm{C} 1 \mathrm{q}$ accumulation in the synapse environment; ephrinB1 modulates synaptogenesis controlling spine formation; miRNA-324-5p supresses CCL5 release providing proper signalling for synaptogenesis; and TGF $\beta-1$ promotes synapse formation by inserting NLG-2 in the postsynaptic terminal through CAMKII signalling.

Figure 6. Modulation of synaptic plasticity by astrocytes.

Astrocyte-secreted molecules control synaptic plasticity using different mechanisms (clockwise from the top left): thrombospondins (TSP) impacts synaptic transmission by inserting glycine receptors and removing AMPA receptors from postsynaptic terminal; hevin works by recruiting NMDA receptors to postsynaptic terminal mediated by the bridging of NLG- $1 \beta$ and NRX-1 $\alpha$; TNF- $\alpha$ modulates synaptic transmission through increasing the density of postsynaptic AMPA receptors and a decrease of density of postsynaptic GABA receptors; chordin modulates synaptic plasticity promoting maturation of AMPA receptors by increasing the density of AMPA receptors containing GluA2 subunit; astroglia-secreted L-serine is an obligator precursor of D-serine, which acts on postsynaptic NMDA receptors; cholesterol promotes stabilization of postsynaptic AMPA receptors, number of synaptic vesicles and levels of SNAP-25; finally BNDF supports synaptic transmission by inducing clusters of synaptobrevin and phosphorylation of TrKB.

Figure 7. Astrocytic involvement in synaptic elimination.

Astrocytes sense weak synapses and promote synaptic pruning through MERTK and MEGF10 signalling (top left); TGF- $\beta$ released by astrocytes induces complement cascade $\mathrm{C} 1 \mathrm{q}-\mathrm{C} 3$ and subsequent synaptic elimination by microglia through microglial C3R (top right); astroglial ApoE modulates synaptic pruning according isoform, with ApoE4 inducing larger accumulation of C1q in the synapse (middle); IL-33 released by astrocyte induces microglia to engulf synapses through unknown mechanisms (bottom). 
Tables

Table 1. Astrocyte-secreted molecules involved in synaptogenesis.

\begin{tabular}{|c|c|c|c|c|c|}
\hline Molecule & Nature & Synapse Type & $\begin{array}{l}\text { Synaptogenic } \\
\text { Effect }\end{array}$ & Mechanism/Ligand & Reference \\
\hline Thrombospondins & Matricellular Proteins & Excitatory & Promote & $\begin{array}{c}\text { Mobilization by Gabapentin Receptor } \alpha 2 \delta 1 \text { of Rac } 1 \\
\text { GTPase, promoting actin reorganization and } \\
\text { consequent spine adjustment favouring synaptic } \\
\text { formation } \\
\text { Through } \beta 1 \text {-Integrin receptor } \\
\text { Possibly through astroglial NLG2 adhesion } \\
\text { molecule }\end{array}$ & $\begin{array}{c}\text { (Eroglu et al., 2009; Koh } \\
\text { et al., 2020; Risher et al., } \\
\text { 2018; Stogsdill et al., } \\
\text { 2017) }\end{array}$ \\
\hline Hevin & Matricellular & Excitatory & Promote & $\begin{array}{l}\text { Essential to promote spatial arrangement between } \\
\text { Neuronal NLG1 and NRX1 } \alpha \text {, two isoforms that do } \\
\text { not interact with each other }\end{array}$ & (Singh et al., 2016) \\
\hline Glypican 4 and 6 & Heparan Sulphate Proteoglycan & Excitatory & Promote & $\begin{array}{l}\text { Regulation of release of axonal pentraxin } 1 \\
\text { clustering AMPAR in the postsynaptic terminal } \\
\text { promoting active synapse formation }\end{array}$ & $\begin{array}{l}\text { (Allen et al., 2012; Farhy- } \\
\text { Tselnicker et al., 2017) }\end{array}$ \\
\hline TGF $\beta-1$ & Cytokine & Excitatory & Promote & $\begin{array}{c}\text { Through D-serine/NMDAR } \\
\text { signalling }\end{array}$ & (Diniz et al., 2012) \\
\hline
\end{tabular}


Inhibitory Promote Induction of cluster formation of neuronal NGL2 in postsynaptic terminals through CAMKII signalling

(Diniz et al., 2014)

\begin{tabular}{|c|c|c|c|c|c|}
\hline Cholesterol & Lipid & Excitatory & Promote & Through SREBP2 and FABP7 signalling & $\begin{array}{l}\text { (Ebrahimi et al., 2016; } \\
\text { Ferris et al., 2017) }\end{array}$ \\
\hline miR-324-5p & microRNA & Excitatory & Promote & $\begin{array}{l}\text { Inhibition of astroglial CCL5 expression and } \\
\text { maintenance of MAPK/CREB signalling }\end{array}$ & (Sun et al., 2019) \\
\hline Ephrin-B1 & Transmembrane Protein & Excitatory & Promote & Synaptic remodelling increasing spine formation & (Nguyen et al., 2020) \\
\hline $\begin{array}{l}\text { Specificity protein } \\
1, \mathrm{Sp} 1\end{array}$ & Transcription factor protein & Excitatory & Promote & Regulating complement proteins expression & (Hung et al., 2020) \\
\hline Norrin & $\begin{array}{l}\text { Agonist of frizzled-4 and } \\
\text { Leucine-rich repeat-containing G- } \\
\text { protein coupled receptor } 4 \\
\text { (LGR4) }\end{array}$ & $\begin{array}{l}\text { Dendrites and } \\
\text { dendritic } \\
\text { spines }\end{array}$ & Promote & $\begin{array}{l}\text { Regulates growth of dendrites and the density of } \\
\text { dendritic spines }\end{array}$ & (Miller et al., 2019) \\
\hline
\end{tabular}


Table 2: Astrocyte-specific molecules involved in cognitive processes and behaviours.

\begin{tabular}{|c|c|c|c|c|c|}
\hline Molecule & Approach & Specie & Behavioural and Cognitive Effects & Test & Reference \\
\hline \multicolumn{6}{|l|}{ Memory and Cognition } \\
\hline Ephrin-B1 & $\begin{array}{l}\text { Astrocytic-specific ablation of Ephrin-B1 } \\
\text { / astrocytic over-expression of Ephrin-B1 }\end{array}$ & Mouse & $\begin{array}{l}\text { Enhanced contextual memory / Impaired } \\
\text { contextual memory }\end{array}$ & Fear conditioning test & $\begin{array}{l}\text { (Koeppen et } \\
\text { al., 2018) }\end{array}$ \\
\hline $\begin{array}{l}\text { Brain and Muscle ARNT- } \\
\text { Like } 1, \text { Bmal1 }\end{array}$ & $\begin{array}{l}\text { Ablation of Bmal1 in GLAST-positive } \\
\text { astrocytes in supraoptical nucleus }\end{array}$ & Mouse & $\begin{array}{l}\text { Disrupted object recognition memory and } \\
\text { spatial memory }\end{array}$ & $\begin{array}{l}\text { Novel object location test; } \\
\text { spatial object location test }\end{array}$ & $\begin{array}{l}\text { (Barca-Mayo } \\
\text { et al., 2017) }\end{array}$ \\
\hline Interleukin-6, IL-6 & $\begin{array}{l}\text { Astrocytic-specific deletion of IL-6 or IL- } \\
6 \mathrm{R}\end{array}$ & Mouse & Impaired spatial learning & $\begin{array}{l}\text { Hole-board test; Morris } \\
\text { water maze }\end{array}$ & $\begin{array}{l}\text { (Erta et al., } \\
\text { 2015) }\end{array}$ \\
\hline $\begin{array}{l}\text { Monocarboxylate } \\
\text { transporter 1, MCT1 }\end{array}$ & MCT1 deficient mouse & Mouse & Impaired avoidance learning & $\begin{array}{l}\text { Step-through inhibitory } \\
\text { avoidance test }\end{array}$ & $\begin{array}{l}\text { (Tadi et al., } \\
\text { 2015) }\end{array}$ \\
\hline $\begin{array}{l}\mathrm{NE}, \mathrm{cAMP}, \mathrm{Ca}^{2+} \\
\text { adrenoceptors }\end{array}$ & $\begin{array}{l}\text { Monitoring of astrocytic cAMP levels by } \\
\text { Epac1-based red fluorescent cAMP probe } \\
\text { and } \mathrm{Ca}^{2+} \text { imaging on awake mouse }\end{array}$ & Mouse & $\begin{array}{l}\text { Regulation of sustained attention (vigilance), } \\
\text { modulation of contextual memory }\end{array}$ & $\begin{array}{l}\text { Air puff and head-fixed } \\
\text { fear conditioning tests }\end{array}$ & $\begin{array}{l}\text { (Oe et al., } \\
\text { 2020) }\end{array}$ \\
\hline $\begin{array}{l}\text { Glutamate transporter 1, } \\
\text { GLT-1 }\end{array}$ & Astrocytic-specific deletion of GLT-1 & Mouse & Impaired avoidance and preference learning & $\begin{array}{l}\text { Laser conditioned place } \\
\text { avoidance test; open field } \\
\text { test; real-time place } \\
\text { preference test } \\
\end{array}$ & $\begin{array}{l}\text { (Gomez et al., } \\
\text { 2019) }\end{array}$ \\
\hline$?$ & $\begin{array}{l}\text { Optogenetic and chemogenetic activation } \\
\text { of CA1 astrocytes }\end{array}$ & Mouse & Enhanced spatial and contextual memory & $\begin{array}{c}\text { T-maze test; fear } \\
\text { conditioning test (novel } \\
\text { context and auditory cue) }\end{array}$ & $\begin{array}{l}\text { (Adamsky et } \\
\text { al., 2018) }\end{array}$ \\
\hline Glucocorticoid receptors & $\begin{array}{l}\text { Astrocytic-specific deletion of } \\
\text { glucocorticoid receptors }\end{array}$ & Mouse & $\begin{array}{c}\text { Impaired contextual and associative } \\
\text { memory, impairments in astroglial glucose } \\
\text { metabolism }\end{array}$ & $\begin{array}{c}\text { Conditioned place } \\
\text { preference/aversion test; } \\
\text { Shock application and test } \\
\text { of conditioned fear }\end{array}$ & $\begin{array}{l}\text { (Tertil et al., } \\
\text { 2018) }\end{array}$ \\
\hline $\begin{array}{l}\text { Neuronal adenosine } \\
\text { receptors } A_{1} \text { and } A_{2 A}\end{array}$ & $\begin{array}{l}\text { Selective activation of astrocytes in } \\
\text { medial subdivision of central amygdala } \\
\text { using cannabinoids or DREADD results }\end{array}$ & Mouse & $\begin{array}{l}\text { Impaired contextual memory, reduced fear } \\
\text { expression }\end{array}$ & $\begin{array}{l}\text { Delayed auditory fear } \\
\text { conditioning test }\end{array}$ & $\begin{array}{l}\text { (Martin- } \\
\text { Fernandez et } \\
\text { al., 2017) }\end{array}$ \\
\hline
\end{tabular}


in activation of neuronal $\mathrm{A}_{1}$ and $\mathrm{A}_{2 \mathrm{~A}}$

adenosine receptors

\begin{tabular}{|c|c|c|c|c|c|}
\hline Adenosine $\mathrm{A}_{2 \mathrm{~A}}$ receptors & $\begin{array}{l}\text { Astrocytic deletion of Gs-coupled } \\
\text { adenosine receptor } \mathrm{A}_{2 \mathrm{~A}}\end{array}$ & Mouse & $\begin{array}{l}\text { Improved spatial memory and contextual } \\
\text { memory }\end{array}$ & $\begin{array}{l}\text { Morris water maze; open } \\
\text { field test }\end{array}$ & $\begin{array}{l}\text { (Orr et al., } \\
\text { 2015) }\end{array}$ \\
\hline Adenosine $\mathrm{A}_{2 \mathrm{~A}}$ receptors & $\begin{array}{l}\text { Astrocytic deletion of Gs-coupled } \\
\text { adenosine receptor } \mathrm{A}_{2 \mathrm{~A}}\end{array}$ & Mouse & Impaired working memory & $\begin{array}{l}\text { Y-maze spontaneous } \\
\text { alternation test; } 8 \text { baitd- } \\
\text { arms radial arm maze }\end{array}$ & $\begin{array}{l}\text { (Matos et al., } \\
\text { 2015) }\end{array}$ \\
\hline Trombospondin-1, TSP1 & Activation of astroglial TSP1 release & Mouse & Hyperactivity and disrupted attention & $\begin{array}{l}\text { Rearing test; open field } \\
\text { test; marble burying test; } \\
\text { rotarod test; Open field test } \\
\text { with bright light stimulus }\end{array}$ & $\begin{array}{l}\text { (Nagai et al., } \\
\text { 2019) }\end{array}$ \\
\hline Mitochondrial ROS & $\begin{array}{l}\text { Astrocytic-specific disruption of } \\
\text { mitochondrial ROS production }\end{array}$ & Mouse & Impaired object recognition memory & $\begin{array}{l}\text { Novel object recognition } \\
\text { test }\end{array}$ & $\begin{array}{l}\text { (Vicente- } \\
\text { Gutierrez et } \\
\text { al., 2019) }\end{array}$ \\
\hline$\beta_{2}$-adrenoceptors, $\beta_{2} \mathrm{AR}$ & $\begin{array}{l}\text { Selective pharmacological inhibition of } \\
\text { astrocytic } \beta_{2} \mathrm{AR}\end{array}$ & Rat & $\begin{array}{l}\text { Impaired long-term memory formation and } \\
\text { memory consolidation }\end{array}$ & $\begin{array}{l}\text { Contextual and auditory } \\
\text { fear conditioning; } \\
\text { inhibitory avoidance test } \\
\end{array}$ & $\begin{array}{l}\text { (Gao et al., } \\
\text { 2016) }\end{array}$ \\
\hline $\begin{array}{l}\text { Cannabinoid receptor } 1, \\
\qquad \mathrm{CB}_{1} \mathrm{R}\end{array}$ & $\begin{array}{l}\text { Astrocytic-specific deletion of } \\
\text { hippocampal } \mathrm{CB}_{1} \mathrm{R}\end{array}$ & Mouse & Impaired object recognition memory & $\begin{array}{l}\text { Novel object recognition } \\
\text { test }\end{array}$ & $\begin{array}{l}\text { (Robin et al., } \\
\text { 2018) }\end{array}$ \\
\hline Lactate & $\begin{array}{l}\text { Disruption of glycogen metabolism in } \\
\text { astrocytes }\end{array}$ & Mouse & Impaired object recognition memory & $\begin{array}{l}\text { Novel object recognition } \\
\text { test }\end{array}$ & $\begin{array}{l}\text { (Vezzoli et al., } \\
\text { 2019) }\end{array}$ \\
\hline Lactate & $\begin{array}{l}\text { Inhibition of glycogen phosphorylase into } \\
\text { the basolateral amygdala }\end{array}$ & Rat & Impaired preference memory & $\begin{array}{l}\text { Conditioned place } \\
\text { preference }\end{array}$ & $\begin{array}{l}\text { (Boury-Jamot } \\
\text { et al., 2016) }\end{array}$ \\
\hline Lactate & Chemical inhibition of lactate production & Mouse & Impaired spatial learning & Morris water maze test & $\begin{array}{l}\text { (Harris et al., } \\
\text { 2019) }\end{array}$ \\
\hline Protein S100B, $\mathrm{Ca}^{2+}$ & $\begin{array}{l}\text { Chemogenetic activation of astroglial } \\
\mathrm{Ca}^{2+} \text { signalling / inactivation of } \\
\text { endogenous S100B in chemogenetically }\end{array}$ & Rat & $\begin{array}{l}\text { Increased cognitive flexibility / impaired } \\
\text { cognitive flexibility }\end{array}$ & $\begin{array}{l}\text { Attentional set-shifting } \\
\text { task }\end{array}$ & $\begin{array}{l}\text { (Brockett et } \\
\text { al., 2018) }\end{array}$ \\
\hline
\end{tabular}


activated astrocytes

\begin{tabular}{|c|c|c|c|c|c|}
\hline $\begin{array}{l}\text { Transcription factor } \\
\text { specificity protein } 1, \mathrm{Sp} 1\end{array}$ & Astroglia-specific Sp1 knockout & Mouse & Impaired object recognition memory & $\begin{array}{l}\text { Novel object recognition } \\
\text { test }\end{array}$ & $\begin{array}{l}\text { (Hung et al., } \\
\text { 2020) }\end{array}$ \\
\hline $\begin{array}{l}\text { InsP }_{3} \text { receptor, type } 2 \\
\quad \operatorname{Ins}_{3} \mathrm{R} 2\end{array}$ & Genetic ablation of $\operatorname{Ins}_{3} \mathrm{R} 2$ & Mouse & $\begin{array}{l}\text { Impaired remote contextual, object } \\
\text { recognition and spatial memory }\end{array}$ & $\begin{array}{c}\text { Novel object recognition } \\
\text { test; contextual fear } \\
\text { conditioning test; Barnes } \\
\text { maze test }\end{array}$ & $\begin{array}{l}\text { (Pinto-Duarte } \\
\text { et al., 2019) }\end{array}$ \\
\hline SNARE protein & $\begin{array}{l}\text { Astroglial expression of dominant } \\
\text { negative SNARE, dnSNARE }\end{array}$ & Mouse & $\begin{array}{l}\text { Impaired spatial memory, working memory } \\
\text { and object recognition memory }\end{array}$ & $\begin{array}{l}\text { Morris water maze test; } \\
\text { novel object recognition } \\
\text { test; hole board test }\end{array}$ & $\begin{array}{l}\text { (Sardinha et } \\
\text { al., 2017) }\end{array}$ \\
\hline $\begin{array}{l}\text { DREADD metabotropic } \\
\text { receptor }\end{array}$ & $\begin{array}{l}\text { Astrocytic-specific activation of } \mathrm{G}_{\mathrm{i}^{-}} \\
\text {coupled receptor hM4Di }\end{array}$ & Mouse & Impaired remote memory & $\begin{array}{l}\text { Non-associative place } \\
\text { recognition; fear } \\
\text { conditioning test } \\
\end{array}$ & $\begin{array}{l}\text { (Kol et al., } \\
\text { 2019) }\end{array}$ \\
\hline \multicolumn{6}{|l|}{ Motor activity } \\
\hline $\begin{array}{l}\text { Brain and Muscle ARNT- } \\
\text { Like 1,Bmal1 }\end{array}$ & $\begin{array}{l}\text { GLAST-positive Astrocyte ablation of } \\
\text { Bmal1 in SCN }\end{array}$ & Mouse & $\begin{array}{c}\text { Aberrant locomotor behaviour associated to } \\
\text { impaired circadian cycle }\end{array}$ & $\begin{array}{l}\text { Running wheels under } \\
\text { standard LD cycle and } \\
\text { constant Darkness } \\
\end{array}$ & $\begin{array}{l}\text { (Barca-Mayo } \\
\text { et al., 2017) }\end{array}$ \\
\hline $\begin{array}{l}\text { Brain and Muscle ARNT- } \\
\text { Like 1, Bmal1 }\end{array}$ & $\begin{array}{l}\text { Ablation of Bmal1in SCN } \\
\text { Aldh1L1 positive astrocytes }\end{array}$ & Mouse & $\begin{array}{l}\text { Arrhythmic locomotor behaviour associated } \\
\text { to circadian cycle }\end{array}$ & $\begin{array}{l}\text { Running wheels under } \\
\text { standard LD cycle and } \\
\text { constant Darkness }\end{array}$ & $\begin{array}{l}\text { (Tso et al., } \\
\text { 2017) }\end{array}$ \\
\hline $\begin{array}{c}\text { Interleukin-6, IL-6; } \\
\text { intereleukin-6 receptor, } \\
\text { IL-6R } \\
\end{array}$ & $\begin{array}{l}\text { Astrocytic-specific deletion of IL-6 or IL- } \\
6 \mathrm{R}\end{array}$ & Mouse & $\begin{array}{c}\text { Reduced locomotor and exploratory } \\
\text { behaviours }\end{array}$ & Hole-board test & $\begin{array}{l}\text { (Erta et al., } \\
\text { 2015) }\end{array}$ \\
\hline Interleukin-6, IL-6 & $\begin{array}{c}\text { Transgenic mice over- IL-6 specifically in } \\
\text { astrocytes }\end{array}$ & Mouse & Reduced exploratory behaviour & $\begin{array}{l}\text { Open field test; light/dark } \\
\text { transfer test }\end{array}$ & $\begin{array}{l}\text { (Roberts et al., } \\
\text { 2019) }\end{array}$ \\
\hline Mitochondrial ROS & $\begin{array}{l}\text { Astrocytic-specific disruption of } \\
\text { mitochondrial ROS production }\end{array}$ & Mouse & $\begin{array}{c}\text { Reduced locomotor and exploratory } \\
\text { behaviour }\end{array}$ & Open field test & $\begin{array}{l}\text { (Vicente- } \\
\text { Gutierrez et } \\
\text { al., 2019) }\end{array}$ \\
\hline
\end{tabular}




\begin{tabular}{|c|c|c|c|c|c|}
\hline $\begin{array}{l}\text { Cryptochrome (Cry } 1) \\
\text { gene }\end{array}$ & $\begin{array}{l}\text { Astrocytic-specific induction of Cry1 and } \\
\text { neuronal Cry1 knockout }\end{array}$ & Mouse & $\begin{array}{l}\text { Regulation (initiation and maintenance) of } \\
\text { locomotor behaviour associated to circadian } \\
\text { cycle }\end{array}$ & Running wheels & $\begin{array}{l}\text { (Brancaccio et } \\
\text { al., 2019) }\end{array}$ \\
\hline $\begin{array}{l}\text { Adenosine } \mathrm{A} 2_{\mathrm{A}} \text { receptor, } \\
\qquad \mathrm{A}_{2 \mathrm{~A}} \mathrm{R}\end{array}$ & Astrocytic-specific deletion of $A 2_{A} R$ & Mouse & Increased psychomotor behaviour & $\begin{array}{l}\text { MK-801 psychomotor } \\
\text { response }\end{array}$ & $\begin{array}{l}\text { (Matos et al., } \\
\text { 2015) }\end{array}$ \\
\hline $\mathrm{Ca}^{2+}$ & $\begin{array}{l}\text { Astrocytic } \mathrm{Ca}^{2+} \text { signalling evoked by } \\
\text { synaptically released dopamine }\end{array}$ & Mouse & Increased locomotor behaviour & Locomotor chambers & $\begin{array}{l}\text { (Corkrum et } \\
\text { al., 2020) }\end{array}$ \\
\hline$\underset{\mathrm{Ca}^{2+}}{\mathrm{InsP}_{3} \text { receptor type } 2}$ & $\begin{array}{l}\text { Selective reduction of astrocytic } \mathrm{Ca}^{2+} \\
\text { signalling }\end{array}$ & Mouse & Impaired motor-skills learning & Motor-Skill Training & $\begin{array}{l}\text { (Padmashri et } \\
\text { al., 2015) }\end{array}$ \\
\hline $\begin{array}{l}\text { Transcription factor } \\
\text { specificity protein } 1, \mathrm{Sp} 1\end{array}$ & Astrocytic Sp1 knockout & Mouse & Impaired motor learning & Rotarod test & $\begin{array}{l}\text { (Hung et al., } \\
\text { 2020) }\end{array}$ \\
\hline $\begin{array}{c}\text { Histamine } 1 \text { receptor, } \\
\mathrm{H}_{1} \mathrm{R}\end{array}$ & Astrocytic $\mathrm{H}_{1} \mathrm{R}$ knockout & Mouse & Reduced locomotor behaviour & $\begin{array}{l}\text { Home cage locomotor } \\
\text { recording }\end{array}$ & $\begin{array}{l}\text { (Karpati et al., } \\
\text { 2019) }\end{array}$ \\
\hline \multicolumn{6}{|l|}{ Mood and emotion } \\
\hline Interleukin-6, IL-6 & $\begin{array}{l}\text { Astrocytic-specific deletion of IL-6 or IL- } \\
6 \mathrm{R}\end{array}$ & Mouse & $\begin{array}{c}\text { Increased anxiety and increased aggressive } \\
\text { behaviour }\end{array}$ & $\begin{array}{l}\text { Plus-maze test; Morris } \\
\text { water maze; resident- } \\
\text { intruder test }\end{array}$ & $\begin{array}{l}\text { (Erta et al., } \\
\text { 2015) }\end{array}$ \\
\hline Interleukin-6, IL-6 & $\begin{array}{l}\text { Transgenic mice expressing elevated } \\
\text { levels of astrocytic IL-6 }\end{array}$ & Mouse & Increased depressive-like behaviour & $\begin{array}{l}\text { Forced swimming test; tail } \\
\text { suspension test }\end{array}$ & $\begin{array}{l}\text { (Roberts et al., } \\
\text { 2019) }\end{array}$ \\
\hline $\begin{array}{l}\text { Epoxide hydrolase (sEH) } \\
\text { EET }\end{array}$ & $\begin{array}{c}\text { Astrocytic-specific deletion of Ephx2 } \\
\text { gene (which encodes sEH, a key enzyme } \\
\text { in epoxyeicosatrienoic acid, EET, } \\
\text { signalling) }\end{array}$ & Mouse & $\begin{array}{l}\text { Enhanced resilience to stress and } \\
\text { antidepressant-like effects }\end{array}$ & $\begin{array}{c}\text { Chronic social defeat } \\
\text { stress; forced swimming } \\
\text { test; Chronic mild stress } \\
\text { and sucrose preference test }\end{array}$ & $\begin{array}{l}\text { (Xiong et al., } \\
\text { 2019) }\end{array}$ \\
\hline $\begin{array}{l}\text { Glutamate transporter-1, } \\
\text { GLT1 }\end{array}$ & $\begin{array}{l}\text { Astrocytic-specific inducible deletion of } \\
\text { GLT1 }\end{array}$ & Mouse & $\begin{array}{l}\text { Excessive Repetitive behaviour including } \\
\text { self-grooming and tic-like head shakes }\end{array}$ & $\begin{array}{l}\text { Grooming and tic-like } \\
\text { movements in a novel } \\
\text { environment; Grooming in } \\
\text { a familiar environment }\end{array}$ & $\begin{array}{l}\text { (Aida et al., } \\
\text { 2015) }\end{array}$ \\
\hline
\end{tabular}




\begin{tabular}{|c|c|c|c|c|c|}
\hline $\begin{array}{l}\text { Glutamate transporter-1, } \\
\text { GLT-1 }\end{array}$ & $\begin{array}{l}\text { Selective pharmacological inhibition of } \\
\text { astrocytic GLT-1 }\end{array}$ & Rat & Antidepressant effect & $\begin{array}{c}\text { Forced swimming test; } \\
\text { novelty-supressed feeding } \\
\text { test }\end{array}$ & $\begin{array}{l}\text { (Gasull-Camos } \\
\text { et al., 2017) }\end{array}$ \\
\hline $\begin{array}{c}\text { Glutamate transporter-1, } \\
\text { GLT-1, Glutamate } \\
\text { Aspartate Transporter, } \\
\text { GLAST }\end{array}$ & $\begin{array}{l}\text { Selective knockdown of GLAST and } \\
\text { GLT- } 1 \text { in astrocytes from IL }\end{array}$ & Mouse & Increased depressive-like behaviour & $\begin{array}{l}\text { Tail suspension test; forced } \\
\text { swimming test; sucrose } \\
\text { preference test }\end{array}$ & $\begin{array}{l}\text { (Fullana et al., } \\
\text { 2019) }\end{array}$ \\
\hline Menin & $\begin{array}{l}\text { Astrocytic-specific down regulation of } \\
\text { Menin encoding gene MEN1 }\end{array}$ & Mouse & $\begin{array}{l}\text { Increased depressive-like behaviour and } \\
\text { Impaired social behaviour }\end{array}$ & $\begin{array}{l}\text { Forced swimming test; tail } \\
\text { suspension test; sucrose } \\
\text { preference test; social } \\
\text { interaction test } \\
\end{array}$ & $\begin{array}{l}\text { (Leng et al., } \\
\text { 2018) }\end{array}$ \\
\hline Glypican 4, Gpc4 & Juvenile Gpc4 knockout & Mouse & Hyperactivity & Open field test & $\begin{array}{l}\text { (Dowling and } \\
\text { Allen, 2018) }\end{array}$ \\
\hline $\begin{array}{l}\text { Histamine } 1 \text { receptor, } \\
\mathrm{H}_{1} \mathrm{R}\end{array}$ & Astrocytic $\mathrm{H}_{1} \mathrm{R}$ knockout & Mouse & Increased aggressive behaviour & Resident intruder test & $\begin{array}{l}\text { (Karpati et } \\
\text { al., 2019) }\end{array}$ \\
\hline $\mathrm{Ca}^{2+}$ & $\begin{array}{c}\text { Reduction of } \mathrm{Ca}^{+2} \text { signalling in striatal } \\
\text { astrocytes }\end{array}$ & Mouse & Excessive self-grooming behaviour & $\begin{array}{c}\text { Self-Grooming Behaviour } \\
\text { measurement (open field } \\
\text { chamber) }\end{array}$ & $\begin{array}{l}\text { (Yu et al., } \\
\text { 2018) }\end{array}$ \\
\hline \multicolumn{6}{|l|}{ Sleep } \\
\hline FABP7 & $\begin{array}{l}\text { Fabp7 deficiency; FABP7.T61M } \\
\text { missense mutation }\end{array}$ & $\begin{array}{l}\text { Human; } \\
\text { mouse }\end{array}$ & Fragmented sleep & $\begin{array}{c}\text { Human sleep analysis; } \\
\text { EEG/EMG monitoring and } \\
\text { analysis }\end{array}$ & $\begin{array}{l}\text { (Gerstner et } \\
\text { al., 2017) }\end{array}$ \\
\hline $\mathrm{Ca}^{2+}$ & $\begin{array}{l}\text { Genetic ablation of astrocytic } \mathrm{InsP}_{3-} \\
\text { receptors }\end{array}$ & Mouse & $\begin{array}{l}\text { Fragmentation of slow-wave sleep and } \\
\text { increased the frequency of sleep spindles }\end{array}$ & $\begin{array}{l}\text { Sleep-wake state scoring } \\
\text { (filtered ECoG and EMG } \\
\text { signals) }\end{array}$ & $\begin{array}{l}\text { (Bojarskaite et } \\
\text { al., 2019) }\end{array}$ \\
\hline$?$ & $\begin{array}{l}\text { Optogenetic (channelrhodopsin-2) } \\
\text { stimulation of astrocytes in posterior } \\
\text { hypothalamus }\end{array}$ & Mouse & Induction of sleep & $\begin{array}{l}\text { EEG, EMG and video } \\
\text { recordings }\end{array}$ & $\begin{array}{l}\text { (Pelluru et al., } \\
\text { 2016) }\end{array}$ \\
\hline Food intake & & & & & \\
\hline
\end{tabular}




\begin{tabular}{|c|c|c|c|c|c|}
\hline $\begin{array}{l}\text { DREADD metabotropic } \\
\text { receptor }\end{array}$ & $\begin{array}{l}\text { DREADD-mediated stimulation of dorsal } \\
\text { vagal complex astrocytes }\end{array}$ & Mouse & Reduced food intake & $\begin{array}{l}\text { Feeding assays; home cage } \\
\text { food seeking }\end{array}$ & $\begin{array}{l}\text { (MacDonald et } \\
\text { al., 2020) }\end{array}$ \\
\hline Adenosine & $\begin{array}{l}\text { DREADD-mediated stimulation of medial } \\
\text { basal hypothalamus astrocytes }\end{array}$ & Mouse & Reduced food intake & Feeding assays & $\begin{array}{l}\text { (Yang et al., } \\
\text { 2015) }\end{array}$ \\
\hline Adenosine $A_{1}$ receptor & $\begin{array}{l}\text { Optogenetic stimulation of astrocytes in } \\
\text { medial basal hypothalamus }\end{array}$ & Mouse & Reduced food intake & $\begin{array}{l}\text { In Vivo Photostimulation } \\
\text { and Feeding Assays }\end{array}$ & $\begin{array}{l}\text { (Sweeney et } \\
\text { al., 2016) }\end{array}$ \\
\hline $\begin{array}{l}\text { Nuclear factor } \kappa \text {-light- } \\
\text { chain-enhancer of } \\
\text { activated B cells, NFkB }\end{array}$ & $\begin{array}{l}\text { Inhibition of NFkB signalling in } \\
\text { astrocytes }\end{array}$ & Mouse & Increased food intake & $\begin{array}{l}\text { Acute high-fat diet intake } \\
\text { measure }\end{array}$ & $\begin{array}{l}\text { (Buckman et } \\
\text { al., 2015) }\end{array}$ \\
\hline $\mathrm{Ca}^{2+}$ & $\begin{array}{l}\text { Selective activation of } \mathrm{Ca}^{2+} \text { signalling in } \\
\text { hypothalamic astrocytes }\end{array}$ & Mouse & Reduced food intake & $\begin{array}{c}\text { Food intake and feeding } \\
\text { assays }\end{array}$ & $\begin{array}{l}\text { (Chen et al., } \\
\text { 2016) }\end{array}$ \\
\hline
\end{tabular}



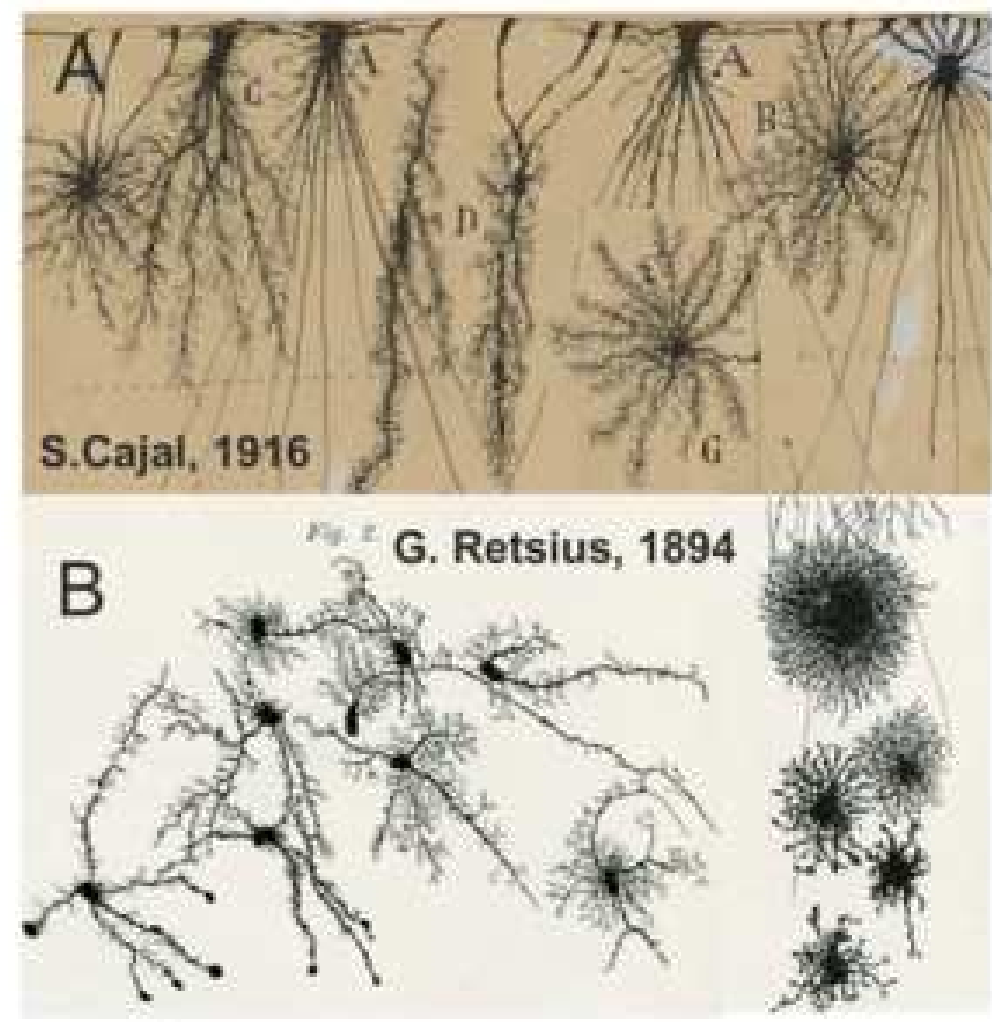

C O. Deiters, 1862
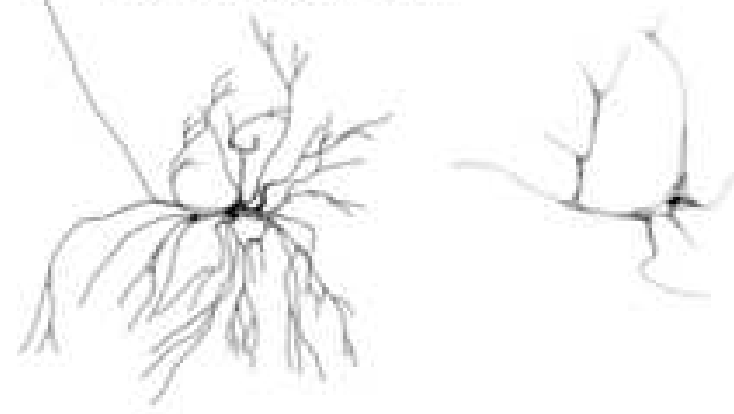

D

A. Kölliker, 1862

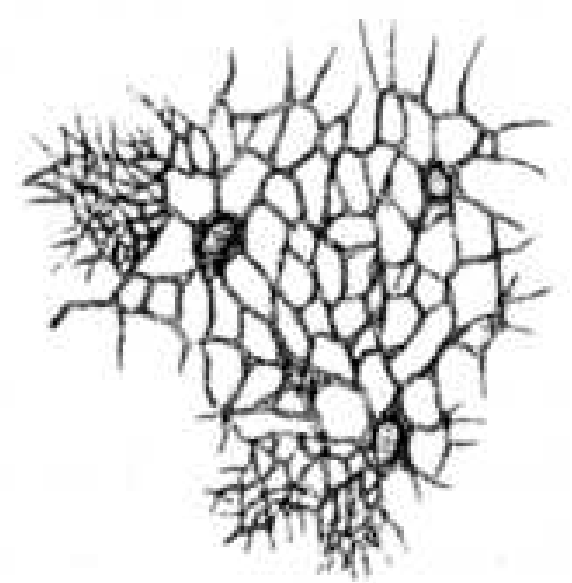

E

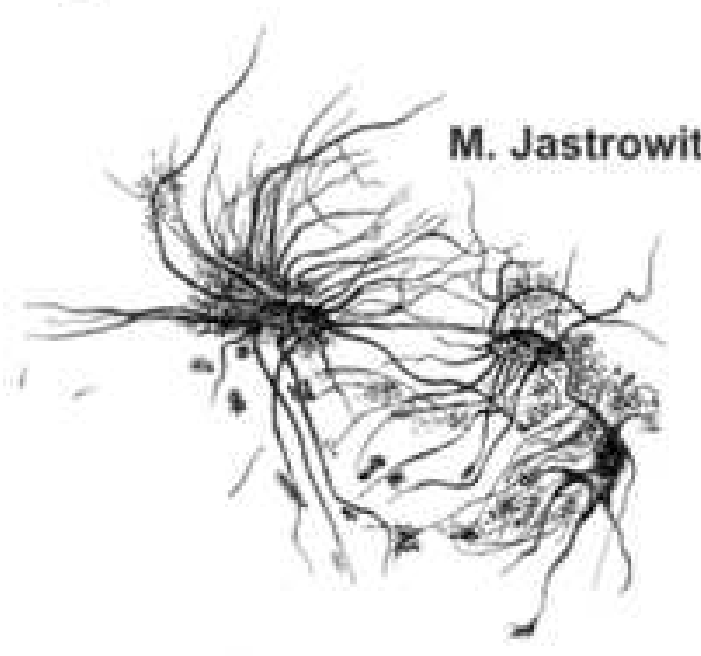

F

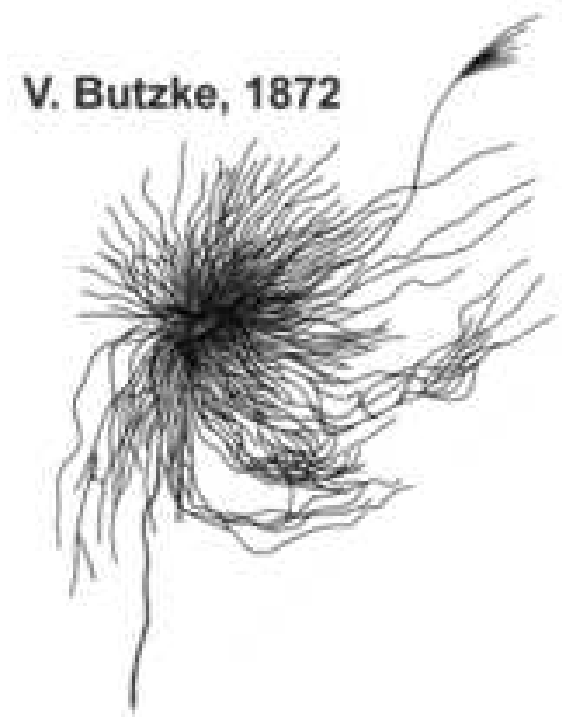

G
E. Rindfleisch, 1873 


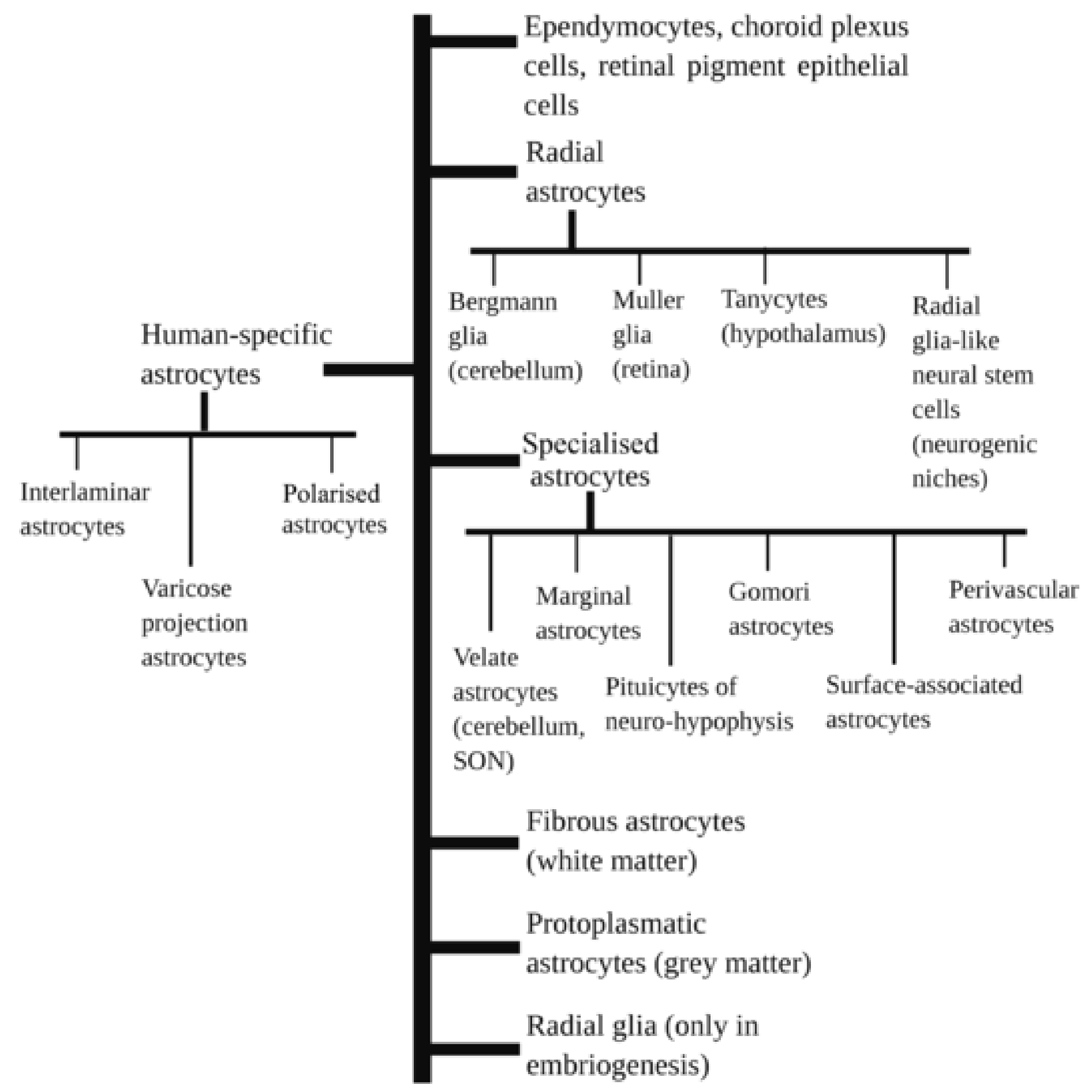




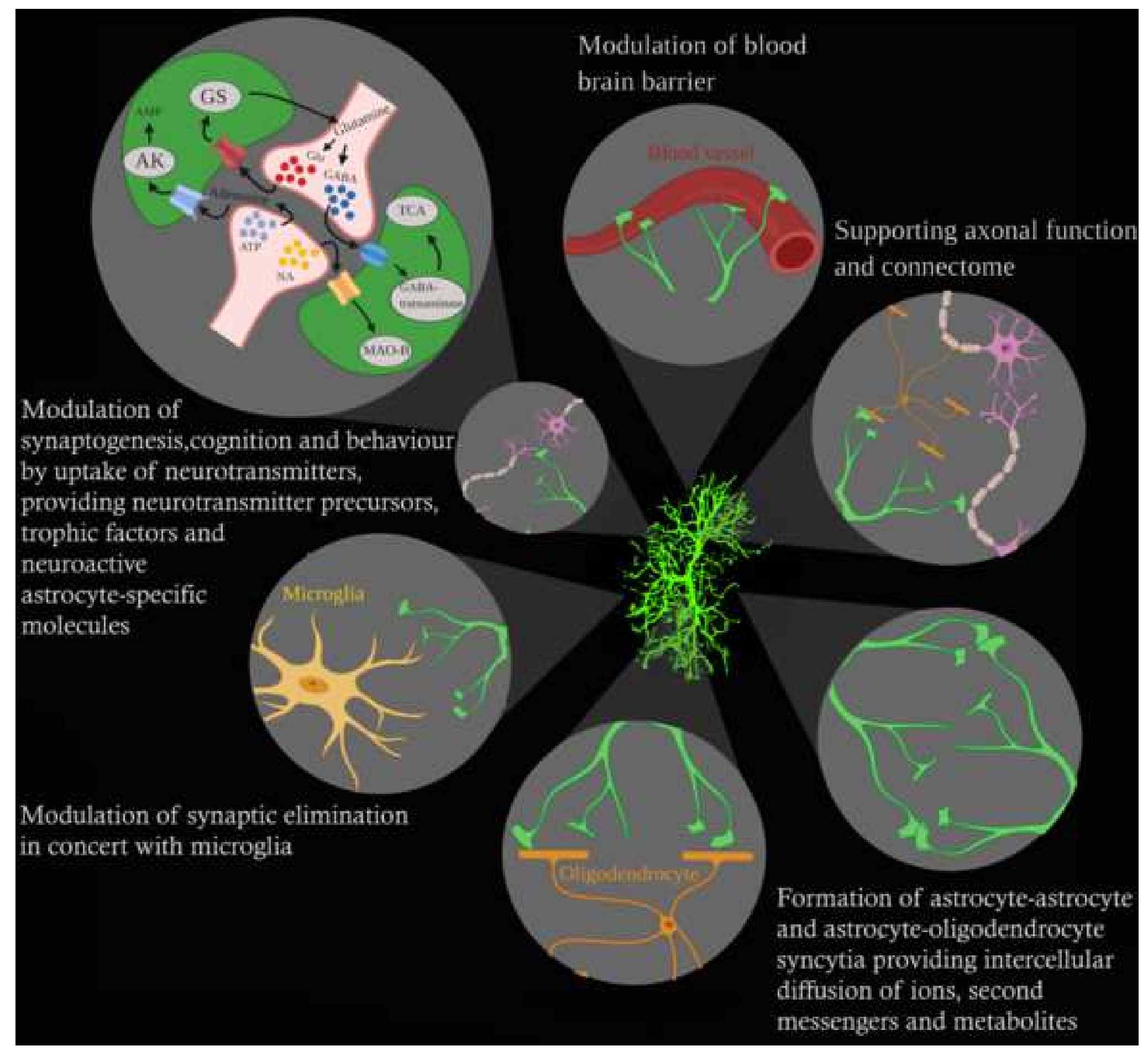




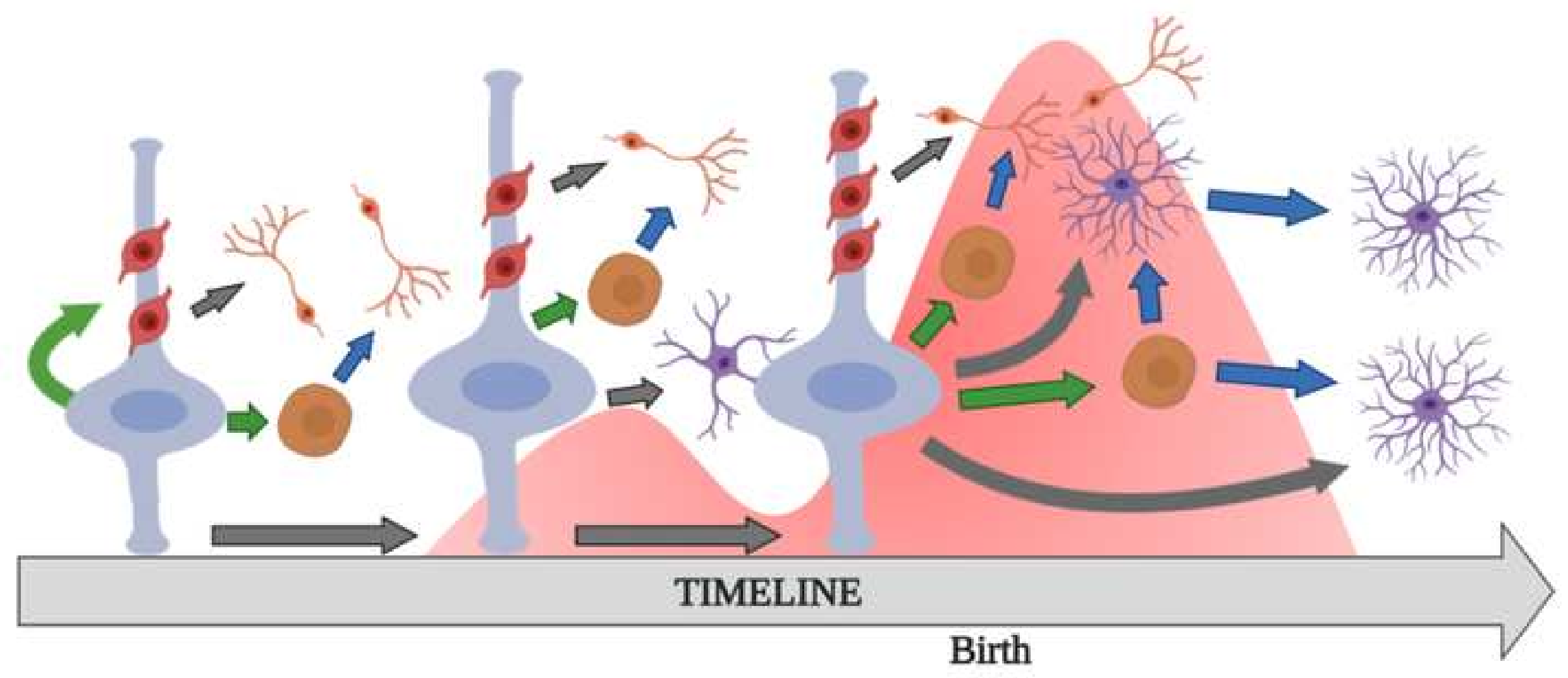

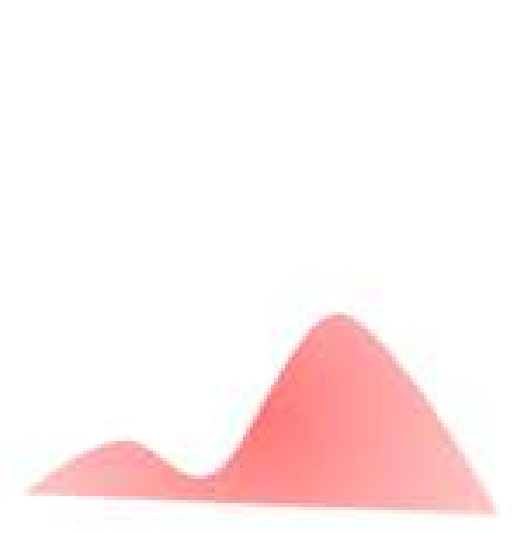

Synaptogenesis waves
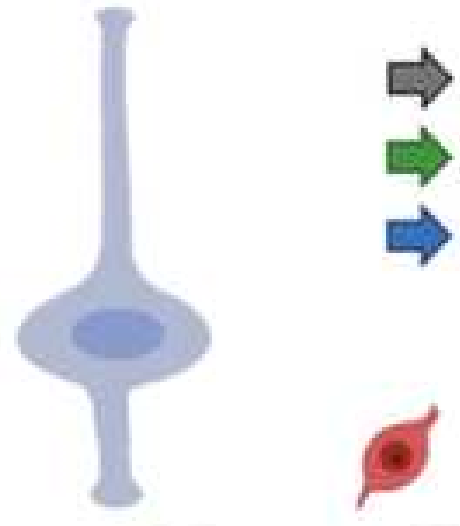

Radial glia
$\Rightarrow$ Transformation

$\Rightarrow$ Asymmetric division

$\Rightarrow$ Symmetric division
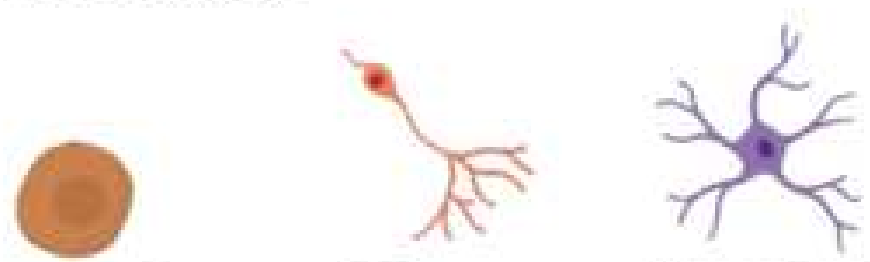

Neurone progenitor cell astrocyte

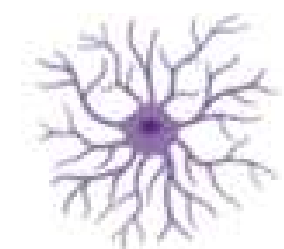

Astrocyte 


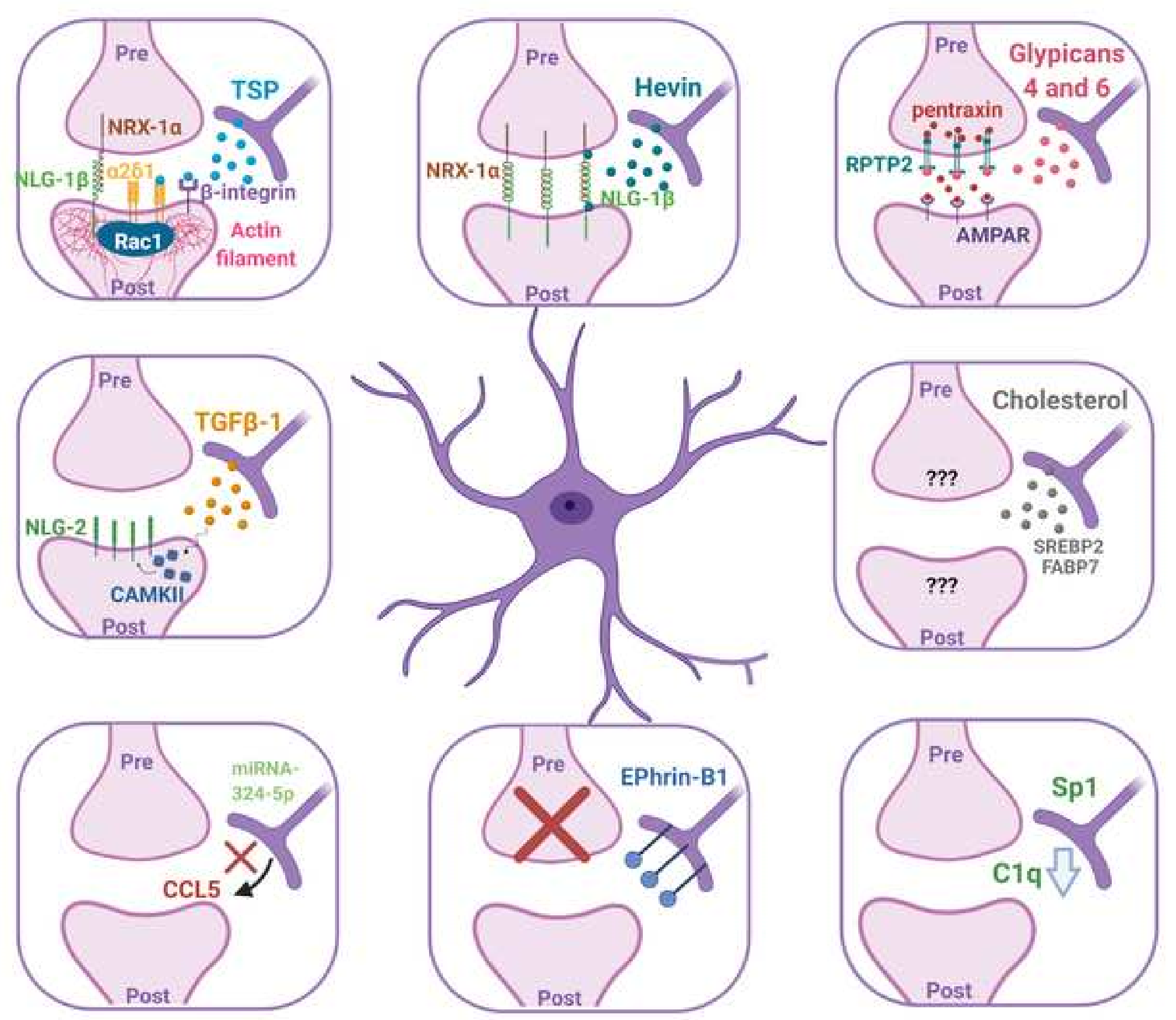




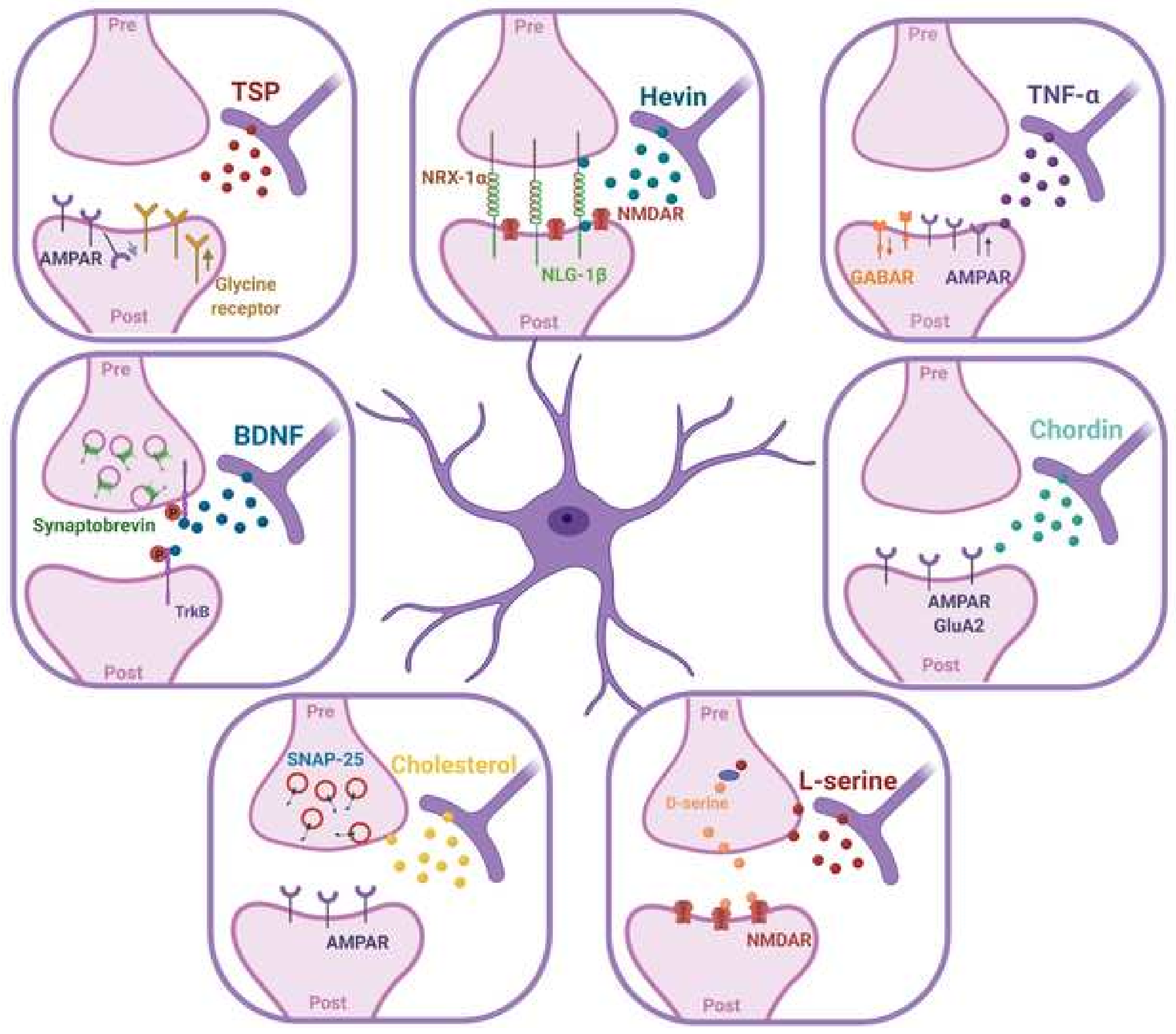




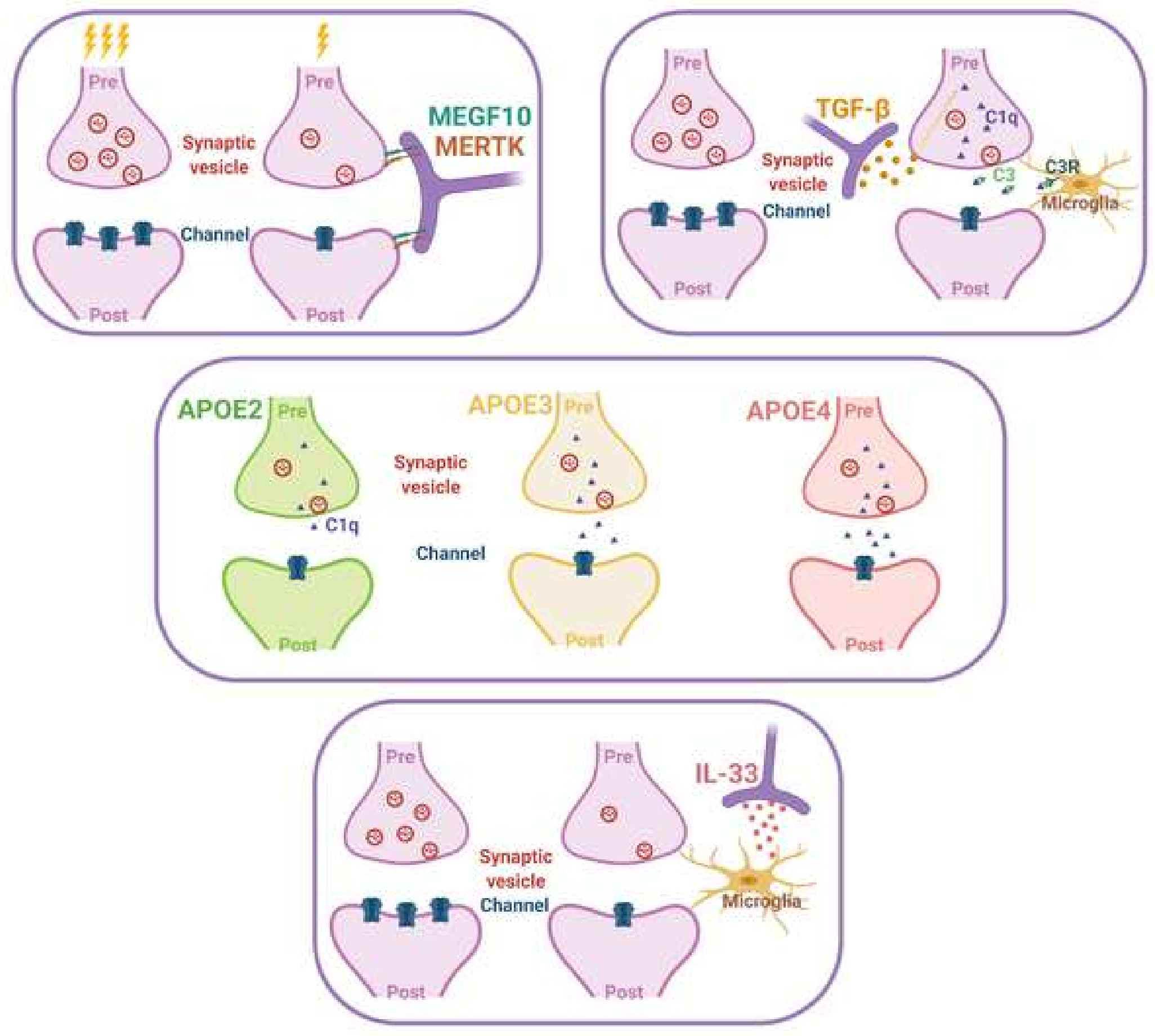

